Melanie Grosse, Wolfram Lorenz, Suria Tarigan, Adam Malik (Eds.)

\title{
Tropical Rainforests
} and Agroforests

\section{under Global Change}

Proceedings

International Symposium (October 5-9, 2008, Kuta, Bali, Indonesia)

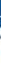

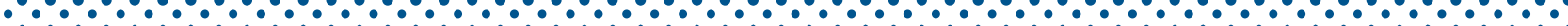

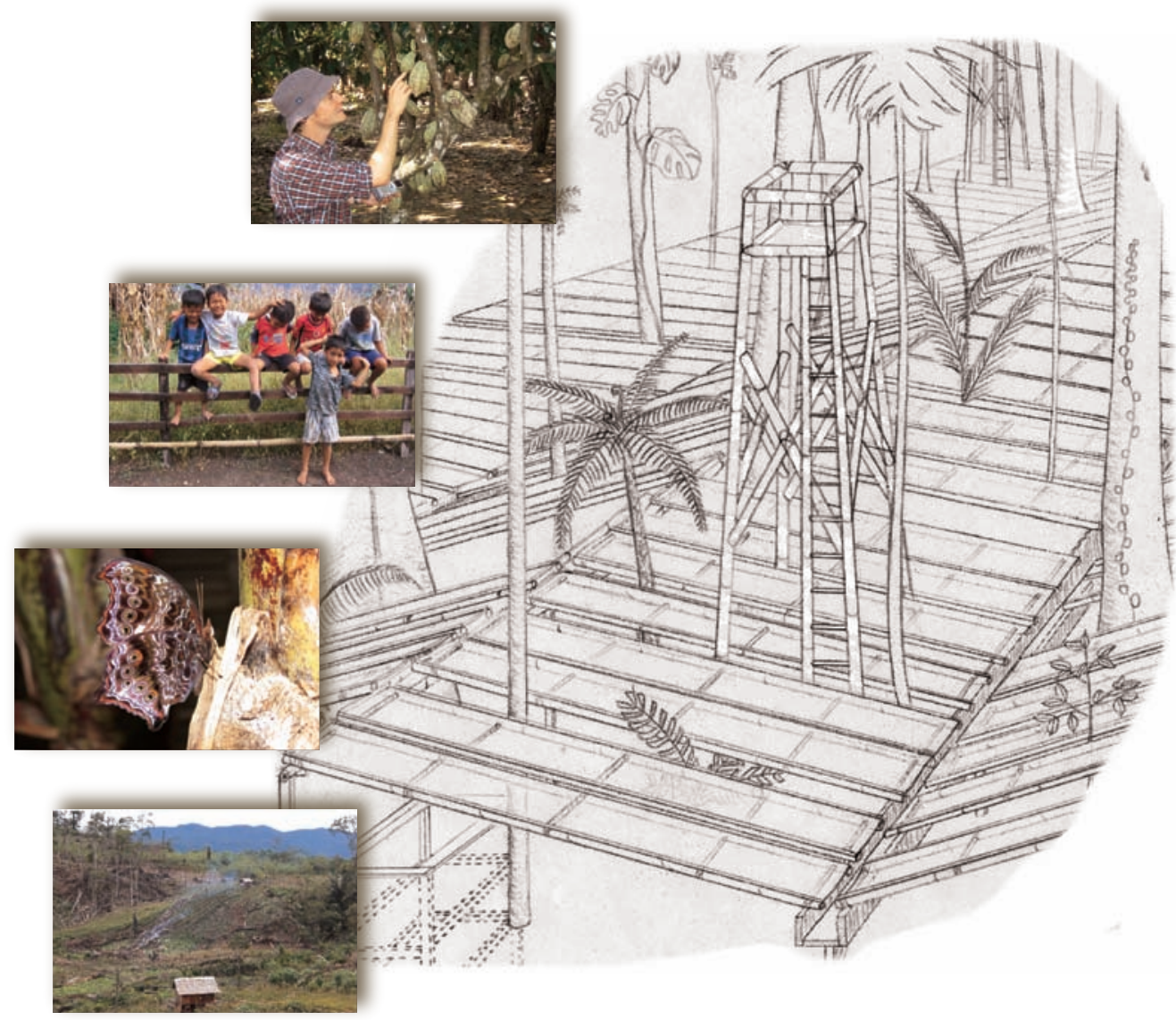



Melanie Grosse, Wolfram Lorenz, Suria Tarigan, Adam Malik (Eds.)

Tropical Rainforests and Agroforests under Global Change

This work is licensed under the Creative Commons License 2.0 "by-nd", allowing you to download, distribute and print the document in a few copies for private or educational use, given that the document stays unchanged and the creator is mentioned. You are not allowed to sell copies of the free version. 
erschienen in der Reihe der Universitätsdrucke

im Universitätsverlag Göttingen 2008 
Melanie Grosse, Wolfram Lorenz, Suria Tarigan, Adam Malik (Eds.)

Tropical Rainforests and Agroforests under Global Change

Proceedings

International Symposium

October 5-9, 2008, Kuta, Bali, Indonesia

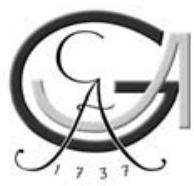

Universitätsverlag Göttingen 2008 


\section{Bibliographische Information der Deutschen Nationalbibliothek}

Die Deutsche Nationalbibliothek verzeichnet diese Publikation in der Deutschen

Nationalbibliographie; detaillierte bibliographische Daten sind im Internet über

$<$ http://dnb.ddb.de $>$ abrufbar.

Global Forest Decimal Classification: (GFDC) 180, 26, (213.5)

Editors:

Melanie Grosse

Centre for Tropical and Subtropical

Agriculture and Forestry "CeTSAF"

Buesgenweg 1

37077 Goettingen, Germany

mgrosse@uni-goettingen.de

\section{Wolfram Lorenz}

Centre for Tropical and Subtropical

Agriculture and Forestry "Ce'TSAF"

Buesgenweg 1

37077 Goettingen, Germany

wlorenz@gwdg.de

Surya Tarigan

Gedung Kerjasama Jerman

Institut Pertanian Bogor

Jl. Raya Gunung Gede

Bogor 16153, Indonesia

storma-ipb@indo.net.id

Adam Malik

Jurusan Manajemen Kehutanan

Fakultas Pertanian

Universitas Tadulako

Kampus Bumi Tondo

Palu 94118, Indonesia

storma-palu@gwdg.de
Centre for Tropical and

Subtropical

Agriculture and Forestry

"CeTSAF"

Büsgenweg 1

U N I K A S S E L 37077 Göttingen, Germany

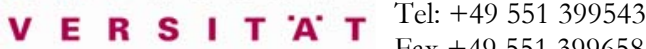

Fax +49 551399658

www.storma.de

storma@gwdg.de

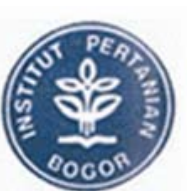

Institut Pertanian Bogor Jl. Raya Gunung Gede

Bogor 16153, Indonesia

Tel.: +62 251346176

Fax: +62 251346177

storma-ipb@indo.net.id

Universitas Tadulako

Kampus Bumi Tondo

Palu 94118, Indonesia

Tel.: +62 451451728

Fax: +62 451451728

storma-palu@gwdg.de

This work is protected by German Intellectual Property Right Law.

It is also available as an Open Access version through the publisher's homepage and the Online Catalogue of the State and University Library of Goettingen (http://www.sub.uni-goettingen.de). Users of the free online version are invited to read, download and distribute it. Users may also print a small number for educational or private use. However they may not sell print versions of the online book.

Satz und Layout: Nils Klann

(C) 2008 Universitätsverlag Göttingen

http://univerlag.uni-goettingen.de

ISBN: 978-3-940344-51-9 


\section{Preface}

This proceeding volume results from the contributed abstracts to the international symposium "Tropical Rainforests and Agroforests under Global Change" which was organized by SFB 552 STORMA and took place in Kuta, Bali, Indonesia, October 5-9, 2008.

Tropical rainforests disappear at an alarming rate and agroforests are becoming increasingly intensified causing unprecedented losses in biodiversity and ecosystem services. Despite an increased recognition of the value of these goods as hot spots of biodiversity, carbon sinks, and sustainable income sources, rainforests and agroforestry systems continue to be seriously threatened by human-induced global change such as agricultural intensification and climate change. Understanding these processes needs an integrated scientific approach linking ecological, economic, and social approaches at different scales, from the household and village level to landscapes and regions.

The global human population is expected to increase further in the near future with the probable consequence of an expansion and intensification of agriculture and the associated destructive impacts on the natural environment. These impacts will particularly happen in regions where agricultural intensification is a relatively recent process such as frontier zones in the humid tropics. Currently, too little is known how to control this process and to identify ecological-socioeconomic trade-offs or synergies of land use and conservation. Land-use systems need management decisions based on the assessment of environmental costs and benefits and a thorough knowledge of ecosystem properties.

This international symposium provides an open platform for all scientists from socio-economic and natural sciences interested in the effects of global change on rainforests and agroforests. Balancing the ecological and socio-economic benefits of different agroforestry systems, comparing patterns and processes in managed agroforest and natural forest, and modeling the dynamics of land-use change and related resource degradation under various policy scenarios are major topics of this symposium.

These topics have been addressed since 2000 by the Collaborative Research Center "The Stability of Rainforest Margins in Indonesia - STORMA". This collaboration is jointly conducted by two Indonesian Universities, the Agricultural University of Bogor (Institut Pertanian Bogor, IPB) and the University of Palu (Universitas Tadulako, UNTAD), and two German Universities, the Georg-August-University of Göttingen and the University of Kassel. Being an interdisciplinary, large-scaled, research program, STORMA research is addressing three interconnected thematic foci. Following these foci, the conference structure addresses three fields.

In the first focus, we deal with agroforestry management in an ecological and socio-economic context. Low-intensity agroforestry may support high biodiversity stabilizing ecosystem functioning, in particular when shaded by natural trees and neighbored by natural forest. In contrast, high-intensity agroforestry with planted shade trees and in an agricultural landscape context may be characterized by less environmental benefits and high agrochemical inputs.

In the second focus, we investigate climate change effects on tropical rainforests and agroforests. Human-induced climate change is already causing changes in extremes of temperatures with strong consequences in the future. First evidence is appearing that changes in temperature extremes can affect tropical forest growth and indirectly forest carbon stocks. Furthermore, annual precipitation has declined over much of the humid tropics during the 20th century.

In the last focus, we develop integrated concepts of land use in tropical landscapes. Rain forest margins around the world comprise a variety of land-use systems, with forest gardens, annual crops in slash-and-burn and agroforestry systems. An understanding of the dynamics of land-use change and related resource degradation under various policy scenarios is required, and strategies to reduce and potentially reverse degradation processes are to be developed. 
We are grateful to our sponsors, namely the Deutsche Forschungsgemeinschaft (DFG), the Federal Ministry of Education and Research (BMBF), the Federal Ministry for Economic Cooperation and Development (BMZ), the Georg-August-University of Göttingen, and the University of Kassel. Very warm thanks go to your partner universities Institut Pertanian Bogor (IPB) in Bogor and Universitas Tadulako (UNTAD) in Palu for their cooperation in the Collaborative Research Center (Sonderforschungsbereich SFB 552) "Stability of Rainforest Margins in Indonesia - STORMA". Support by the Udayana University, Denpasar, Bali, and the Governor of Bali is gratefully acknowledged.

Melanie Grosse, Wolfram Lorenz, Suria Tarigan, Adam Malik 


\section{Contents}

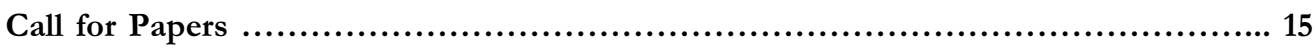

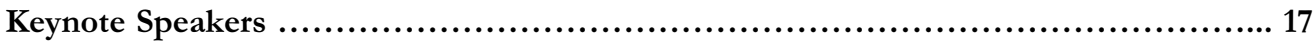

Christian H. Schulze

The importance of countryside habitats and wooded corridors for maintaining species richness of tropical birds and butterflies.

Daniel Murdiyarso

Making forestry works for climate change mitigation and adaptation

Erwin Beck

Functional aspects of tropical biodiversity, revealed by gradient analysis

Gerald Hang

Links between paleoclimates and human history.

Gerald Moser

ENSO drought effects in Southeast Asia - their past, present and future......

Kamaljit S. Bawa

Institutions for Conserving Biodiversity in an Era of Global Change

Manfred Zeller

Linkages between poverty and sustainable agricultural and rural development in the uplands of Southeast Asia ....... 25

Rainer Finkeldey

Genetic variation of dipterocarps: from molecular phylogeniesto the identification of the origin of timber

Richard Bardgett

Integrating aboveground-belowground relationships into land-use systems

Robin Matthews

Modelling the dynamics of land use change and greenhouse gas emissions at the tropical forest margins

Rüdiger Pethig

Land use, biomass harvesting and ecosystem services in a theoretical integrated ecological-economic model

Stephan Klasen

Institutions, Growth, and Rainforest Conversion.

Susan Page

Turning up the Heat! Carbon-Climate-Human Interactions in Tropical Peatlands - Positive Feedbacks to

Global Warming

Susanne Stoll-Kleemann

Success Factors of the Protection and Sustainable Use of Tropical Rainforests in Biosphere Reserves and Protected Areas

Timothy H. Brown

Sustaining Economic Growth, Rural Livelihoods, and Environmental Benefits: Strategic Options for

Forest Assistance in Indonesia

Wiebke Kirleis

Human Landscapes in Sulawesi: The impact of people on tropical rainforest since prehistoric times 36

Yann Clough

Cacao agroforestry: an ecological perspective on synergy potentials between agriculture and conservation 38 
A. Tanra Tellu

Community Based Rattan Concervation (Case Study in the Forest Areas of Lore Lindu National Park)........

A. Tanra Tellu

Characteristics of Rattan and Its Marketing Channel in Central Sulawesi.......

Agus Lanini

Land Tenure Rights and Stabilization the Region of Lore Lindu National Park

Andreas Hemp

Global change impacts on Kilimanjaro's forests and agro-forests.

Andreas Neef

The politics of land use planning and forest protection in northern Lao PDR

Anne-Marie Tremblay

Participatory action research in processing litchi fruit by ethnic minority farmers in mountainous areas of

Northern Thailand.

Anthon Monde

Impact of Forest Conversion into Cocoa land on soil degradation

B. N. Satbish

Ecological and economic analysis of Coffee Agroforestry Systems: a case study from central western Ghats 47

Bea Maas

Six years of rainforest margin modification does not affect bird diversity but endemic species on Sulawesi

Budi I. Setiawan

Water balance analysis to estimate the availability of surface and ground water in Palu watershed

Charles Laffitean

Rainforest Reprieve: The Rainforest Preservation Agreement Between The World Wildlife Fund For Nature and April

Charles Laffitean

Political complexities of negotiating treaties like 1987's Montreal Protocol to address greenhouse gases and deforestation

Cynthia Nazario-Leary

Development of a Native Forest Understory Agroforestry System for Restoration, Invasive Species Control and Sustainable Use.

Damayanti Buchori

Insect Pollinator Community in Brassicaceae Plantations at the Southern Margin of Halimun Salak

National Park, Indonesia

Daniela Leitner

Effects of ENSO droughts on C, N, P dynamics in a tropical rainforest and agroforestry systems in

Central Sulawesi, Indonesia.

Felix Kalaba

Contribution of agroforestry management practices to biodiversity, livelihoods and socio-economic well being of rural communities in Southern Africa

Hendrik Freitag

Introducing „Rainforestation Farming“ to rural communities in Palawan, Philippines.

Herien Puspitawati

Gender Divison of Labor within Households. 57 
Iason Diafas

Using Choice Modeling to Estimate local communities' Economic Values of Forest-related Ecological Services in Kenya.....

James B. Kung'u

Opportunities for Carbon Trading Among Smallholder Agroforestry Farmers in Sub Saharan Africa.

Jan Barkmann

Differences in Power Structures regarding Access to Natural Resources at the Village Level in Central Sulawesi (Indonesia)

Jan Barkmann

Socio-economic conditions of biodiversity conservation in the Phnom Kulen National Park region,

Central Cambodia.

Jan Priebe

The impact of economic vulnerability on deforestation at the rainforest margin

Jana Jubrbandt

The 'cocoa cycle' in Central Sulawesi: Will pest pressure and aging plantations drive cocoa production into a recession?

Jana Jubrbandt

Yield determinants in cocoa agroforestry systems in Central Sulawesi: Is shade tree cover a good predictor for intensification?

Janett Steiner

Risk Management and land use change in the face of ENSO-Events - coping strategies of rural poor in

Central Sulawesi, Indonesia

Kathrin Stenchly

Spider diversity and their relation to cacao agroecosystem management in Sulawesi, Indonesia

(Arachnida: Araneae)......

Laurène Feintrenie

Evaluation of the production potential of complex agroforests. The example of rubber agroforests in

Lubuk Beringin (Indonesia).

Luitgard Schwendenmann

Using stable isotopes of water to trace plant water uptake in a cacao agroforest, Sulawesi, Indonesia 71

Marhawati Mappatoba

Co-Management as Strategy to Balance Community and Conservation Interests in the LLNP

Markus Fischer

Effects of altitude, disturbance and land use on the plant species diversity of Kilimanjaro ecosystems

Norbert B. Binternagel

Vulnerability and adaptability of rural households in face of ENSO-droughts - evidence from periphery regions of Central Sulawesi

Oleg Panferov

How much shade the shade trees provide?

Pavel Propastin

Patterns of vegetation response to ENSO warm events in Indonesia during the period 1982-2007

Perdita Poble

Human ecological dimensions in sustainable utilization and conservation of tropical mountain forests in southern Ecuador .78

Perdita Poble

Applied Ethnobotany in southern Ecuador: A key to sustainable land use and biodiversity conservation 
Ramadanil Pitopang

Biological Diversity of the Morowali Nature Reserve Central Sulawesi, Indonesia

Robert Rudolf

Determinants of Rural Income Generation at the Rainforest Margin

Saharia Kassa

Analysing Stakeholders Needs at Community Conservation Agreement in Lore Lindu National Park

Stefan Erasmi

Animal and plant diversity and its relationship to landscape structure along a tropical land-use intensity gradient.

Stefan Erasmi

Field based inventory of shadow in cacao agroforestry systems: an approach to model the horizontal and vertical structure at the plot level from hemispherical photography......

Stefan Schwarze

Has the Lore Lindu National Park been working? An analysis of the effectiveness of the LLNP in protecting the forest.

Sumita Sen

Community based agro-forestry management in North-east India: Issues of its sustainabilty

Triadiati

Leaf-Litter Decomposition And Nutrient Released in Cacao Agroforestry Ssystem at Lore Lindu National Park, Central Sulawesi.....

Ulrich Schuler

Towards agricultural sustainability in a limestone area in Northern Thailand by modeling different land-use-scenarios

Umrah

Preferences of Dolichoderus thoracicus to some nutrition source containing Trichoderma sp. and dispersion of

Trichoderma on cocoa pod.

Xenia van Edig

Poverty assessment for rural Central Sulawesi, Indonesia - A panel data analysis

Focus 2: Climate change effects on tropical rainforests and agroforests

Abdul Rauf

Dynamic of energy flow under different land use on Lore Lindu National Park.

Abdul Rauf

Rainfall properties and vegetation characters relationship with interception lost in Tropical rainforest

Aiyen Tjoa

Nutrient leaching potential in Cacao Agroforestry of Central Sulawesi affected by Urea and Rainwater supply......

Alexandra Zach

Wood CO2 efflux across an elevation transect in an Andean moist forest.

Alwin Keil

The impact of El Niño-related drought on smallholder farmers in Central Sulawesi, Indonesia: Who is most vulnerable?

Ashraf Salem

Demographic Study on the Woody Vegetation in Wadi Allaqi, South Eastern Egypt.....

Christina Seeberg-Elverfeldt

Carbon Finance - Impacts of Environmental Service Payments on Households in Central Sulawesi, Indonesia...... 101 
Daniele Cicurza

Herbs composition and variation in a mountain forest of Central Sulawesi

Ellyn Cook

High-resolution, multi-proxy records of palaeoenvironmental change through the last millennium from

Lakes Lindu and Kalimpaa, Central Sulawesi, Indonesia.....

Erma Pribastanti

Hydraulic conductivity and percentage of embolism of cacao and gyricidia tree on drought experiment

Gerald Moser

The Sulawesi Throughfall Displacement Experiment - Simulated ENSO Drought Effects on

Primary Rainforest.

Gerhard Gerold

Effects of "ENSO-events" and rainforest conversion on river discharge and nutrient output in Central Sulawesi (Indonesia)

Heike Culmsee

Diversity and productivity of primary pre- to upper montane forests in Central Sulawesi.

Henry Barus

Arbuscular Mycorrhizal Preliminary Study in Natural Forest and Cacao Agroforestry of Central Sulawesi.....

Hermann Behling

Vegetation, climate dynamics and human impact in neotropical mountain ecosystems during the late Quaternary.

Jan Barkmann

Socio-economic Resilience to Enso Droughts by Intensified Paddy Rice Production in

Central Sulawesi (Indonesia)?

Kurniatun Hairiah

Tree roots anchoring soil and reducing landslide risk during high rainfall episodes as basis for adaptation and mitigation to climate change through agroforestry

Luitgard Schwendenmann

Effects of an experimental drought on a cacao agroforestry, Sulawesi, Indonesia

Oleg Panferov

Effects of complex landscape on fluxes between atmosphere and rainforest in Central Sulawesi, Indonesia

Oliver van Straaten

The effect of a simulated ENSO drought on soil CO2 production and CO2 efflux in cacao agroforestry plantation in Central Sulawesi, Indonesia.

Rütger Rollenbeck

Climatic variability and impact of landuse change in south ecuador

Samuel Agele

Environmental and physiological regulations of productivity in tropical fruit tree species under variable climate and extreme weather events: case of the humid south of Nigeria.

\section{Stefan Köhler}

The use of passive collector method to measure the input of mineral nutrients from precipation and dust in the vicinity of Lore Lindu National Park

Stefan Köhler

Central Laboratory Unit of Stability Rain Forest Margins (STORMA) project - A Laboratory in tropic.....

Victor Timmer

Carbon sequestration potential of planted tree fallows in semi-arid eastern Tanzania 
Viviana Horna

Interannual variabibility in water use of a neotropical equatorial dry forests.

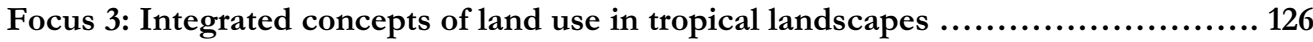

Alfredo R. Huete

Satellite measurements of dynamic human- environment and climate interactions in tropical Monsoon Asia

Alfredo R. Huete

Satellite Time-Series Vegetation Seasonal and Temporal Variations of Human Savannah and Forests in

Northeast Thailand.

Alwin Keil

Maize boom in the uplands of Northern Vietnam: What are the socio-economic and environmental implications?

Andreas Neef

Towards Incentive-Based Policies for Protecting Watersheds in Southeast Asian Uplands.

Bernhard Schuldt

Seasonal response of tree xylem flux to climatic variation and experimental drought in Central Sulawesi

Camille Saint-Macary

Does rice self-sufficiency foster environmental sustainability in the uplands of Northern Vietnam?

Carsten Gut₹ler

Effects of rainforest conversion on throughfall.

Carsten Gutzler

Plot level measurements of water- and nutrient-cycle

Chapika Sangkapitux

Willingness of upstream and downstream resource managers to engage in reward schemes for environmental services.

Christina Seeberg-Elverfeldt

Institutions for Payments for Environmental Service programmes -Evidence from community

resource management arrangements in Indonesia

Cindy Hugenschmidt

A model approach using the SWAT model to assess rainfall-runoff relations under different land use conditions in Northern Thailand

Damayanti Buchori

Insect Pollinator Community in Brassicaceae Plantations at the Southern Margin of Halimun Salak

National Park, Indonesia

Dirk. Hölscher

Sap flux of tropical trees: a model based analysis of species-specific responses to environmental variables

Eleanor Milne

Observations on agricultural expansion in the Sinop area of Mato Grosso state, Brazil

Fadly Y. Tantu

Fish Juvenile Diversity migrated inshore in River Palu Estuary: Implications for Conservation.

Frank von Walter

Integrated Modelling of Smallholder Land-use Decisions on the Availability of Rattan

Frank von $W$ alter

Ex-ante Analysis of an Agroforestry Land-use option in Southern Ecuador 145 
Hendrik Freitag

Aqua Palawana - The Aquatic Biodiversity Research and Conservation Project on the Philippine Island of Palawan.

Jusri Nilawati

Diversity of Endemic Fish in Sulawesi Lakes and Threats of Habitat Loss due to Global Climate Change

Kerstin Wiegand

The effects of species and landscape properties on extinction thresholds in fragmented landscapes

Laurène Feintrenie

Combining spatial analysis and perception surveys to understand the dynamic of rubber agroforests conversion

in Muara Bungo district (Jambi, Indonesia)

Marion Mebring

Sustainable Land Use in the Buffer Zone - The Villagers' Perspective

Michael Köbler

Soil water dynamics and tree water use in a cacao agroforest under experimental drought, Sulawesi, Indonesia .......

Muhammad Ardiansyah

Crop type mapping in small scaled tropical land-use patterns from multitemporal TerraSar-X data.......

Nunik S. Ariyanti

Bryophytes on Tree Trunks in Natural Forest, Selectively Logged Forest and Cacao Agroforestsin

Central Sulawesi

Pavel Propastin

Derivation and validation of temporal LAI and fPAR data sets for Central Sulawesi: integration of medium- und fine-resolution satellite data with in situ measurements.

Pepijn Schreinemachers

An integrated assessment of four innovations to maintain the litchi orchards in northern Thailand

Piyachat Ratana

Satellite Time-Series Vegetation Seasonal and Temporal Variations of Human Savannah and Forests in

Northeast Thailand.

Ramadanil Pitopang

Structure and Floristic Composition of old Growth Secondary Forest in Lore Lindu National Park,

Central Sulawesi, Indonesia.

Reiner Finkeldey

Human impact on intraspecific diversity of tropical trees: Case studies from Africa

Retno I Pujaningsib

Management of Anoa conservation for the seek of socio-economic improvement for the indigenous people arround Lore Lindu National Park

Robin Matthews

Balancing ecosystem services: analysing tradeoffs between food production, carbon storage, and fuel production in tropical forests

Shababuddin

Tropical land-use changes affect diversity, mean body size and ecosystem functioning of dung beetles

Shababuddin

Regional differences in the decay of the dung beetle communities along land-use gradients in Central Sulawesi, Indonesia 
Soekisman Tjitrosoedirdjo

Mikania Micrantha: an invasive alien Plant species threatens the rehabilitation of logged over natural forests in Indonesia

Sri S. Tjitrosoedirdjo

Data Base Development on Invasive Alien Plant Species in Indonesia

Stefan Köhler

Effects of soil fertility on cocoa yields in agroforestry plantations in central Sulawesi

Tanty S. Thamrin

Community coping mechanism in dealing with scarcity of food in NTT

Ulrich Schuler

SOTER based soil mapping in NW-Thailand

Wolfram Loren $\%$

The impact of decentralization on natural resource management in Indonesia. Does the concept of 'conservation districts' contribute to stability of rainforest margins at protected areas?

Karl Stabr

Innovative soil mapping methods for land evaluation 
CALL FOR PAPERS

INTERNATIONAL SYMPOSIUM

\title{
TROPICAL RAINFORESTS AND AGROFORESTS UNDER GLOBAL CHANGE
}

\author{
October 5-9, 2008 \\ Bali, Indonesia \\ Jointly organized by: \\ Georg-August-University of Göttingen and University of Kassel (Germany) \\ Institut Pertanian Bogor and Universitas Tadulako (Indonesia)
}

\section{THEMATIC SCOPE}

Tropical rainforests disappear at an alarming rate causing unprecedented losses in biodiversity and ecosystem services. Despite an increased recognition of the value of these goods at national and international levels, rainforests continue to be seriously threatened by human-induced global change such as agricultural intensification and climate change. Understanding these processes needs an integrated scientific approach linking ecological, economic and social approaches at different scales, from the household and village level to landscapes and regions.

The global human population is expected to increase further in the near future with the probable consequence of an expansion and intensification of agriculture and the associated destructive impacts on the natural environment. These impacts will particularly happen in regions where agricultural intensification is a relatively recent process such as frontier zones in the humid tropics. Currently, too little is known how to control this process and to identify ecological-socioeconomic trade-offs or synergies of land use and conservation. Land-use systems need management decisions based on the assessment of environmental costs and benefits and a thorough knowledge of ecosystem properties.

Human-induced climate change is already causing changes in extremes of temperatures and precipitation and is likely to continue for many centuries affecting tropical forest growth and carbon stocks. Climate scenarios predict a warming trend and more frequent occurrence of droughts of increasing severity. Such scenarios are of serious concern for the future of the rainforest and agroforestry that depend on irrigation or regular rainfall. Assessments of land-use practices need to be linked to sustainable alternatives with concepts and data-driven models of large-scale land-use change in tropical, human-dominated landscapes.

\section{OBJECTIVES}

This international symposium provides an open platform for all scientists from socio-economic and natural sciences interested in the effects of global change on tropical rainforest and agroforestry resources. Interdisciplinary papers that strive to integrate environmental, technological and socio-economic issues are especially welcome. We will invite some of the excellent papers for a synthesis book of an international publisher. The symposium will feature the following three interconnected thematic foci of interdisciplinary research. 
FOCUS 1: Agroforestry management in an ecological and socio-economic context

Low-intensity agroforestry may support high biodiversity stabilizing ecosystem functioning, in particular when shaded by natural trees and neighbored by natural forest. In contrast, high-intensity agroforestry with planted shade trees and in an agricultural landscape context may be characterized by less environmental benefits and high agrochemical inputs. Papers presenting the ecological and socioeconomic benefits of different management practices comparing and relating them to patterns and processes in natural forests are welcome.

FOCUS 2: Climate change effects on tropical rainforests and agroforests

Human-induced climate change is already causing changes in extremes of temperatures and precipitation and is likely to continue for many centuries. First evidence is appearing that changes in temperature extremes can affect tropical forest growth and indirectly forest carbon stocks. Furthermore, annual precipitation has declined over much of the humid tropics during the 20th century. Papers presenting climate change effects on rainforests and agroforestry integrating socio-economic and ecological consequences are most welcome.

FOCUS 3: Integrated concepts of land use in tropical landscapes

Rain forest margins around the world comprise a variety of land-use systems, with forest gardens, annual crops in slash-and-burn and agroforestry systems. An understanding of the dynamics of land-use change and related resource degradation under various policy scenarios is required, and strategies to reduce and potentially reverse degradation processes are to be developed. Papers presenting spatially explicit models or scenario analyses are especially welcome.

\section{KEYNOTE SPEAKERS}

Richard Bardgett (Lancaster University, UK)

Kamaljit S. Bawa (University of Massachusetts-Boston, USA, and ATREE, India)

Erwin Beck (University of Bayreuth, Germany)

Timothy H. Brown (The World Bank, Indonesia)

Yann Clough (University of Göttingen, Germany)

Rainer Finkeldey (University of Göttingen, Germany)

Gerald Haug (University of Zürich, Switzerland)

Wiebke Kirleis (University of Kiel, Germany)

Stephan Klasen (University of Göttingen, Germany)

Robin Matthews (The Macaulay Institute, Aberdeen, UK)

Gerald Moser (University of Göttingen, Germany)

Daniel Murdiyarso (Center for International Forestry Research CIFOR, Indonesia)

Meine van Noordwijk (International Centre for Research in Agroforestry ICRAF, Indonesia)

Susan Page (University of Leicester, UK)

Rüdiger Pethig (University of Siegen, Germany)

Christian H. Schulze (University of Vienna, Austria)

Susanne Stoll-Kleemann (University of Greifswald, Germany)

Manfred Zeller (University of Hohenheim, Germany)

Managing Board: Teja Tscharntke, Christoph Leuschner, Edzo Veldkamp, Heiko Faust (University of Göttingen, Germany), Edi Guhardja (University of Bogor, Indonesia) and Arifuddin Bidin (University of Palu, Indonesia). 
Keynote Speakers 


\section{Christian H. Schulze}

University of Vienna, Austria

\section{The importance of countryside habitats and wooded corridors for maintaining species richness of tropical birds and butterflies}

Global biodiversity is seriously threatened by two key factors: (1) human activities modifying and transforming natural habitats and (2) climate change. Although climate change particularly affects biotas of higher latitudes, at least some effects, such as a shift in the altitudinal distribution of bird species, are also documented for tropical areas. However, the major threat for tropical biodiversity is certainly habitat loss caused by human land-use activities.

As shown for birds, continental lowland forest species are especially threatened by habitat loss. Particularly understorey species with narrow ranges suffer from forest disturbance and modification, and anthropogenic habitats may be able to support only a small fraction of the forest species pool. Also for range-restricted understorey forest butterflies most land-use systems appear to be of limited conservation value. However, many studies on effects of forest modification and conversion on butterflies do not provide reliable data for evaluating the importance of land-use systems for butterfly conservation. This is due to an inadequate spatial sampling (ignoring significant differences of beta diversity between habitats) and/or neglecting potential effects of the isolation of land-use systems from remaining forest (many records in land-use systems may represent "tourists" depending on remaining forest).

Additionally, the increasing isolation of remaining forest areas negatively affects biodiversity, particularly when the countryside, in which forest patches are embedded, acts as an effective barrier for movements of forest species. Strips of gallery forest along rivers (protected by law e.g. in Costa Rica) may represent corridors or stepping stones facilitating the re-colonization of forest patches by forest species. However, as shown by our studies from the southern Pacific slope of Costa Rica such wooded strips are only of limited conservation value for most forest understorey species.

There is evidence for birds that island species appear to be more robust to habitat conversion than continental species. Perhaps a lower extinction risk of island species (compared to continental species) is the result of higher population densities (due to decreased interspecific competition) and expanded niches (due to increased intraspecific competition). The later may facilitate the colonization of human-disturbed habitats by forest species. Further studies testing these hypotheses will be of high relevance for developing conservation priorities for continental and island biotas in the tropics.

ChristianSchulze,christian.schulze@univie.ac.at 


\title{
Daniel Murdiyarso
}

\author{
CIFOR, Indonesia
}

\section{Making forestry works for climate change mitigation and adaptation}

Managing forests under sustainable systems would potentially contribute to climate change mitigation. These could be implemented by enhancing sink capacity of forests through afforestation and reforestation. As important source of terrestrial carbon, reducing deforestation and forest degradation (REDD) in the tropics are among the best ways to reduce greenhouse gas emissions. Stern (2006) reported that avoided deforestation is the least expensive option for climate change mitigation. He found that the opportunity cost of forest protection in 8 countries responsible for $70 \%$ of emissions from land use could be around $\$ 5 \mathrm{~B} / \mathrm{y}$ initially, although over time marginal costs would rise. The question is, would this benefit be attracting to tropical forest countries regarding the opportunity costs of not utilizing tropical forests? The inclusion of REDD in the new climate region post-2012 merit further evidence for a full implementation.

Forest ecosystems are among the terrestrial systems that can be used by the community to adapt to climate change. Ecosystem services should be identified and utilized to increase the resilience of forestdependant community. Among adaptation strategies discussed here is the services provided by the forested watershed regarding sustainable supply of surface and groundwater recharge. The implementation of project activities should identify the synergies and trade-offs between mitigation and adaptation and consider the type of activities, the scale of project in particular ecosystems, and the level of stakeholder participation. Mitigation pathways may be used as entry point, while narrowing the knowledge gaps of forest-water relationship to better inform decision-making processes. Nevertheless, synergies between mitigation and adaptation measures should be developed whenever ecosystems and societies are considered to be vulnerable to climate change.

Daniel Murdiyarso,D.MURDIYARSO@CGIAR.ORG 


\section{Erwin Beck}

University of Bayreuth, Germany

\section{Functional aspects of tropical biodiversity, revealed by gradient analysis}

Four types of ecosystem services have been differentiated in the Millenium Ecosystem assessment: 1) Cultural services, 2) Provisioning services, 3) Regulating services, and 4) Preserving services. The services 1) - 3) are mainly services of the ecosystems defined towards human needs and their monetary value can at least partly be computed. In contrast the preserving services are the basic ecosystem-bound outputs of ecosystems which brought them into existence and warrant their persistence. These services are also known as functionality in an ecosystem. Functional traits of an ecosystem are difficult to recognize, analyze, quantify and even more difficult to convert into monetary units. Assessment of these services requires an understanding of the particular ecosystem, which best could be gained by ecological experiments. However, in highly biodiverse tropical ecosystems, experiments are difficult to carry out, for logistic as well as for legal reasons. In this situation analysis of parameters along distinct environmental gradients can be used as a likewise powerful approach to gain insight into structure, dynamics and functionality of an ecosystem.

In a study of a tropical mountain rainforest in South Ecuador, gradient analysis has been used as well as a comparison of the natural ecosystem with its anthropogenic replacement system "pastureland", respectively abandoned pastureland. Both ecosystems are located in the perhumid eastern Cordillera of the Andes, where they border each other at the bottom of the San Francisco valley, suggesting that their initial environmental conditions had been the same. The area is an extraordinary hotspot of biodiversity of vascular and non-vascular plants and of several animal groups investigated so far.

Altitudinal gradients provide ideal settings to study effects of various ecological factors across small spatial scales. Collectively, the non-linear changes of abiotic factors with elevation are mirrored by changes in the vegetation, e.g. species composition, plant life-forms, root-to-shoot ratio of biomass and physiological parameters. Also, distribution patterns of most animal species reveal altitudinal preferences and limits, which in many cases can be related to their thermal physiology. Food-webs also change with altitude, if the elevational ranges of the involved species are overlapping, but discordant. Resulting from the outstanding biodiversity (resulting in a very scattered occurrence of individual plant species) on the one hand, and from seasonal changes of abiotic factors as such (rainy and dry season) and in particular with reference to altitude, biotic interactions are usually of weak nature. This holds for above- and belowground plant-animal interactions as well as for plant-fungal interactions (mycorrhiza). The fact that strong biotic interactions appear to be almost exceptional, conforms to the lack of keystone plant and animal species which by making better use of resources would suppress competitors. Stability of the extraordinary diverse ecosystem "natural mountain rainforest" appears to result from a multitude of weak biotic interactions, favoured by resource limitation and a high dynamics at least of the vegetation cover. At the level of correlations an influence of the plant diversity on the velocity of the nutrient cycle in the forest can be shown.

On the opposite side of the valley the natural forest has been replaced by pastures. As a consequence of a non-sustainable destructive land-use, wide areas have already been abandoned as the pasture grass has been overgrown by the aggressive tropical bracken (Pteridium arachnoideum). On the longer run, a few species of violently propagating bushes share the area with the bracken. Wide areas of the Ecuadorian and Peruvian Andes are covered by this type of a successional vegetation, indicating an apparently stable ecosystem, which by contrast to the forest is dominated by a few keystone plant species characterized by an enormous potential of growth and asexual and/or sexual propagation. Ongoing balanced competition 
apparently keeps this species-poor system stable. Even from the non-flowering bracken, a multitude of invertebrates have been collected, but none of them appears to produce populations which can endanger the fern. Patchwise infection of bracken by a pathogenic ascomycete fungus is conspicuous, but like the fauna, is not detrimental to the fern. Again, biotic interactions appear to be weak except for competition. Irrespective of its apparent stability, resilience of this species-poor ecosystem against serious disturbances is much smaller than of the species-rich forest, because of the occurrence of keystone species. Disappearance of one of them would change the entire structure of the ecosystem.

With regard to the provisioning and regulating ecosystem services of the area, it may be of interest that a hydroelectric power plant has been constructed on the forested side of the valley where the vegetation secures a permanent constant flow of water.

Erwin Beck,erwin.beck@uni-bayreuth.de 


\section{Gerald Haug}

ETH Zurich, Switzerland

\section{Links between paleoclimates and human history}

A unifying theme in paleoclimate research is well summarized by a piece of advice that I once heard the late Sir Nicolas Shackleton give to an audience of paleoceanographers: "Whatever you do, do it in high resolution." The underlying message, I believe, is that much 'noise' in geologic records is actually composed of meaningful environmental signals. A central goal is to use new approaches and techniques that do justice to the complexity of geologic records, in order to allow previously hidden signals to emerge.

On the centennial to subdecadal timescale, climate archives with an appropriate memory are anoxic marine basins and lakes. In the anoxic Cariaco Basin off northern Venezuela, millimeter to micrometerscale geochemical data in the laminated sediments of the Cariaco Basin have been interpreted to reflect variations in the hydrological cycle and the mean annual position of the Intertropical Convergence Zone (ITCZ) over tropical South America during the past millennia. These data with decadal to (sub)annual resolution show that the Terminal Collapse of the Classic Maya civilization occurred during an extended dry period from 700 to $900 \mathrm{AD}$. Data of comparable quality and resolution have been extracted from sediments of lake Huguang Maar in coastal southeast China. The record indicates a stronger winter monsoon prior to the Bølling Allerød warming, during the Younger Dryas, and during the middle and late Holocene, when cave stalagmite oxygen isotope data indicate a weaker summer monsoon. A remarkable similarity in the records of ITCZ migration in east Asia and the Americas from 700 to 900 AD raises the possibility that the coincident declines of the Tang Dynasty in China and the Classic Maya in Central America were catalyzed by the same ITCZ migrations. Comparison of our records with the Chinese dynastic history suggests that drought played a role in the terminations of Dynasties during the past 4000 years.

GeraldHang,gerald.hang@erdw.ethz.ch 


\section{Gerald Moser}

University of Göttingen, Germany

\section{ENSO drought effects in Southeast Asia - their past, present and future}

The El Nino Southern Oscillation (ENSO) phenomenon has caused severe droughts during the past in Southeast Asia, affecting significantly ecosystems, agriculture and socio-economics. Analyses of the climate history have shown that ENSO already exists for 15000 years. It seems that its intensity was low before $5000 \mathrm{BC}$ and that its frequency and intensity increased since then. During the second millennium only few severe ENSO occurred. Since the end of the 19th century intensification could be observed; this was pronounced since the 1950ies. Climate models predict a still increasing frequency and intensity of ENSO in the future caused by global warming. For natural ecosystems this intensification is assumed to cause a significant selective force leading to a displacement of drought sensitive species. The amounts and predictability of agricultural yields in periods of frequent and severe droughts will decrease, causing an expressed destabilisation of the socio-economic status of farmer's households and their vulnerability to poverty. This economic insecurity combined with a threatening decrease in ecosystem services could accelerate land-use change and deforestation. Drought tolerant crops and adapted management systems will therefore become of striking importance.

GeraldMoser,gmoser@gwdg.de 


\section{Kamaljit S. Bawa}

University of Massachusetts-Boston, USA, Ashoka Trust for Research in Ecology and the Environment, India

\section{Institutions for Conserving Biodiversity in an Era of Global Change}

Humanity's quest for sustainability will be the dominant theme of the twenty first century. The major challenges to this quest are the inter-related problems of environmental degradation and poverty, exacerbated now with climate change. Progress on technological, social and economic fronts would be necessary to meet these challenges. However, existing institutions in much of the developing world do not have the capacity to respond to complex environmental and social challenges. New institutions are required to cope with poverty, environment, and sustainability. Such institutions should be problem driven with explicit goals of addressing environmental degradation, poverty alleviation and social change. Moreover these institutions should transcend traditional disciplinary boundaries to generate new ideas and technologies, and link new findings with changes in policy and governance. I will provide some examples of such institutions and their innovative sustainability programs and discuss ways to make further progress in meeting environmental, social, and economic challenges in the tropics.

Kamalït S. Bawa, Kamal.bawa@umb.edu 


\section{Manfred Zeller}

University of Hohenheim, Germany

\section{Linkages between poverty and sustainable agricultural and rural development in the uplands of Southeast Asia}

Most of the upland areas of Southeast Asia are characterized by insufficient infrastructure, low productivity in smallholder crop and animal production, mounting environmental problems such as soil and forest degradation and loss of biodiversity, increasing population pressure, and widespread poverty. While some upland areas in South East Asia have been experiencing considerable progress during the past twenty years, others have stagnated or even declined with respect to economic, social and environmental objectives of development. The conceptual framework for this paper builds on the critical triangle of sustainable rural development. Here, equity or poverty alleviation, economic growth, and the protection of the environment are the three major political objectives. In the short-run and medium-run, there exist trade-offs and synergies between these three objectives. The purpose of the paper is to describe major trends in the upland areas of selected countries in South East Asia. The paper begins with a review of definitions of sustainability, and proceeds with a conceptual analysis of the two-way linkages between poverty and the environment, and poverty and economic growth in rural areas. This is followed by empirical findings from research on agriculture and forestry as the major land uses in upland areas of selected South East Asian countries. Based on the results of different case studies from Cambodia, Laos, Vietnam and Indonesia, we seek to contrast stories of relative success with those of failure in order to identify priorities for policy design and future research. The paper concludes with policy implications for rural and agricultural development policies, and suggests future areas of pro-poor policy-relevant research.

ManfredZeller,manfred.zeller@uni-hohenheim.de 


\section{Rainer Finkeldey}

University of Göttingen, Germany

\section{Genetic variation of dipterocarps: from molecular phylogenies to the identification of the origin of timber}

Dipterocarps are dominant components of lowland tropical rainforests in evergreen and seasonal tropical climates in Southeast-Asia. Due to the exploitation for their valuable timber, dipterocarp forests are heavily affected by deforestation, forest fragmentation, and non-sustainable forest management including selective logging. The development of non-manipulable tools to infer the origin of timber and wood products is an urgent need within the context of forest certification in order to follow the chain-ofcustody, and to control the international trade with tropical timber.

Phylogenetic analyses in dipterocarps have been based on sequence analyses of several chloroplast DNA regions, the internal transcribed spacer region and single copy genes of the nuclear genome. We extended these analyses to a large number of dipterocarp species from Indonesia, from the Philippines and from Vietnam.

We also analysed genetic variation within and among geographically distinct populations of the most common and widespread emergents of lowland dipterocarp forests in Indonesia, Shorea leprosula and Shorea parvifolia. Since no clear variation among geographic regions was detectable at chloroplast DNA markers, we applied universal AFLPs (Amplified Fragment Length Polymorphisms) in order to identify markers with pronounced frequency differences between geographic regions in Indonesia. SCARs (Sequence Characterized Amplified Regions) markers have been developed from AFLP markers that unambiguously differentiate between the islands Sumatra and Borneo.

We aim to develop a large and reliable set of DNA markers for the verification of the geographic origin of timber. For that purpose DNA isolation methods have been adapted for wood and evaluated by the amplification and sequencing of DNA fragments of different lengths in processed and unprocessed wood probes. Informative DNA markers will be tested in wood probes of defined origins.

RainerFinkeldey,rfinkel@gwdg.de 


\section{Richard Bardgett}

Lancaster University, UK

\section{Integrating aboveground-belowground relationships into land-use systems}

Throughout history it has been known that soil microbes are integral to soil fertility. However, it is only during the last few decades that ecologists have begun to explore belowground communities and their functional significance for plant communities and ecosystem processes. This interest is due, in part, to technological advances that have enabled scientists to extract and characterize soil microbial communities and to assess their function. It is also due to an increasing recognition by ecologists, who have traditionally focused on aboveground organisms, of the importance of belowground organisms as structuring forces in terrestrial ecosystems. The aim of this talk is to illustrate the often unexpected significance of linkages between plants and soil microbial communities in driving plant community and ecosystem services in natural and managed systems, and to illustrate how some of these concepts might be integrated into sustainable land use systems to maximize the efficiency of soil nutrient cycling and nutrient retention, including carbon storage. Specifically, I will refer to some of our recent studies which illustrate the importance of plant-soil-microbial linkages for: (a) nitrogen cycling and the partitioning of chemical forms of nitrogen by co-existing plant species in agricultural grasslands systems; (b) phosphorus cycling, and the maintenance of plant productivity in forested systems; and (b) soil carbon cycling, and especially the goal of sequestering carbon in soil in agricultural systems, an issue that is high on the political agenda.

RichardBardgett,r.bardgett@lancaster.ac.uk 


\section{Robin Matthews}

Macaulay Institute, Aberdeen, UK

\section{Modelling the dynamics of land use change and greenhouse gas emissions at the tropical forest margins}

An estimated 13 million hectares of tropical forest are destroyed each year, resulting in the emission of 5.8 Gt of CO2, about $20 \%$ of total anthropogenic emissions of GHGs. The drivers of this destruction are many and varied, including a combination of commercial wood extraction, permanent cultivation, livestock development, and the extension of overland transport infrastructure. To add to this pressure, the increasing demand for biofuels in the US and Europe has led many tropical countries to see the growing of crops such as maize and sugarcane for biofuel feedstock as opportunities to kick-start their economies, which, in addition to diverting existing crop production away from use as food, has resulted in some areas of tropical forest being cleared for these crops.

Currently, this $20 \%$ of emissions is outside the Clean Development Mechanism of the Kyoto Protocol. There are now discussions within the UN Framework Convention on Climate Change to try and develop mechanisms to reduce emissions from deforestation and degradation (REDD). A suggested mechanism is to reward countries that demonstrate a decrease in deforestation rate below a baseline based on average historical deforestation rates. However, it is unclear how targets that are agreed at the national level under international-level REDD rules will be translated to changes in the behaviour of the indigenous people, farmers, ranchers, and loggers who live on the land, and, indeed, whether the approach would be sufficient to overcome the many pressures at the local level leading to deforestation, including the need to produce food, and the economic opportunities afforded by growing biofuel crops. New ways to link the technical and institutional advances on REDD to local stakeholders are needed so that the various scenarios considered reflect local ambitions and response options. Active 'negotiation support' will be needed to achieve the 'free and prior informed consent' status that is seen as a moral imperative to agreements that potentially affect livelihoods of people outside of the centres of political power. Simulation modelling is one tool that allows analysis by stakeholders of different potential mechanisms before intervening in a real system. Many such deforestation models exist - one example is the FALLOW model (van Noordwijk, 2002), which simulates some of the factors influencing land use change in forest margins and the impact that these changes have on carbon stocks and biodiversity, with particular focus on the spatial interactions between different parts of the landscape containing forests and agriculture.

Recently, agent-based simulation modelling has been arousing interest due to its ability to model individual decision-making entities and their interactions, to incorporate social processes and non-monetary influences on decision-making, to conceptually reproduce non-linearities ('tipping points') often observed in space-time processes of innovation and change, and to dynamically link social and environmental processes. Various ways in which agent-based land use models have been applied were reviewed recently by Matthews et al. (2007). One such agent-based model is the People and Landscapes Model (PALM, Matthews, 2006), which simulates a number of decision-making entities (e.g. farm households) located on a landscape made up of a number of heterogeneous land units, each of which contains routines to simulate its water balance and carbon and nitrogen dynamics (including GHG emissions) over time. Decisions made by the household agents result in actions which may influence the fluxes of water, carbon and nitrogen within the landscape. PALM has been used to evaluate economic instruments such as taxes ('sticks') or incentives ('carrots') aimed at reducing GHG emissions and the impact that this may have on farmer livelihoods (Matthews \& Bakam, 2007). Like other simulation models, a disadvantage of agentbased models is that they can often require more data than is available, particularly in relation to the degree of 'co-variation' between individual characteristics. However, a number of 'hybrid' approaches are 
Keynote Speakers

now available, which combine a location-specific analysis of spatial patterns with macro-economic data, broadly 'generic' processes valid beyond local parameterisation, and at least some social/economic stratification among the agents

In this paper, we discuss the potential of such models to understand the complex dynamics of land use transitions at the tropical forest margins, give some examples of their use, and outline some of the challenges facing their general applicability.

RobinMatthews,r.matthews@macaulay.ac.uk 


\section{Rüdiger Pethig}

University of Siegen, Germany

\section{Land use, biomass harvesting and ecosystem services in a theoretical integrated ecological-economic model}

In an integrated dynamic general equilibrium model of the economy and the ecosystem, humans and wildlife species compete for land and prey biomass. Humans rely on ecosystem services that depend, in turn, on biodiversity and on the size of habitat for non-human species. As is well known, conversion of land for economic use as well as harvesting of biomass by humans are among the most important links between the ecosystem and the economy. In our model these activities are endogenous and we capture their pervasive intertemporal repercussions in the ecosystem which, in turn, impact on the quality and quantity of ecosystem services. We introduce a competitive allocation mechanism in both submodels such that economic prices and ecosystem (shadow) prices guide the allocation in the economy and in the ecosystem, respectively. We distinguish the scenarios of a habitat for which property rights are either enforced or not enforced. We show that fully enforced property rights are not enough to secure efficiency in the no-policy case and that each property-rights scenario calls for specific corrective policies.

The main purpose of the paper is methodological and conceptual but it aims, at the same time, to demonstrate that the application of a general-equilibrium competitive allocation mechanism to a microfounded integrated ecological-economic system yields specific and new insights with regard to efficient management of the ecosystem and its services.

Rüdiger Pethig,pethig@vwl.wiwi.uni-siegen.de 


\section{Stephan Klasen}

University of Göttingen, Germany

\section{Institutions, Growth, and Rainforest Conversion}

This paper investigates the linkages between institutions, technological change, economic growth and rainforest conversion in a sample of villages at the rainforest margin in Indonesia. The paper first examines to what extent economic growth is driven by institutional changes with a particular emphasis on the role of property rights, which in turn affects the introduction of growth-enhancing agricultural technologies. These institutional changes are themselves a result of immigration and the resulting population pressure. Regarding the impact on rainforest conversion, the paper uses satellite data of these villages in 1981 and 2001 and finds that high population pressure and early access to infrastructure hastened rainforest conversion. Conditional on these findings, higher economic growth appears to be associated with lower rates of deforestation.

StephanKlasen, sklasen@gwdg.de 


\author{
Susan Page \\ University of Leicester, UK
}

\title{
Turning up the Heat! Carbon-Climate-Human Interactions in Tropical Peatlands - Positive Feedbacks to Global Warming
}

The status of the world's peatlands is a matter of considerable concern since their degradation can lead to carbon emissions to the atmosphere and loss of carbon sink function. Tropical peatlands, located mostly in SE Asia, make a significant contribution to global terrestrial carbon storage, both in terms of their above-ground biomass (peat swamp forest) and thick deposits of peat; they are estimated to contain at least $50 \mathrm{Gt}$ of the global soil carbon store. The carbon sink role of tropical peatland ecosystems is, however, being impacted by rapid land-use changes that increase their susceptibility to degradation and fire. Recent estimates of carbon emissions arising from drainage and oxidation of tropical peatlands are within the range 100-240 Mt C yr-1. Over the past decade widespread fires have also had a major impact on the carbon balance. Page et al. (2002) calculated 810-2570 Mt C were released into the atmosphere as a result of the ENSO-related 1997/98 fires on Indonesian peatlands; significant emissions also occurred during the 2002 and 2006 fire events. In order to provide accurate spatial and temporal values for these emissions it is necessary to study the impact of peatland fires at a landscape scale and to acquire detailed information on fire history (location and return period), fire severity and the dynamics of post-fire vegetation succession and fire susceptibility. To facilitate this, we have employed a multi-temporal remote sensing approach for a study area of 450,000 ha of peatland in Central Kalimantan (Indonesian Borneo) in order to investigate the impacts of deforestation and drainage on peatland fires and vegetation dynamics. The results show that once disturbed, peat swamp forest, in common with other tropical forests, becomes more susceptible to degradation and fire as a result of the modification and fragmentation of the naturally closed structure of the forest, with repeated fires producing a heavily modified secondary ecosystem dominated by ferns, grasses and sedges, in which both fire risk and fire return period increase and, hence, a return to pre-fire vegetation becomes almost impossible. Over a 16 year period, more than $93 \%$ of the study area was burnt on at least one occasion; fires are now a regular feature of every dry season, not just those of ENSO-years. Scaling up the emissions data for the study area indicates that fires, alongside drainage and degradation, are resulting in globally significant carbon emissions from SE Asian peatlands and a rapid loss of their carbon sink function.

SusanPage,sep5@le.ac.uk 


\section{Susanne Stoll-Kleemann}

University of Greifswald, Germany

\section{Success Factors of the Protection and Sustainable Use of Tropical Rainforests in Biosphere Reserves and Protected Areas}

Tropical Rainforests face many types of threats to their ecological integrity. This is the reason why they are subject to strong conservation efforts around the world resulting in the establishment of protected areas and biosphere reserves. Having adopted a protected area in legal terms does not automatically lead to the "real" protection of the tropical rainforest included in the protected area. Harmful practices originate from the failure of policies, laws and decision-making processes to provide effective guidance and conservation incentives to managers and others involved. Conservation managers and other stakeholders involved in the protection and sustainable use of tropical rainforests confirm that problems at the operational level are closely linked with broader governance issues. This paper presents results from the interdisciplinary research project GoBi (Governance of Biodiversity), which evaluates the success or failure for implementing protected areas and biosphere reserves. Its main hypothesis is that the ecological outcome of implementing protected areas depends on the appropriateness of the selected governance and management systems with regard to the local context, and on broader economic and political issues. The study is based on a large set of expert interviews $(n=177)$ and a global survey with UNESCO Biosphere Reserves ( $\mathrm{n}=213$ ) as well as case studies in nine countries on four continents. One of the case studies is the Lore Lindu Biosphere Reserve (Central Sulawesi) to which special reference will be made in the paper. The research project GoBi connects different kinds of data by means of an integrative model to be used as a decision support tool in biodiversity conservation and sustainable resource use. The results show that typical imperfections of governance and management institutions such as enforcement and monitoring problems, insufficient political support, lack of stakeholder involvement, corruption, lack of capacity and leadership play an important role in determining success or failure for implementing successfully protected areas and biosphere reserves. Adaptable institutional arrangements including responsive leadership and capacity building are necessary to protect and sustainably manage tropical rainforests that have complex social, political, cultural and ecological dimensions.

Susanne Stoll-Kleemann, susanne.stoll-kleemann@uni-greifswald.de 


\section{Timothy H. Brown}

The World Bank, Jakarta, Indonesia

\section{Sustaining Economic Growth, Rural Livelihoods, and Environmental Benefits: Strategic Options for Forest Assistance in Indonesia}

Increasingly, global changes affect the prospects for Indonesia's forests. Man-made policies and incentives have a greater influence than biophysical processes in the medium term. Global pressures include rising demand for raw materials, shifts in trade and competitiveness, rising commodity prices, rule of law and its effect on investment climate, and now, the potential for forest carbon markets.

Indonesia's forest resources are not contributing as they could to poverty reduction, economic and social development, and environmental sustainability. Over-exploitation, inefficiency and weak governance in the forest sector have contributed to illegal logging and trade, forest degradation and loss, underperforming plantation lands, losses in government tax earnings, and indebted firms. Industrial output, employment, and competitiveness are declining. Official statistics do not measure illegal earnings from unsustainable practices, nor the high costs of environmental degradation.

Forests produce environmental services that contribute to quality of life, both directly (water supply, soil fertility, pest control) and indirectly (watershed and biodiversity protection). When markets do not exist, forest resources and services are undervalued, and essential services are undersupplied. If also laws are not enforced, the upstream sources of environmental services can become degraded, imposing externality costs on downstream users. Forest degradation contributes to decreasing water quality, soil fertility, and land productivity as well as increasing water shortages, fires and haze, health impacts, downstream siltation and flooding. Short run, private, financial incentives are at odds with long run, public economic and sustainability needs.

There is increasing recognition that all of these impose costs on the people, put pressure on state assets and budgets and increase conflict, which also increases uncertainty and costs. Under economic globalization, weak governance impedes investment, raises costs, and hinders international competitiveness and access to key markets (for forestry and other products). Indonesia spends hundreds of millions of dollars on rehabilitation of critical land and degradation problems created by past forest management practices. Increasing investment in land conversion to bio-fuels threatens continued encroachment and degradation of forest and peat lands. Improving policy consistency, reducing distortions, and improving management will help Indonesia to become more efficient and competitive, improve environmental services, and free up budgetary resources for priority needs for investment and job creation.

Reducing deforestation and the use of fire in land conversion would have multiple benefits to the economy, the society and the environment - even without considering climate change and potential global financial incentives. Local economic benefits include improvement in forest asset values and local livelihoods; health benefits include the value of cleaner water and the reduction of haze pollution; environmental benefits include biodiversity preservation and tourism potential. A more balanced forest and land management approach would help to achieve this range of benefits, compared to the ongoing extractive approach that degrades Indonesia's natural assets. A more diversified, efficient, competitive and sustainable future is feasible, based on more plantation-grown timber, less degradation and encroachment, alternative timber sources, retooled mills and higher value-added processing, with more small-scale enterprises and employment. 
In terms of Indonesia's pro-growth, pro-jobs, pro-poor strategy and long term economic sustainability, it makes sense to strive toward these objectives. Yet, progress is slow because incentives are mismatched, rule of law is weak, and ownership and responsibility are poorly defined. As well, those who benefit from the current system have the means to resist change, even at the expense of the local public good. At the same time, the costs of change to a new system are poorly understood - and the benefits of change would accrue to different groups.

Now, with the potential for payments for carbon sequestration in forests, there may be a source of finance to offset the cost or provide an incentive to take on needed changes. Beyond the local issues, Indonesia's forests also contribute to the global problem of climate change - and have the potential to produce the global public good of carbon storage and sequestration. Emissions from deforestation and land use change (including conversion by fire, especially on peat lands) are a large source of greenhouse gas emissions. The Government recognizes this and is developing an initiative on Reduced Emissions from Deforestation and Degradation (REDD) in collaboration with donors, NGOs, and scientists. Indonesia has the potential to gain hundreds of millions of dollars through a successful REDD effort. (Not all emissions from land use change and fire use would be eligible for payments under a REDD scheme.)

For Indonesia to access these resources, it must have credible policies, programs and institutional arrangements in place. Forestry and land use in Indonesia is a complex story of policy, institutional and governance issues. To address emissions from forestry and land use and achieve REDD payments, Indonesia will have to address fundamental management and governance issues that have existed for some time. The potential for REDD payments may help to create new political will and financial incentives for implementing changes that improve forest sector outcomes. There are still significant legal, political, financial, management and incentive challenges that have to be faced on the road to improving forest management. Improvements in policy and governance are needed if REDD incentive payments are to compete successfully against the private financial incentives that induce land use changes that increase emissions and undermine provision of environmental services for the public good, both locally and globally.

Timotby H.Brown, tbrown2@worldbank.org 


\title{
Wiebke Kirleis
}

University of Kiel, Germany

\section{Human Landscapes in Sulawesi: The impact of people on tropical rainforest since prehistoric times}

\begin{abstract}
Although many of us are used to consider landscape and environmental settings as a natural fact, there is reason to take up a different position. In many fields of the humanities and social science there is the concept of human landscapes. This concept denies the existence of an untouched physical landscape after people began to found settlements and produce pottery. The Neolithic farmers were the first humans who have shaped the environment according to their needs. In contrast, the foregoing communities of huntergatherers are said to have acted in a sustainable way that hardly affected nature. Vegetation history may support this concept since human impact from hunter-gatherer communities is hardly detectable in pollen records.
\end{abstract}

The Indo-Malaysian Archipelago has a long history of hunter-gatherer communities that extends from the Pleistocene to the mid-Holocene. Seven to six thousand years before the present (BP) agriculture started to spread from the Chinese mainland via Taiwan and the Philippines to the Malaysian archipelago, eventually reaching as far as western Micronesia. Earliest Neolithic agricultural and sedentary assemblages found in Sulawesi date from 4,000 BP. Since that time, agriculturalists have colonised and shaped the tropical rainforest, at least in easily accessible areas.

In Sulawesi traces of human-environment interactions may be found in both natural and anthropogenic archives. Three regions in particular allow the reconstruction of human impact on tropical rainforest. These are the northern arm of Sulawesi, the southwestern arm of Sulawesi and central Sulawesi. The earliest evidence of human activity in northern Sulawesi dates from 8,000 BP and comes from a shell midden at the shoreline of Lake Tondano. The midden belongs to a pre-ceramic culture that practised hunting and gathering. However, there is little evidence for the presence of people in the Lake Tondano area in the pollen record until the late Holocene when progressive deforestation of the Tondano uplands and the spread of grasslands is recorded.

The southwestern arm of Sulawesi has produced the most complete pre-ceramic sequences of late Pleistocene and Holocene stone tool working in the whole Indo-Malaysian Archipelago. Stone tools that range in age between 29,000 to 17,000 years have been recorded. Additionally, a number of sites indicate hunter-gatherer communities known as the Toalian, dating from 7,000 years ago and overlapping with the appearance of pottery in the region. Again, the activities of these hunter-gatherers were not reflected in pollen records from the region so their affect on the rainforest remains uncertain. The palaeo-ecological record from Lake Tempe indicates saline input along the Cenrana river that, around 2,500 BP, reached inland to Lake Tempe. This finding supports the hypothesis that there was formerly a saline channel that transected the peninsula in the vicinity of the Tempe basin and allowed maritime trade along the Cenrana river.

Both the environmental history and archaeological record of the Besoa valley in Central Sulawesi show evidence for long-term human impact in the area, most notably through frequent burning and shifting cultivation. Palaeo-records from sites between 1,000 and 1,200 $\mathrm{m}$ asl show past human impact on vegetation development and demonstrate how human activity has altered rainforest composition in the area of the Lore Lindu Biosphere Reserve and National Park for at least 2,000 years. This impact is reflected by high amounts of charred fragments in the pollen record plus low values of arboreal pollen, typically resulting from logging and shifting cultivation. In parts of the biosphere reserve, periodical burning has prevented any forest recovery at all. In the Bada and the Besoa valleys, large stone jars and 
human statues are associated with iron and carved-paddle-impressed pottery. This indicates that they date to the Early Metal phase in eastern Indonesia. The lack of a defined chronology for Sulawesi's prehistory subsequent to the Toalian industry makes dating of the sites difficult. The absence of Chinese pottery suggests the Bada valley sites are older than 500 years and palaeobotanical investigations and radiocarbon dating of sediments from inside the Besoa valley jars suggest a minimum age of 1,000 years for this sites.

Both the archaeological and the palaeobotanical records show the existence of human landscapes in different parts of Sulawesi since colonisation by agriculturalists started around 4,000 BP. This means that, in many parts, the existing rainforest has been shaped by humans over the long term. Although human impact left a considerable mark in valley locations, steep mountain areas were less affected. The records of the Besoa valley in Central Sulawesi in particular offer opportunities to implement some of the aims of the conservation philosophy of the Lore Lindu Biosphere Reserve. Given that the integration of local people and their cultural values into the maintenance of the area's high biodiversity and cultural heritage is one of the more important aims of the biosphere reserve concept, it might be one goal to develop new sources of income by implementing nature and culture-based tourism. Recommendations for conservation policy that may be drawn from the area's environmental history include consideration of the impact of human activity in the more easily accessible areas, particularly in face of recent settlement developments.

Wiebke Kirleis,wiebke.kirleis@ufg.uni-kiel.de 


\section{Yann Clough}

University of Göttingen, Germany

\section{Cacao agroforestry: an ecological perspective on synergy potentials between agriculture and conservation}

Indonesia has become the third largest cacao producer in the world in a record time. The expansion of cacao agroforests in the highlands of Central Sulawesi improved local livelihoods but fuelled agricultural expansion and landscape change. This is a significant development in terms of nature conservation, as this region hosts a major protected area, Lore Lindu National Park, which acts as a refuge for Wallacean flora and fauna. Conversion of forests to agroforests and subsequent intensification is common at the edge of the forest. When compared to most annual crops, agroforests can be species-rich and diverse, providing habitat for a large range of species of organisms and conserving some of the species from the original natural forests. This is conditional on the way cacao agroforests are managed. We collected two years of data covering cacao yield, pests and disease incidence, as well as extensive surveys of several organism groups including vertebrates, arthropods and plants and fungi in over 40 smallholder cacao plots. Here, we show how different aspects of management including shading, weeding and fertilisation practices affect the biodiversity of smallholder cacao, and explore whether biodiversity-friendly forms of management imply losses or benefits in terms of yield. We will put the results in the context of the current trend towards declining yields and increased threat by pests and diseases and discuss how combining production and conservation could sustain cacao production in the study region.

Yann Clough,yclough@gwdg.de 


\section{Focus 1:}

Agroforestry management in an ecological and socio-economic context 


\section{A. Tanra Tellu}

University of Palu, Indonesia

\section{Community Based Rattan Concervation (Case Study in the Forest Areas of Lore Lindu National Park)}

The research about the community-based rattan conservation had been conducted in the settlement area of the prop forests of Lindu Lore National Park. The aims of this is to discover the community-based rattan conservation model, and to evaluate the economic values of the rattan processing for community that are expected to provide the benefits for the community who involve in rattan processing development. This study was carried out by exerting integrated models between the community education and the study of educational output. Therefore, this study was a descriptive experimentation through the andragogic participative approach. The data collection was done via the questionnaire, interviews, PRA and FGD. The data collected were analyzed quantitatively and qualitatively. Based on the data analysis results, it could be concluded that the community can assess that the rattan conservation has an positive effort, therefore its should be support in developing this matters and need to be supported its development by the parties who have interest ini sustainably rattan conservation. The rattan conservation model that could be developed are the rattan cultivation, and selectively or wisely rattan collection. This conservation model could be applied by formatting in collaboration rattan farmer groups, and carry out the conservation through the traditional forest approach and social forest approach.

\section{A. Tanra Tellu, tellu33@yahoo.com}


Focus 1: Agroforestry management in an ecological and socio-economic context

\section{A. Tanra Tellu}

University of Palu, Indonesia

Jamal Sanusi, University of Palu, Indonesia

Musrizal Muin, University of Palu, Indonesia

Syamsu Alam, University of Palu, Indonesia

\section{Characteristics of Rattan and its Marketing Channel in Central Sulawesi}

The study was aimed at (1) describing the morphological characteristics, anatomical structures, physical and mechanical properties of different rattan species traded in Central Sulawesi Province; (2) establishing identification keys for rattan species in Central Sulawesi based on morphological characteristics, anatomical structures, physical and mechanical properties; (3) setting up quality standards of rattan based on their morphological characteristics, physical and mechanical properties; (4) analyzing the marketing channel patterns of traded market and taking them into account in designing a model appropriate for ideal marketing channel.

This study was conducted in Central Sulawesi. It was a descriptive study employing quantitative and qualitative approaches. The identification of morphological characteristics rattan was conducted through direct observation and measurement, whilst their anatomical stuctures were determined by using Polyethilene Glycol method and maceration. The physical and mechanical properties of rattan were tested according to ASTM D.143-52-1970. The rattan marketing channel was investigated by direct tracing, in depth interviews, and focus group discussion.

The study indicated that the morphological, anatomical structures, physical and mechanical properties of rattan varied amongst the species. The differences are supposed to have important criteria in identifying different species and quality of rattan. The current marketing channel found in the research site can be described as follows: collectors - local buyer - raw material processing industry - inter-islands exporters handycrafts industry - consumers. As the marketing channel was influenced by the quality of rattan, it is believe that and ideal marketing channel should be: collectors - processing industry - handycrafts industry - consumers.

\section{A.TanraTellu,tellu33@yahoo.com}


Focus 1: Agroforestry management in an ecological and socio-economic context

\section{Agus Lanini}

University of Palu, Indonesia

\section{Land Tenure Rights and Stabilization the Region of Lore Lindu National Park}

Knowing and understanding the land tenure system on the basis of adat law (customary law), and land tenure system base of state law (Basic Agrarian Law). Those study will be conducted through juridical sociologies approach by finding the social and legal fact in the society then in the last analyze it will found alternative solve of the problem.

Land tenure siytem on the basis of customary law in the District Donggala as manifestation of the local values of the local institution/organization that regulate local communities as a rule of land tenure. It is also means social function of land through land use whether for the owner who open the plot or the local communities member.

Meanwhile, state law as Basic Agrarian Law recognized local communities land tenure system as established in the Act No. 5, 1960 eventhough it is contrary with two kinds whether in the subtance of the BAL or its implementation. Article 5 of BAL mentioned land regulation are based on the adat law but in the other article of BAL mentioned local (adat) communities recognized as long as its still established (many criteria) as its requirement. Local communities refuse it with shown their exisitance. Other side of the BAL failed in regulated land tenure is the biroucrarcy. Several procedures should be fullfill by applicant who want to registrate their land. This condition tend to be very difficult for the local communities in accessing the procedures. It is there for many land in the villages are not registrated yet.

As the consequence, local (adat) communities in the villages are more comply with their customary law in using their land than state law (BAL). It is means land tenure/land titling system should consider the local communities values. At least local government of central Sulawesi revise some land regulation in related with land tenure rights.

AgusLanini,aguslanini@,hotmail.com 
Focus 1: Agroforestry management in an ecological and socio-economic context

\author{
Andreas Hemp \\ University of Potsdam, Germany
}

\title{
Global change impacts on Kilimanjaro's forests and agro-forests
}

During the last 80 years Kilimanjaro has lost a third $(600 \mathrm{~km} 2)$ of its forest, in the lower areas mainly due to logging, in the upper areas due to increasing fires as a result of climate change. Here, alpine vegetation belts moved downslope on Kilimanjaro replacing upper montane forest and the forest line was lowered by $800 \mathrm{~m}$ in some areas. The loss of $150 \mathrm{~km} 2$ of cloud forest - the most effective source in the subalpine fog interception zone - during the last three decades means a considerable reduction in water yield. Moreover, the massive logging inside the still existing forest changes species composition and structure. In particular the moist Ocotea forests that cover most of the southern slopes are undergoing serious destruction caused by the intensive illegal logging of camphor trees. This overexploitation has resulted in forests free of mature Ocotea covering an area of $110 \mathrm{~km} 2$. Thus, one third of the actual camphor zone is already depleted and the remaining part is being heavily modified. In addition, about $15 \%$ of the indigenous forests have been converted into forest plantation areas on the northern slopes since 1950, mainly using fast growing exotic tree species. On the southern and eastern slope of Kilimanjaro the Chagga people living on the mountain for several hundreds of years have converted about $1000 \mathrm{~km} 2$ of former submontane and lower montane forest to multi-purpose home gardens, i.e. banana fields farmed using an agroforestry system also producing coffee. Reduced water yield from the forests affects the Chagga people directly, because their irrigated home gardens fully depend on a steady water outflow from the forest. This problem will be further exacerbated by continuing population growth and associated increases in demands of water, forest products and arable land. Moreover, the maintenance of this efficient and sustainable system is threatened by the introduction of sun-tolerant coffee varieties to the region and low coffee prizes on the world market. If current fire incidence continues, fires will have destroyed most of Kilimanjaro's upper montane cloud forests within the next few decades and thus, its most effective water source in the fog interception zone. Forest destruction by logging at lower altitudes further reduces amount and stability of water flow. These global change impacts present a serious threat to the long-term sustainability of the livelihood of the Chagga people on Kilimanjaro, and of the population living in the surrounding area.

Andreas Hemp, andreas.hemp@uni-potsdam.de 
Focus 1: Agroforestry management in an ecological and socio-economic context

\author{
Andreas Neef \\ University of Hohenheim, Germany
}

\title{
The politics of land use planning and forest protection in northern Lao PDR
}

Village-based Land Use Planning and Land Allocation (LUP/LA) is one of the cornerstones of the rural development policy of the Government of Lao PDR (GoL). In northern Laos the implementation of this policy started in the mid-1990s. Drawing on qualitative fieldwork conducted in three provinces in March 2007 and February 2008, this paper analyzes the impact of the GoLs environmental and rural development policies on ethnic minority villagers' access to resources and their food security as well as the protection of forests in upland areas.

The GoL primary goal in natural resource management is to reverse the trend of declining forest cover in Lao PDR by expanding forest conservation areas and by allocating conservation and protection forest to local communities. In its political rhetoric, the GoL's land and forest allocation policy aims at improving access of local communities to natural resources on the basis of various processes, such as delineation of village boundaries, transfer of resource management responsibilities to village committees and allocation of permanent land use rights to farm households. At the same time, the government of Lao PDR is getting increasingly serious in its fight against swidden cultivation, with the target of eliminating this practice by the year 2010. This policy goes along with the relocation of upland communities to the lowlands, which has dramatically increased the pressure on natural resources and undermined various customary forms of resource access and resource management. Such forced resettlements of villages from upland forest areas - causing a doubling of the population in some lowland and midland regions - and various types of 'encouragement' to establish commercial tree plantations have considerably reduced fallow periods within only a few years, a process that has taken several decades in neighbouring countries, such as Thailand and Vietnam, where swidden cultivation has also been branded as a backward and unsustainable practice by policy makers and extension workers. Expansion of rubber cultivation with strong institutional and economic support by Chinese companies is widely regarded by provincial and district authorities as a single model of permanent land use in sloping land and as a panacea for simultaneously solving the problems of slash and burn agriculture, food insecurity and forest destruction. In fact, however, an expansion of rubber plantations into watershed protection areas, into village use forests and into communities' wet-rice areas can be observed, with serious consequences for the availability of non-timber forest products and villagers' food security and income opportunities.

In conclusion, the current ambiguities and uncertainties surrounding the land and forest allocation process in upland areas of northern Lao PDR raise doubts whether provincial and district governments are able and willing to provide villagers with a sufficiently high degree of legal certainty with regard to access to and use of natural resources. The consequences are not only disastrous for rural people's livelihoods, but also for the future of the country's once abundant forests.

Andreas Neef,neef@uni-hohenheim.de 
Focus 1: Agroforestry management in an ecological and socio-economic context

\author{
Anne-Marie Tremblay \\ University of Chiang Mai, Thailand \\ Andreas Neef, University of Hohenheim, Germany
}

\title{
Participatory action research in processing litchi fruit by ethnic minority farmers in mountainous areas of Northern Thailand
}

Smallholders of the Hmong ethnic minority group are growing litchi in mountainous areas in the north of Thailand. Socially and economically marginalized, their bargaining power and access to high-value markets are limited, forcing them to accept the farm-gate price offered by exploitative middlemen. In recent years, growers have got low prices for their fresh litchi fruits to the point that some of them cut down their orchards to plant vegetables instead. Yet, on sloping lands, fruit-based agroforestry systems are considered beneficial in minimizing soil erosion and in protecting adjacent forests.

Concerns over potentially irreversible land degradation in sloping land prompted a group of academics from Hohenheim University, Germany, and Chiang Mai University, Thailand, to invite farmers to add value to fresh litchi fruits through drying and jam-making. A community-based fruit processing facility was established as an economically viable strategy to conserve litchi orchards. The prospect to gain higher financial benefits for marketing safe and quality litchi products encouraged 25 farmers to comply with Good Agricultural Practices (GAP) guidelines and to reduce the use of hazardous chemicals. They organized themselves as a litchi growers group and expressed readiness to adapt their cultivation methods to respond to the increasing demands from consumers for sustainable natural resources management.

Drawing on qualitative research methods, such as semi-structured interviews with members of the growers group and participant observation of the planning and decision-making processes between farmers, the paper assesses the key determinants in adopting these institutional innovations and the influences of the various actors involved. It is argued that participatory market development can be a valuable tool in providing sufficient economic incentives for farmers to adopt sustainable technologies, such as Integrated Pest Management (IPM) and water-saving irrigation techniques. This approach can also assist in scaling up sustainable land use practices from the community to the watershed level, since litchi growers from other communities begin to see the economic value of sound agricultural practices.

In sum, our research provides a new framework for the sequencing of innovation processes. We conclude that institutional innovation processes have to go hand in hand with or even precede the dissemination of technical innovations.

Anne-Marie Tremblay,atremb5@yahoo.fr 
Focus 1: Agroforestry management in an ecological and socio-economic context

\author{
Anthon Monde \\ University of Palu, Indonesia \\ Anthon Monde, University of Bogor, Indonesia \\ Kukuh Murtilaksono, University of Bogor, Indonesia
}

\title{
Impact of Forest Conversion into Cocoa land on soil degradation
}

Sustainable Agricultural development needs quality land use management and suitable so that farm activities dot appear land use degradation and. It can use farmers sustainable. Its condition will impact on farmer welfare and also will minimize environment and natural resource. This research was conducted in Nopu watershed. It was one of subs Gumbasa watershed. Data collection of erosion and surface runoff was done with using plot erosion which put on various age of cocoa. The results of this research showed that various age of cocoa, soil physic properties and land cover influenced significantly toward erosion and surface runoff. Land use with small cocoa produced high erosion because land cover level was low. In other hand land use with big cocoa that has produced much land cover would decrease erosion. Rainforest conversion to cocoa land use caused soil physic properties (organic matter, bulk density, soil porosity and permeability) decreased significantly. Surface runoff increased significantly with big cocoa because soil density increased and land porosity decreased so that water infiltration decreased. The conclusions of the research were 1). Rainforest conversion to cocoa land use decreased soil physic quality, 2). Rainforest conversion to cocoa land use increased surface runoff, 3). Erosion was influenced significantly by level of land cover on cocoa land use.

Anthon Monde, anthonmonde@yahoo.com 
Focus 1: Agroforestry management in an ecological and socio-economic context

\section{B.N Sathish}

University of Agricultural Sciences, Ponnampet, India

C.G. Kushalappa, University of Agricultural Sciences, Ponnampet, India Syam Viswanath, University of Agricultural Sciences, Ponnampet, India

S. Raghavendra, Institute of Wood Science and Technology, Bangalore, India

\section{Ecological and economic analysis of Coffee Agroforestry Systems: a case study from central western Ghats}

The concept of protected areas for conservation in the past can't ensure the protection of all the earth's biodiversity as it is highly dependent on the surrounding landscape. In the present scenario of an alarming deforestation rate in the tropics, it is challenging to find out the alternative conservation approaches which can reduce the pressure on forested ecosystems. In this context, the present study is an attempt to through light on the conservation significance of Coffee Agroforestry Systems (CAFS) as an alternative tool. The present study was conducted in the CAFS Kodagu district, Peninsular India by using stratified random sampling technique. The preliminary results indicated that, species rich ness was higher (96) in CAFS of moist deciduous vegetation compard to CAFS under semi-evergreen vegetation type. Shannon diversity values were higher for the CAFS of semi-evergreen vegetation compared to CAFS of moist deciduous vegetation. Standing timber of trees with $\mathrm{gbh} \geq 30 \mathrm{~cm}$ was higher in CAFS under semi-evergreen vegetation $(84.75 \pm 7.36 \mathrm{cu} . \mathrm{m})$ compared to CAFS under moist deciduous vegetation $(59.79 \pm 7.23 \mathrm{cu} . \mathrm{m})$. While the economic value of trees in CAFS under moist deciduous vegetation was higher $(7.01 \pm 0.65$ rupees) compared to CAFS under semi-evergreen vegetation type (4.93 \pm 0.56 rupees). In addition to providing support to various flora, fauna and economic returns the CAFS also reduce the pressure on the primary forest by providing timber, fuel wood and a wide ecosystem services.

B.NSathish,satibn@gmail.com 
Focus 1: Agroforestry management in an ecological and socio-economic context

\author{
Bea Maas \\ University of Vienna, Austria \\ Dadang Dwi Putra, Celebes Bird Club, Indonesia \\ Matthias Waltert, University of Göttingen, Germany \\ Teja Tscharntke, University of Göttingen, Germany \\ Christan H. Schulze, University of Vienna, Austria
}

\title{
Six years of rainforest margin modification does not affect bird diversity but endemic species on Sulawesi
}

The ongoing rapid decline of tropical forests and the resulting global loss of biodiversity is a major issue in conservation biology. Southeast Asian rainforests are particularly threatened due to the high demand of natural resources by the still exponentially increasing human population within this region. Protected forest areas provide one of the last glimmers of hope for the survival of forest species. However, the replacement of traditional land-use systems formerly acting as bufferzone habitats at the margin of established reserves and the enormous pressure on the forest margin itself by illegal logging activities may devalue forest margin habitats thereby negatively affecting the status of entire conservation areas. To quantify such potentially negative effects on biodiversity, we studied temporal changes of bird communities within the forest margin zone at the eastern border of Lore Lindu National Park (Central Sulawesi, Indonesia). Therefore, in January and February 2008 repeated point counts $(\mathrm{N}=8$ per census point) were conducted at 15 sites already surveyed 6 years ago by Waltert et al. (2004, Conservation Biology 18: 1339-1346). Census points surveyed in 2002 represented habitats ranging from natural and secondary forests to agroforestry systems and annual cultures. Since, only few sites remained in a similar condition. One of four natural forest sites was clear-cut and a second site was heavily disturbed by logging activities. Young secondary forests were almost completely converted into agroforestry systems and former agroforestry systems lost most of their shade trees. Although the extent of habitat disturbance increased, total bird species richness remarkably remained identical (Nov. 2001-Jan. 2002 as well as Jan.Feb. 2008: 58 recorded species). However, depending on their habitat preferences, birds responded very differentially. While open land species benefited from forest disturbance and land-use intensification, species richness, abundance and spatial occurrence of forest birds - predominately represented by Sulawesi endemic species - declined significantly. This is emphasizing the strong negative impact, particularly on range-restricted species, by recent human activities within the forest margin zone. Our results underline that species numbers are inadequate for evaluating the ecological impact of land-use changes when not taking into account species identities. From a conservation perspective they can be rather misleading as indicator for the sustainability of land use. While recent and ongoing human activities at the margin of Lore Lindu National Park represent a serious threat for (endemic) forest birds, widespread open-land species appeared to profit, thereby contributing to the biotic homogenization of forest margin biota. In a short term, the prevention of further illegal logging activities by law enforcement may be the only way to slow down the rapid degradation of forest margin habitats and the resulting decline of biodiversity.

BeaMaas,beamaas@gmx.at 
Focus 1: Agroforestry management in an ecological and socio-economic context

\section{Budi I. Setiawan}

University of Bogor, Indonesia

Jörg Priess, University of Kassel, Germany Sance Lipu, University of Bogor, Indonesia

Chusnul Arif, University of Bogor, Indonesia

\section{Water balance analysis to estimate the availability of surface and ground water in Palu watershed}

Palu watershed is located in the province of Central Sulawesi, Indonesia covers about 7,500 km2. There lies a protected national park, which is called Lore Lindu. The national park has experienced land use changes due to deforestation for agroforestry with which reaches $0.6 \%$ per year since 1972 . This trend leads to reduce canopy cover that would decrease its capability to intercept rainfall and at the same time that would increase the throughfall. It turns out it would accelerate surface runoff or water discharge of Palu river. It was figured out then the annual discharge increased $220 \mathrm{~mm}$ due to fast runoff during storm events. This study aims at finding interrelationships of the water balance components that might be used then as a tool to estimate the rainfall-runoff relation under different compositions of surface covers in the watershed scale. The Hydrological Standard Tank Model (HTMs) was applied and the daily data of rainfall, calculated evapotransparation, and water discharge from 2001-2005 were inputted successively to obtain best-fitted 12 parameters of HTMs. It was clear that during these periods the parameters that represent surface covers should be recalibrated in order to minimize the Root Mean Square Error (RMSE) between the measured and the calculated discharges. The model could also estimate availability of water stored in the underground but throughout observation is deemed necessary for better precision.

Budi I. Setiawan, budindra@ipb.ac.id 
Focus 1: Agroforestry management in an ecological and socio-economic context

\section{Charles Laffiteau}

University of Texas at Dallas, USA, and Dublin City University, Ireland

\section{Rainforest Reprieve: The Rainforest Preservation Agreement Between The World Wildlife Fund For Nature and April}

This paper (dissertation) examines the relatively recent phenomenon of international agreements between non-governmental organizations (NGOs) and multi-national corporations (MNCs), by attempting to answer the question: "Is the World Wildlife Fund for Nature (WWF) agreement with Asia Pacific Resources International Holdings Ltd. (April), to preserve tropical rainforests in Sumatra, Indonesia, a model for other international environmental agreements between NGOs and MNCs?" This case study analyzes the agreement between the WWF and April as well as a less successful agreement between the WWF and Asia Pulp and Paper in order to ascertain what elements would be needed in other such agreements in order for them to be considered successful by all concerned parties. The research also discusses the reasons why such agreements are called for due in part to the fact that many of the world's developing countries lack the means or the political will to implement and enforce environmental regulations in conjunction with achieving their sustainable economic development objectives. The conclusions support the argument that, in the absence of environmental governance institutions with the ability to address environmental degradation in countries trying to achieve sustainable economic development, the best way to deal with these concerns in the interim is through similar environmental protection agreements between NGOs and MNCs. This research suggests that such agreements can not only address ecologically sound agroforestry management practices which are in the long term interests of both the NGO and MNC signatories, but that they can also attend to the sustainable socio-economic development needs of the nations' citizens who are most affected by these agreements.

CharlesLaffiteau, claffitean@sbcglobal.net 
Focus 1: Agroforestry management in an ecological and socio-economic context

\section{Charles Laffiteau}

University of Texas at Dallas, USA, and Dublin City University, Ireland

\section{Political complexities of negotiating treaties like 1987's Montreal Protocol to address greenhouse gases and deforestation}

Climate change due to global warming is one of many issues confronting countries which they cannot successfully deal with on their own. The purpose of this paper is to attempt to ascertain why international attempts by governments and international institutions to forestall climate change and reduce its negative impacts by regulating and reducing greenhouse gas emissions and deforestation have not been successful. This question is answered through an empirical study of the international politics of regulating chemicals which lead to ozone depletion and comparing this with the complexity of the politics surrounding reductions in deforestation and CO2 emissions. Part I reviews the world's growing awareness of global environmental issues as well as the relatively successful attempts which have been made based on the 1987 Montreal Protocol to govern the production of ozone depleting chlorofluorocarbons. Part II examines the growing influence of environmental NGOs on many different governments' responses to concerns about environmental degradation in addition to unsuccessful attempts by nations to prevent climate change by reducing deforestation and carbon gas emissions. Part III compares and contrasts the politics of ozone depletion with the political complexity of the problem of climate change brought on by global warming and analyzes alternative strategies for regulating the production of greenhouse gas emissions and reducing deforestation world wide. The Conclusions section then offers suggestions on how greenhouse gas emissions might be regulated and levels of deforestation reduced by governments in the near term (utilizing existing and new legislation), and even more effectively in the future by developing new international environmental governance and regulation regimes.

CharlesLaffiteau, claffitean@sbcglobal.net 
Focus 1: Agroforestry management in an ecological and socio-economic context

\section{Cynthia Nazario-Leary}

University of Hawaii, USA

Tamara Ticktin, University of Hawaii, USA

Travis Idol, University of Hawaii, USA

\section{Development of a Native Forest Understory Agroforestry System for Restoration, Invasive Species Control and Sustainable Use}

The drastic decline in abundance of native Hawaiian plants has had ecological, cultural and economic consequences in Hawai i. Changes in land-tenure and habitat destruction have reduced forest cover and degraded existing native forests. Combined with invasion of non-native species, these changes have resulted in a diminished ability by cultural practitioners to locate and access traditionally important native plants. Our research aims to address this issue with the development of a novel agroforestry system in which the understory of existing forests, particularly those that have been degraded due to the presence of invasive species, is enriched with plantings of desired native species. The goal is to establish a system which is capable of promoting native plant restoration, suppressing invasive weed species, and supporting sustainable harvesting of plant material. Three native plant species (Microlepia strigosa, Pipturus albidus, Alyxia stellata) were selected for the agroforestry system based on their cultural importance and restoration potential. Species were outplanted in 2006 in two locations that differed in overstory canopy cover but in which the midstory was dominated by the invasive tree Ardisia elliptica. Six replicate plots, each 6 × $6 \mathrm{~m}$, were assigned to either a control or midstory clearing treatments. Plant size and nonnative seedling regeneration were monitored quarterly and biannually, respectively. Percent light transmittance, canopy cover, and soil moisture content were also compared among treatments and locations. The fern species (M. strigosa) demonstrated the greatest overall survival and growth and was the only species to survive in the intact understory. Across plant species, growth and survival were greatest in cleared treatments which corresponded to increases in light availability. Soil moisture content was variable across treatments and locations. Nonnative seedling regeneration declined in cleared planted treatments. There is significant harvestable material of $M$. strigosa two years after outplanting. These results suggest that agroforestry systems can be developed for restoration and invasive species control as well as enrichment of culturally important native plant resources.

Cynthia Nazario-Leary,cnazario@hawaï.edu 
Focus 1: Agroforestry management in an ecological and socio-economic context

\section{Damayanti Buchori}

University of Bogor, Indonesia

Bandung Sahari, Indonesia Nature Conservation Foundation

Akhmad Rizali, Indonesia Nature Conservation Foundation

\section{Insect Pollinator Community in Brassicaceae Plantations at the Southern Margin of Halimun Salak National Park, Indonesia}

Insect pollinators in brassicaceae plantations at the southern margin of Halimun Salak National Park was studied between November 2006 and Oktober 2007. Insect samplings were conducted in 15 plots of brassicaceae (Brassica rapa) plantations situated in different distances from the nearest forest (between 0 and $2000 \mathrm{~m}$ ). Insects were sampled during 45 days of flowering season. In total, approximatelly 1029 individual insects belonging to 39 morphospecies and eight families of Hymenoptera were collected from brasicaceae plantations. Apidae was found to dominate the community with species richness and abundance covered about $42 \%$ and $49 \%$ of the total collected specimens respectively. Several species that were recorded to cover large number of individual specimens were (1) Colletidae sp. 002 (356 individual, or $34.6 \%$ of total collected), (2) Ceratini (Tribe) sp. 007 (192 individual, approximately amounted to 18.6\%), and (3) Trigona sp (record sp. 001) with 124 individual (12.05\%). The result of the study showed that species diversity decreased with increasing distance of plots to the nearest forest. Our preliminary data indicates that there is a site-specific species composition of insect pollinator communities and habitat isolation may contribute significantly to the presence of species. Implications of these findings toward conservation of pollinator insects are discussed.

DamayantiBuchori,dami@indo.net.id 
Focus 1: Agroforestry management in an ecological and socio-economic context

\section{Daniela Leitner}

University of Göttingen, Germany

Beate Michalzik, University of Jena, Germany

Aiyen Barus, University of Palu, Indonesia

Gunawan Djajakirana, University of Bogor, Indonesia

\section{Effects of ENSO droughts on C, N, P dynamics in a tropical rainforest and agroforestry systems in Central Sulawesi, Indonesia}

Daniela Leitner, Beate Michalzik, Aiyen Barus, Gunawan Djajakirana "Effects of ENSO droughts on C, N, P dynamics in a tropical rainforest and agroforestry systems in Central Sulawesi, Indonesia" The study aims to characterize the response of $\mathrm{C}, \mathrm{N}, \mathrm{P}$ cycling to experimental drought and land-use practices in Central Sulawesi, Indonesia. In a throughfall exclusion experiment the impacts of a 12-months drought and a subsequent re-wetting cycle in a natural tropical forest and in a cacao agroforest was analysed with regard to vertical fluxes and pools of $\mathrm{C}, \mathrm{N}$ and $\mathrm{P}$. By this project we hope to improve our knowledge about relevant processes for nutrient dynamics and the preservation of forest and agricultural ecosystem functions and services. Since the re-wetting phase was recently launched in April 2008 a significant part of our hypotheses on nutrient dynamics comparing drought and re-wetted ecosystem conditions remain unproven to date. Nevertheless, preliminary results on the soil nutrient status, soil microbial indices, the return of nutrients by leaf litter-fall and element solution concentrations and fluxes along a vertical ecosystem gradient at the two research areas of Marena (agroforest) and Pono (rain forest) are available. Soil nutrient status Under cacao in Marena, carbon, nitrogen and phosphorous stocks down to $150 \mathrm{~cm}$ soil depth amounted to $71.4,8.47$ and $9.52 \mathrm{Mg}$ ha-1 at the control and to $82.3,8.90$ and $6.74 \mathrm{Mg}$ ha-1 at the roof sites. Corresponding values for $\mathrm{C}, \mathrm{N}$ and $\mathrm{P}$ at the forest site in Pono are 132.8, 9.05 and $3.20 \mathrm{Mg}$ ha-1 at the control and to $130.9,8.44$ and $3.45 \mathrm{Mg}$ ha-1 at the roof sites. Compared to the agroforest, $\mathrm{C}$ stocks under forest are approximately twice as high, those of $\mathrm{P}$ two-fold lower, those of $\mathrm{N}$ similar. Element concentrations in solutions along a vertical ecosystem gradient Mean concentrations of DOC, $\mathrm{DN}$ and $\mathrm{P}$ in bulk precipitation were similar at both experimental areas in Marena and Pono exhibiting

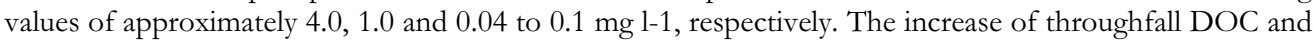
DN concentrations was twice as high in the rainforest compared to the agroforest and half as much in case of P. Compared to the throughfall, amounts of DOC in O layer and Ah solutions remained constant, and decreased in the subsoil. Whereas, concentrations of $\mathrm{P}$ sharply diminished and those of DN increased while passing the $\mathrm{O}$ layer and subsequently the subsoil.

Daniela Leitner, dleitne@gwdg.de 
Focus 1: Agroforestry management in an ecological and socio-economic context

\author{
Felix Kalaba \\ Copperbelt University, Zambia \\ Paxie W Chirwa, University of Stellenbosch, South Africa \\ Felix C. Njovu, Copperbelt University, Zambia \\ Stephen Syampungani, Copperbelt University, Zambia
}

\title{
Contribution of agroforestry management practices to biodiversity, livelihoods and socio- economic well being of rural communities in Southern Africa
}

It has been widely documented that the traditional farming system of shifting cultivation contributes to huge annual losses of forest cover, altering the structure and distribution of species resulting in loss of biodiversity. On the other hand, formal institutional approaches to natural forest biodiversity conservation focused on protecting the tree species in parks and reserves while neglecting their conservation in farming systems. Improved agroforestry systems (AFS) such as improved fallows that mimic shifting cultivation and other AFS provide benefits that contribute to the rural livelihoods, improved socio-economic status and ecosystem functioning of land use systems. There is new and increasing emphasis on the contribution of agroforestry on improving the livelihoods and the ecological services. As opposed to subsistence agriculture, AFS come with the added benefit of the ability to generate cash income from the marketing of diverse products. In southern Africa research that aims to addressed biodiversity and socio-economic issues includes domestication of diverse priority indigenous fruit tree species; and the evaluation of soil fertility replenishing Agroforestry technologies. This paper discusses the contribution of AFS to the improvement of the socio-economic livelihoods of smallholder farmers and the promotion of conservation of biodiversity drawing on evidence from research conducted in southern Africa over last two decades.

Felix Kalaba,kanungwekalaba@yahoo.co.uk.and kanungwe@,cbu.ac.zm 
Focus 1: Agroforestry management in an ecological and socio-economic context

\section{Hendrik Freitag}

State Collections of Natural History Dresden, Germany

\section{Introducing „Rainforestation Farming“ to rural communities in Palawan, Philippines}

A sustainable subnatural approach of agroforestry was formerly practised by indigenous Tagbanua communities in Palawan. The idea was later on adopted and improved by a long-term GTZ project at the Institute of Tropical Ecology, Leyte State University, Visayas, where decades of hands-on experience have been scientifically recorded. Recent studies conclude that the implication of the concept increases both, livelihood standards and habitat conditions. A small-scale attempt was made to introduce the concept to a village in a priority conservation area in Northern Palawan. Most families of the village regularly practice slash-and-burn for rice cultivation. The strategies applied are illustrated:

- A survey in the surrounding forests accompanied by the village headman to record potential "mothertrees" for seed collection

- Several meetings were held with villagers aimed to socialise and to induct the community into the issue

- A one-week workshop was held in local language by local specialists

- Potential mother-trees were visited with the participants and marked by sign boards

- A nursery for tree seedlings, fruit and cash crops was established

- Suitable seeds and wildlings were collected

- Pioneering trees and cash crops were planted

- A people's organisation was founded, which should be responsible for the future management of the activities. The experience gained and the challenges which emerged generated the following theses:

- Large parts of the community addressed are motivated to join the activities

- Local, non-academic facilitators are more reliable to rural communities then academics or foreign activists

- An urgent need for sustainable land-use practices is not seen by local players as long the resources are available in the natural environment

- Short-term and common sources of income are preferred to long-term and untried livelihood strategies

- Potential markets for profitable products are hardly accessible for small communities in rural areas

- Legal policies, administrative barriers and obedience hamper the implementation of related projects The talk aims to promote a critical exchange of ideas about practical conservation and livelihood projects.

Hendrik Freitag, hendrik.freitag@gmx.de 
Focus 1: Agroforestry management in an ecological and socio-economic context

\section{Herien Puspitawati}

University of Bogor, Indonesia

\section{Gender Divison of Labor within Households}

This case study presents the result of a field research conducted in Wonogiri District of Central Java, Indonesia during January-March 2006 as part of the SEANAFE Project on Markets for Agroforestry Tree Products. One of the goals of the study was to examine the gender roles in production, processing, and marketing of agroforestree-tree products-cashew nuts. Primary information was obtained from a variety of respondents, including farmers (20), middlemen (3), processors (3), government agencies, financial institutions, farming cooperatives and NGOs. The respondents were interviewed in depth, either individually or in focus groups. Field work was conducted in Rejosari village, located in the important cashew producing sub-district of Ngadisrono. This village was selected by the government of Wonogiri to be developed as the centre of its cashew nut industry. In general it was found that there was imbalanced of gender partnership in labor division applied at cultivation, processing and marketing of cashew nuts between man and woman. The unequal gender role has also existed in the accessibility and control towards collector traders and whole traders; however, equal gender role has already existed in the accessibility and control towards farming activities and processor and even the role of women is more dominant in processing than that of men. It was also found the unequal gender partnership at community level due to the socio cultural constraints. Recommendations are required such as the agreement among communities in the village to reformulate its regional planning and this will involve both men and women. Women empowerment should be focused on the potential of cashew nut processing skill, for instance, processing broken cashew nut to sandwich (chips), and cashew nut processed chocolate. Farmer club is empowered by increasing the quality of skill and knowledge of women, especially in the area of marketing of processed local commodities, for instance, cassava chip with gadung essence, turmeric instant, and cashew nut nursery.

HerienPuspitawati, herien_puspitawati@email.com 
Focus 1: Agroforestry management in an ecological and socio-economic context

\section{Iason Diafas}

University of Bonn, Germany

Jan Barkmann, University of Göttingen, Germany

\section{Using Choice Modeling to Estimate local communities' Economic Values of Forest- related Ecological Services in Kenya}

This paper presents findings of a study measuring the magnitude, in monetary terms, of the indirect and non-use benefits associated with the conservation of Kakamega forest, Kenya. The study was part of an organized attempt by BIOTA East Africa to estimate the Total Economic Value (TEV) of the forest to the communities residing around the forest. TEV encompasses direct use values (timber, and non-timber forest products), indirect use values (water regulation, soil erosion prevention, etc.) as well as non-use values (existence value, bequest value).

In order to estimate indirect use values, as well as non-use values, the use of stated preference (SP) techniques was deemed appropriate. This was justified on the grounds that there are very limited data on the ecological services of the forest that would facilitate the use of revealed preference methods. Furthermore, SP methods are better suited to estimate non-use values.

The chosen method for measuring the values that the local population attaches to the services of the forest is Choice Modeling (CM). A non-monetary "cost" attribute was used, in order to increase the appeal of the payment vehicle. Following the pretesting of the questionnaire, the survey was administered to 320 respondents in face-to-face interviews. Both willingness to pay (WTP) and willingness to accept (WTA) are estimated through the use of two different designs: one with positive ecological changes and a WTP attribute and another with negative changes and a WTA attribute. A Nested Logit (NL) model was applied. The results show a strong divergence between WTP and W'TA.

IasonDiafas,idiafas@uni-bonn.de 
Focus 1: Agroforestry management in an ecological and socio-economic context

\author{
James B. Kung'u \\ Kenyatta University, Kenya \\ Alfred Gichu, Kenya Forestry Service, Kenya
}

\title{
Opportunities for Carbon Trading Among Smallholder Agroforestry Farmers in Sub- Saharan Africa
}

The Clean Development Mechanism (CDM) of the Kyoto Protocol has been developed to allow developing countries to contribute to the global effort to stabilize Green House Gas (GHG) levels in the atmosphere while at the same time assisting them achieve sustainable development. This is to be achieved through reduced industrial production, energy substitution and efficient production processes or by providing sinks of atmospheric carbon dioxide through the carbon sequestration programmes. Carbon sequestration through agroforestry programmes has been approved as eligible activities for participation under the CDM. Many countries in sub Sahara Africa like Kenya has met the requirements under the United Nations Framework Convention on Climate Change (UNFCCC) for hosting forestry projects under CDM.

This paper report on a research that was aimed at assessing whether the smallholder agroforestry farmers in sub Sahara Africa are able to participate in carbon-offset programmes among other agroforestry outputs. The research tried to establish whether there are social and institutional structures in place that could facilitate carbon trading by assisting farmers and investors to manage and share the benefits. The research was both analytical and descriptive with the study subjects comprising landowners. Simple random sampling was used to select the sampling units while the sample size was determined using the fisher et al. formula. Data was collected using actual measurements, an interview schedule, discussion with relevant extension agents and observation checklists. The study established that opportunities exist for smallholder agroforestry farmers in sub Sahara Africa to incorporate carbon offset as agroforestry product for participation under the CDM. With an average farm size of 3-5 acres that is privately owned but which nevertheless suffer crop failure after every four years in $94 \%$ of the cases, opportunities for promoting tree farming within farming systems are immense. This is despite the technological, investment and physical barriers that seem to deter mass uptake of farm forestry as a profitable enterprise. Currently farmers have been able to stock 2.08 tons per ha of carbon with a market value of Kshs 31,200 through innovative agroforestry technologies and with support from the Government and the other private agencies.

James B. Kung'u, kungu_james@yahoo.com 
Focus 1: Agroforestry management in an ecological and socio-economic context

\section{Jan Barkmann}

University of Göttingen, Germany

Sebastian Koch, University of Göttingen, Germany

Heiko Faust, University of Göttingen, Germany

\section{Differences in Power Structures regarding Access to Natural Resources at the Village Level in Central Sulawesi (Indonesia)}

Southeast Asia has one of the highest rates of forest loss globally. Within SE Asia, Indonesia has some of the largest little-fragmented primary forests while forest is lost at a rate of $1.17 \%$ annually. The Indonesian province of Central Sulawesi contains some of the remaining forests, and provides conservation core areas of the Wallacea biodiversity 'hotspot'. Also ethnic diversity is high. In spite of more than three decades of scientific discussion, the driving forces of tropical rainforest conversion continue to be a matter of debate. In this case study, we explore institutional inter-village differences in such driving forces focusing on power inequalities between "village elites" and depending smallholders.

Lore Lindu National Park (LLNP) is one of only two larger protected areas in Central Sulawesi. In LLNP and the surrounding districts (kecamatan), forest is lost at a rate of around $0.6 \%$ annually mainly due to encroachment by smallholder cacao agro-forestry. In three villages adjacent to LLNP, a census $(\mathrm{n}=898)$ focusing on household characteristics including livelihood strategies, resource access and social position in the village was conducted in 2004. From this census, we knew that the villages represent a gradient of (regional) migration intensity and, consequently, ethnic composition. Village A represents a relatively static type with low immigration and a high share of autochthonous ethnics $(\sim 88 \%)$, whereas village $\mathrm{C}$ is characterised by a high influx of migrants, mostly Buginese from South Sulawesi who mainly arrived since 1980 ( $\sim 4 \%$ Buginese). Village B represents an intermediate type ( $\sim 35 \%$ migrants of differing ethnics). Based on census data, cluster analysis identified socio-economically differing household groups. Also, a relative poverty index was calculated.

In this study, we used results from census analysis as well as informal interviews with key informants in order to select ten households per village that appeared likely to belong to a village elite considering land holdings/wealth, prominent social position in the village (member of formal or traditional leadership), and perceived success in agriculture. With these households, semi-structured in-depth interviews on natural resource use patterns including questions on village-level institutions and the related power structures governing intra-village resource use decisions were conducted in March-June 2007.

In village $A$, all interviewed individuals highlighted the strong influence of local institutions mainly exerted by the Council of Traditional Leaders (Lembaga Adat). Its members belong to a clan of families that represent the first settlers in village A. Regularly, individuals of these families possess large land holdings, and also occupy most positions in the formal village leadership (Kepala Desa, Badan Perwakilan Desa). If a household has too little land to cover its basic needs, the head of the concerned household will appear at a Lembaga Adat meeting, explain his/her cause, and hope for the appropriation of a forest plot. This land stems from a community forest that is located inside LLNP but for which the formal village leadership negotiated "traditional" - i.e., restrictive - use rights from LLNP administration. Likewise, the Lembaga Adat grants permissions for the extraction of timber and non-timber forest products (NTFP) such as rattan. Regularly, punishments are imposed by the formal village leadership if villagers violate resource use regulations set by the Lembaga Adat. Immigration by members of other ethnic groups is strictly discouraged, e.g. by restricting land purchases by locals. Recent poor migrants are discriminated against (smaller land appropriations, restricted use of village public spaces, and access to traditional leadership). 
Focus 1: Agroforestry management in an ecological and socio-economic context

In migration dominated village C, Buginese from South Sulawesi are substantially more prosperous that the autochthonous households mainly due to more effective cacao cropping. Autochthonous as well as Buginese interviewees agree that a widespread laissez-faire attitude on natural resource use prevails. Every household is regarded as responsible for itself. Virtually without institutional restrictions, Buginese migrants as well as some better-off local households acquire land via purchase from poorer, local households. The land-stripped local households, in turn, acquire new land by illegally clearing primary forest inside LLNP. These new plots are of inferior land use quality, and of a highly precarious tenure status. Power inequalities are apparent, but in contrast to village A they are solely based on economic power relations between poor and agriculturally successful households.

Village B is to some degree similar to village A. The Lembaga Adat regulates access to a community forest (here: outside LLNP) which is granted only to autochtonous households. In contrast to village A, land transactions are not restricted, however. Therefore, Buginese migrants as well as better-off local households tend to acquire land via purchase from poorer, local households. Groups of autochthonous, partly land-stripped households (15-20 persons) prepare new agricultural land via conversion of uphill primary forest collectively. This is preferentially done in the area of the community forest.

The high prices for the cash crop cacao as well as the relative land abundance at Central Sulawesi's rainforest margin can be regarded as ultimate driving forces of regional deforestation. Differences in village institutions around LLNP, however, strongly mediate the patterns of natural resource access including forest conversion. In all three villages studied, strong power gradients were observed. In village A, we found traditional, nearly 'feudal' power relationships enforcing strict limitations of land conversion, exerted by a group of autochthonous "first settlers". Additionally, (poor) migrants from nonautochthonous ethnics are discriminated against in terms of land appropriation. In contrast, no such village-level institutions limit forest conversion in village $C$. Here, all traditional power relationships appear replaced by economic power based on petty capitalist-type production of agricultural commodities. While it would be possible in village B for a (better-off) migrant household to convert forest land inside LLNP, the economically powerful migrant households prefer the purchase of better land at the valley bottom for which also land titles can be issued. Village B represents a transitional type in which traditional institutions and power structures still appear in place. Because land transfer to economically potent migrants is allowed, however, forest conversion is only little restricted. With the rise of a group of agriculturally successful migrants, either social conflict or an end to social discrimination against the migrants appears likely.

Jan Barkmann, jbarkma@gwdg.de 
Focus 1: Agroforestry management in an ecological and socio-economic context

\section{Jan Barkmann}

University of Göttingen, Germany

Iris Motzke, University of Göttingen, Germany

Erin Guth, Angkor Centre for Conservation of Biodiversity, Cambodia

Thomas Cherico Wanger, University of Adelaide, New Zealand

\section{Socio-economic conditions of biodiversity conservation in the Phnom Kulen National Park region, Central Cambodia}

Although Cambodia is part of the Indo-Burma Biodiversity 'hotspot', we know very little about its biodiversity, and the socio-economic conditions for biodiversity conservation. For this study, we chose four settlements near and inside Phnom Kulen National Park (PKNP) all located at a single access road from the city of Siem Reap. In these four settlements, 149 rural households were surveyed by structured face-to-face interviews. Based on the survey results, we present and discuss three issues in this contribution: (i) Land use changes along the town-national park gradient resemble an open access colonisation of a forest frontier in the Phnom Kulen National Park region; (ii) forest resource utilisation in general is an important livelihood strategy for local smallholders; (iii) hunting, consumption of wildlife, and its use for traditional medicine in particular play only a minor role for rural households since wildlife populations are already depleted. We found that land use changes are driven by population growth, regional immigration, and missing land rights. The entire study area is characterised by short-fallow shifting cultivation and low-intensity wet rice production. Continuous forest cover is restricted to PKNP. Farther away from town, land availability and average chamkar size (shifting cultivation land) is larger. The use of forest resources (timber and non-timber forest products) is more domi $\neg$ nant closer to still more forested PKNP. In contrast, wage labour is more important closer to town. In terms of importance ratings, this trend is statistically significant at $\mathrm{P} \leq 0.05$. We conclude that a unrestricted colonisation of the forest frontier is in its final stages, and has already reached and partly trespassed PKNP. We did not find a statistically significant relationship between the use of non-timber forest products and an index of relative poverty. The index was constructed from the first factor of an explanatory factor analysis using asset and consumption variables at the household level. Using high value forest resources, namely timber, can contribute to a better material well-being in contrast. Timber extraction is quantitatively restricted, however, due to low availability with the exception of the PKNP where extraction is illegal. Consequently, only few households profit from this resource. This suggests that most forest resources are used only to sustain or complement income levels; their utilisation is rarely a way out of poverty. We cannot rule out, though, that forest resources serve an important insurance against agricultural crop failures or in case of sudden cash need. Because of the lack of an effective conservation infrastructure and widespread dangers from anti-person mines, scientific monitoring data on the status of wildlife populations in the PKNP region do not exist. Thus, our statements on wildlife populations are also based on self-reported observations by local residents. Only few people hunt wildlife professionally, consume wildlife, or use it for traditional medicine. Availability ratings by local residents indicate that availability of most populations of larger wild animals is low. The only exception are wild boars which adjust well to the conditions of an agricultural landscape. Low wildlife availability even within still forested PKNP - probably because of the civil war history of the region - suggest that the PKNP region is exposed to an "empty forest syndrome" where species loss precedes habitat loss. Strategic underreporting of local hunting is likely; still, personal observation and the structure of the illegal wildlife trade in the region suggests that remaining hunting pressure is exerted mainly from well-equipped outsiders with business ties to the nearby Vietnamese centres of wildlife trade. We conclude that although the local level of wildlife utilisation is low remaining hunting pressures may still be too high in face of depleted populations. Because of poverty-driven 
Focus 1: Agroforestry management in an ecological and socio-economic context

pressure on forest and forest resources, conservation projects in the project area need to be complemented by developmental projects. In addition, stricter law enforcement for wildlife protection is urgently required to minimize further direct species decline.

Jan Barkmann, jbarkma@gwdg.de 
Focus 1: Agroforestry management in an ecological and socio-economic context

\section{Jan Priebe}

University of Göttingen, Germany

Stephan Klasen, University of Göttingen, Germany

Stefan Schwarze, University of Göttingen, Germany

\section{The impact of economic vulnerability on deforestation at the rainforest margin}

There has been widespread concern worldwide over agricultural land expansion through deforestation and a number of policies have been proposed and implemented to stop or at least mitigate this trend. An investigation of the Indonesian context is of particular importance. Most of Indonesia's total area is under forest cover and represents nearly half of Asia's remaining rainforest. Moreover, the growing conversion of forest land to agricultural land, the rate of deforestation in Indonesia is among the highest in the world. There is a growing concern about deforestation and agricultural land expansion in the area that could have serious consequences on biodiversity, agricultural productivity, and food security.

In this study the authors aim to investigate the role of non-farm income and income diversification on deforestation of rain forests in Indonesia. Further on, a particular focus will be put on the role of economic vulnerability as a potential driving factor for forest clearing activities via its effect on income diversification.

This study draws on unique panel household data survey obtained from the STORMA research project in Central Sulawesi, Indonesia supported by the German Science Foundation (DFG). The data set comprises 3 waves of detailed income and expenditure household surveys in the study area from 2001 to 2007. Moreover, additional data on forest coverage and land use practices for the whole period were obtained by satellite images and project specific remote sensing efforts.

JanPriebe,jpriebe@uni-goettingen.de 
Focus 1: Agroforestry management in an ecological and socio-economic context

\section{Jana Juhrbandt}

University of Göttingen, Germany

Jan Barkmann, University of Göttingen, Germany

Yann Clough, University of Göttingen, Germany

Teja Tscharntke, University of Göttingen, Germany

\section{The 'cocoa cycle' in Central Sulawesi: Will pest pressure and aging plantations drive cocoa production into a recession?}

Global cocoa production is subject to boom-and-bust-cycles resulting in a geographic shifting of production centres. These 'cocoa cycles' are not only demand driven but are also caused by a complex interplay of socio-economic and ecological factors on the supply side. As cocoa trees exceed the age of approximately 20 years, farmers face the difficulty of naturally declining yields per tree. The abandonment of cocoa plots and the establishment of new plots on forest clearings is a consequence regularly seen, resulting in a highly unsustainable form of land use. Replanting cocoa on the same plot is often avoided because soil fertility is higher and pest pressure is lower on recently converted forest lands. An inputintensive management, a low shade cover and the occurrence of pests and diseases may shorten this cycle significantly. Cocoa agroforestry in Central Sulawesi had a boom phase during the 1990ies. In 2003/2004 the Indonesian cocoa exports already declined due to increased pest pressure and first reports on yield reductions up to $50 \%$ emerged from Sulawesi in 2007, raising the question if cocoa production in Sulawesi may come into a bust phase sooner than expected.

Based on 144 cocoa farming households in 12 villages around the Lore Lindu National Park, we surveyed various production parameters for the duration of one year, including capital and labour, inputs, management activities and yields as well as the occurrence of pests and diseases. Additionally, farmers perceptions on yield decreases due to pest and disease pressure were investigated. During the same period, various agroecological determinants of cocoa yield were monitored in an extensive experiment involving 44 plots with different management treatments in the same area.

The occurrence of pests and diseases is the major threat to cocoa production in the project region. Among these the Cacao Pod Borer (Conopomorpha cramerella) and the Black Pod Disease (Phytophtora sp.) are the most serious. They occur on $100 \%$ and on $99 \%$ of all plots respectivley. The yield losses are $24,3 \%$ on average due to $\mathrm{CPB}$ (median 20\%, maximum $70 \%$ ) and $20,5 \%$ on average due to BPD (median $20 \%$, maximum $50 \%$ ). Only $8 \%$ of the farmers adopt the whole procedure of sanitation to address the problem of CPB and BPD infestation, which includes removing the affected pods completely out of the system. Although other measures are taken by a higher share of respondents $(16 \%$ harvest often and $62 \%$ prune their cocoa trees). Instead, agrochemicals are used by $55 \%$ of all farmers, substantially increasing production costs.

Cocoa trees in our sample are still young ( 9 years on average) but $31 \%$ of the farmers have cocoa trees older than 15 years. These trees are perceived as already low in production due to age. However, until now no mentionable replanting activities have taken place in the region.

Our data suggest that in the majority of plots natural aging of cocoa trees is no issue yet, because age induced yield losses are expected only in about 10 years. Nevertheless high levels of pests and disease pressure could shorten the productive phase of trees significantly. Other studies suggest that adequate plot management measures are able to reduce yield losses due to pest pressure, but rising opportunity costs of labour may deter farmers from implementing them, by that following a short-term rationale. A sustainable form of cocoa agroforestry has the potential to combine a stable economic benefit for the farmers with 
Focus 1: Agroforestry management in an ecological and socio-economic context

the conservation of high biodiversity levels as well as ecosystem services such as carbon storage and environmental buffering capacity.

Jana Jubrbandt, jjubrba@gwdg.de 
Focus 1: Agroforestry management in an ecological and socio-economic context

\section{Jana Juhrbandt}

University of Göttingen, Germany

Jan Barkmann, University of Göttingen, Germany

\section{Yield determinants in cocoa agroforestry systems in Central Sulawesi: Is shade tree cover a good predictor for intensification?}

Research results from cacao agroforests in the area around the Lore Lindu National Park (LLNP) in Central Sulawesi show that already medium-shade tree covers of 35 to $50 \%$ can maintain high shares of forest related biodiversity while doubling farmer net income in comparison to densely shaded plantations. However, unshaded systems often result in even higher economic returns. This entails incentives for further shade removal and intensification. While interesting insights could be obtained using shade tree cover as an easy-to-measure proxy for intensification in cacao agroforestry, shade tree cover is a very simple indicator for a much more complex intensification syndrome. In this contribution, we investigate if shade tree cover is a suitable intensification indicator with respect to the determination of cacao yields.

Results are based in data from a sample of one cacao plot of each of 144 cocoa producing households in 12 villages around LLNP. The plots are not a random selection of cacao plots, but were selected in order to represent a gradient of highly shaded to low-shade plots. For one year, farmers prepared weekly reports on yields and several yield determining factors that can partly be used to describe input intensification in detail (intercrops, input of labour, pesticides, herbicides, plot management measures including shade tree removal). Shade tree cover was recorded at the beginning and the end of the measurement period and shade tree diversity at the end of the period.

Shade cover in 2007 was on average $64.3 \%$. One year later, mean shading decreased to a mere $42.3 \%$. Within the shading gradient, cacao plots show a high variability in structure and species composition with a broad range of intercrops and shade trees. Around 80 different shade tree species and 20 intercrops were identified by farmers on their plots in total. Farmers grow up to 12 shade tree species (median 2) and up to 5 (median 2) intercrops on a single plot. Shade tree cover reduces yield most significantly $(-r=0.379$, $\mathrm{P}<0.001$; Pearson correlation coefficient) as does the number of intercrops $(\mathrm{r}=-0,266 ; \mathrm{P}=0,01)$. Both factors are linearly correlated $(\mathrm{r}=0.273 ; \mathrm{P}=0.01)$. Our data also suggest that shade tree diversity affects yields. Plots with one leguminous shade tree species only (mostly Glyricidia sepium, Jack.) yield on average $835.9 \mathrm{~kg} \mathrm{dry}$ beans $/$ ha versus $477.1 \mathrm{dry}$ beans/ha for all plots with higher shade tree cover diversity. These mono-species shade canopies provide, on average, a lower shade cover than the average canopy $(31,1 \%$ vs. $42.3 \%$ on average). As expected, higher inputs of labour $(\mathrm{r}=0.227 ; \mathrm{P}=0.006)$ as well as of material inputs (cost for pesticides and fertilizers; $r=0.191 ; \mathrm{P}=0.022$ ) also lead to higher yields. Furthermore, input costs show a tendency to be negatively correlated with shading $(r=-0.154 ; \mathrm{P}=0.067)$.

In sum, we observe a high intercorrelation between several factors that may serve as indicators of intensified production in cacao agroforestry. In particular, low diversity of canopy trees and intercrops as well as low labour input go along with low shading levels. These factors as well as low shading itself are correlated with higher yields. Although a more detailed production function analysis of cacao yields would turn up more sophisticated indicators of intensification, already the presented results support the soundness of analytical procedures that indicate intensification by canopy shading. It cannot be judged from our data, however, if also biodiversity and ecosystem functioning aspects of intensification are well indicated by canopy cover values.

Jana Jubrbandt,jjubrba@gwdg.de 
Focus 1: Agroforestry management in an ecological and socio-economic context

\section{Janett Steiner}

University of Göttingen, Germany

Nobert B. Binternagel, University of Göttingen, Germany

Heiko Faust, University of Göttingen, Germany

\section{Risk Management and land use change in the face of ENSO-Events - coping strategies of rural poor in Central Sulawesi, Indonesia}

Climate fluctuations have a strong impact on agricultural cultivation, especially in the tropics (SALAFSKY 1994). One of the most dramatic phenomena of natural climate variation is ENSO (El Niño - Southern Oscillation) (KEIL 2004). Hence, studies show that due to global warming, the frequency and the impacts of extreme events such as El Niño will increase in the future (WATSON ET AL. 2001). In Indonesia El Niño is mostly associated with extreme dry events and caused considerable yield decreases in the past (SALAFSKY 1994; KEIL 2004). Be-sides that land use change is a continuous process in Central Sulawesi and not at least on cost of primary forests. Over the past 20 years the cultivation area of cacao was increased and intensified continuously (MAERTENS 2003).Thus we try to explain the relatively fast land use change in association with periodic drought effects in the area:

First, we evaluate if and how ENSO related droughts are perceived by the rural population. Second, we argue that extreme droughts are perceived as a risk by local farmers, and that the change of land use represents a key strategy in risk management.

Following current socio-geographical risk research we consider risk as a product of natural hazard and vulnerability where not a natural event (e.g. drought) alone, but the socio-cultural and politic-economical factors decide if and which regions and population are at risk (BOHLE 1994). The risk management contains risk reduction, risk mitigation and coping activities (KEIL 2004; HAYMAN \& COX 2005). The qualitative study is based on three villages and 23 semi-standardized, in-depth interviews with mostly small-scale farmers in 2008. The villages differ significant in their development dynamics, composition of population and transformation processes. The selection of the households in between the villages is based on the STORMA village census in 2004 with following studies by WEBER \& FAUST (2006) and SCHIPPERS et al. (2007).

There is evidence that drought is perceived by the local population. The attitudes to the impacts of drought (e.g. time, intensity, length) vary according to their experience, education and land use. If drought is seized it is mostly accompanied with financial problems. Different coping strategies are applied on the household level:

- Looking for other job and income opportunities: e.g. day labourer, extract and sell rattan; sell animals; change of consumption patterns; living from money or rice savings, taking of loans

- Farmers increased or changed to cacao agroforestry systems or have plans to do so because they are profitable and easy to grow. But there is little proof that this land use change represents a key strategy in the risk management of rural farmers

- Risk management strategies are used short sighted, there are almost no long term mitigation strategies to deal with future droughts

JanettSteiner,janetts@care2.com 
Focus 1: Agroforestry management in an ecological and socio-economic context

\section{Kathrin Stenchly}

University of Göttingen, Germany

\section{Spider diversity and their relation to cacao agroecosystem management in Sulawesi, Indonesia (Arachnida: Araneae)}

Indonesia is considered to be the third largest cacao (Theobroma cacao) producer in the world in which the large part of cacao is cultivated by smallholders in Sulawesi. There are several major diseases and pests that threaten cacao production. In particular the Cacao pod borer (Conopomorpha cramerella Lepidoptera) has become a major production-limiting factor in Indonesia. Spiders are common generalist predators in agroecosystems and are recognized as effective natural control agents in agroecology. In this regard a two year study about spider diversity of 44 cacao plantations at the margins of the Lore Lindu National Park, Sulawesi is being conducted since November 2006. The investigation plots within cacao plantations (each $1.6 \mathrm{ha}$ ) are along independent gradients of distance to forest, shade intensity and shade tree diversity. Via trap system consisting of pitfall traps and branch eclectors as well as sweep netting and sifting, spiders were collected from various microhabitats within the cacao plantations. Therefore comparisons between several strata within one plot and between the investigated cacao plots with their spider diversity and spider composition are possible. In addition spider webs from 440 cacao trees with descriptions to their distrubution on stem and lower canopy region, size, classification as well as prey spectrum were recorded. Using habitat factors the spider web descriptions will be analysed to conclude differences in management strategies with their capability for biological pest control. Preliminary results of the sweep netting technique are already showing differences in preferences of certain habitats on family level. Thus the number of individuals from the dominant family Oxyopidae is increasing with decreasing distance from the forest. Species from the family Thomsidae seems to prefer cacao plots next to forest as well. In general the spider fauna of the herb layer of cacao plantations is dominated by spiders of the families Tetragnathidae, Oxyopidae, Araneidae, Thomisidae and Theridiidae.

KatbrinStenchly,stenchly@yahoo.de 
Focus 1: Agroforestry management in an ecological and socio-economic context

\section{Laurène Feintrenie}

French Research Institute for Development, France

Ameline Lehebel-Peron, University of Montpellier II, France

Patrice Levang, French Research Institute for Development, France, and CIFOR, France

\section{Evaluation of the production potential of complex agroforests. The example of rubber agroforests in Lubuk Beringin (Indonesia)}

Indonesian agroforests, smallholders' plantations combining a large number of perennial species, are known to conserve at least $50 \%$ of the biodiversity of the primary forest. In the 1990 s, some scholars predicted that all agroforests would be converted into monocrop plantations before the year 2000. Yet, in Jambi province, rubber agroforests (Hevea brasiliensis) remain an important component of the landscape. Lubuk Beringin, a small village at the foot of the Kerinci Seblat range (district of Muara Bungo), is a perfect example of a site where jungle rubber is still maintained and renewed. Much attention has been paid to rubber production in different agroforestry systems, influence of plantation density, combination of species, frequency of tapping, etc. However, the production potential of a rubber agroforest does not depend solely on rubber, but also on secondary products. Their potential has generally been neglected because of the difficulty to estimate their production. Indeed it seems impossible to apprehend the diversity of agroforests' vegetal composition, and then of secondary products. Besides, interactions between species and influence of space, light and soil resources on each tree make impossible the automatic generation of different type of agroforests by simple modelling. This work proposes a new method of evaluation of complex agroforestry systems potential, based on small sample of plots, survey and economic modelling.

To evaluate the production potential of rubber agroforests, measures were realized in about 20 plots and followed by interviews with their owners. Plots were selected so as to form a synchronic sequence representing all the phases of an agroforest's cycle of production. The objective was to estimate the whole production of this complex agroforest, which is rich in useful species, like fruit trees, timber trees, aromatic trees, etc. Origin, age and production of each tree were determined during a visit of the plot with the farmer. Then, quantities of each product, seasonality, destination and labour needs were evaluated in a second interview with the farmer. To complete this result and apprehend agroforests' diversity at the village scale, a survey on agroforests vegetal composition and production was conducted in the village, and ended in a typology of agroforests. An economic model of agroforest performances was built for each type; these models show examples of agroforests met in the village, but cannot take into account the high diversity of composition and management of this complex system at the regional level. In a second step we intend to conduct quick surveys in other villages so as to draw new models adapted to their specific agroforests and apprehend the diversity of rubber agroforests in Jambi.

Laurène Feintrenie,l.feintrenie@cgiar.org 
Focus 1: Agroforestry management in an ecological and socio-economic context

\section{Luitgard Schwendenmann}

University of Göttingen, Germany

Michael Köhler, University of Göttingen, Germany

Dirk Hölscher, University of Göttingen, Germany

\section{Using stable isotopes of water to trace plant water uptake in a cacao agroforest, Sulawesi, Indonesia}

For soil water use within agroforestry systems, it is often hypothesized that resource partitioning among herbaceous annual plants (crops) and trees reduce competition, because trees might take up water from greater soil depths. However, data on plant water acquisition strategies among different tree species grown in tropical agroforestry systems are scarce. The goal of this study, therefore, was to determine the origin of water used by coexisting trees in an agroforestry system. The study was conducted in a 6-year-old Theobroma cacao L. plantation shaded by Gliricidia sepium Jacq. trees on the island of Sulawesi, Indonesia. Water isotopes $\left(\mathrm{D}\right.$ and $\left.{ }^{18} \mathrm{O}\right)$ in soil water $(0-10,10-30,30-50,50-70$ and $70-100 \mathrm{~cm}$ soil depth) and plant water from 6 cacao and 6 Gliricidia trees were measured over eight months in 2007. In addition, rain water and groundwater samples were analyzed. A mixing model was used to determine to proportional contribution of water from different soil depths. Our fist results indicate that cacao trees obtained the highest proportion of their water from the upper $0-30 \mathrm{~cm}$ soil horizon. In contrast, the shade trees tented to take up a higher share of their water from deeper layers $(30-100 \mathrm{~cm}$ soil depth). These results support the assumption that cacao and shade trees differ in their water uptake pattern. Ongoing analyses of samples from a drought experiment will show whether water uptake of cacao and shade trees changed under drier conditions.

Luitgard Schwendenmann, lschwen@gwdg.de 
Focus 1: Agroforestry management in an ecological and socio-economic context

\section{Marhawati Mappatoba}

University of Palu, Indonesia

\section{Co-Management as Strategy to Balance Community and Conservation Interests in the LLNP}

How to meet the challenge of protecting biological diversity while at the same time securing selfdetermined local livelihood? State-base management approaches to nature conservation have often failed to balance the goal of conservation and the goal to improve livelihood of local community especially in developing countries. Against this background, community agreements on conservation as a comanagement strategy for protected areas, have a considerable potential for dealing with conflicting interests of diverse stakeholders concerning managing the Lore Lindu National Park. Negotiated agreements between communities and protected area authorities are an important strategy to meet this challenge.

In this article, we take a closer look at the community agreements on conservation in the Lore Lindu National Park in Central Sulawesi, were supported by NGOs with different visions and expertise, dedicated community leaders, and a visionary Park management. An applied research project helped to identify potential and challenge of his promising approach. These three NGOs (YTM, TNC and CARE) promoting agreements are part of three worldwide concern and agenda; defend the rights of indigenous people, protect nature, and poverty alleviation. Each of the three organizations working in the Lore Lindu area belongs in one of these agendas, and accordingly has strengths and expertise in different fields. YTM has a strong expertise in advocacy for indigenous rights and in using sensitive approach to strengthen indigenous knowledge and institutions, while TNC has strong expertise in protecting endangered animals and plants from distinction, and CARE has strong expertise in promoting rural development and helping families to escape from poverty. It was concluded that these NGOs will have better opportunities of combining their unique and strengths in the future by working together and coordinating their activities in the form of wise collaboration.

Marbawati Mappatoba,wati_chairil@hotmail.com 
Focus 1: Agroforestry management in an ecological and socio-economic context

\section{Markus Fischer}

University of Bern, Switzerland

Andreas Hemp, University of Potsdam, Germany

\section{Effects of altitude, disturbance and land use on the plant species diversity of Kilimanjaro ecosystems}

Natural ecosystems at Mt Kilimanjaro range from savanna at $700 \mathrm{~m}$ a.s.l. to the vegetation-free Kibo peak at almost $6000 \mathrm{~m}$. Intermediate natural vegetation zones include lowland rain forest, several forest zones dominated by Ocotea (camphor) at lower, Podocarpus at intermediate, and Erica species at higher elevations of up to $4000 \mathrm{~m}$, and afro-alpine Helichrysum dwarf scrub vegetation. Based on 1500 vegetation records - in 0.1 ha plots - taken all over the mountain we examined a) altitudinal effects on plant species diversity in natural vegetation, b) effects of burning of Erica forests, c) effects of logging of Ocotea (camphor) forests, d) effects of replacing lower-elevation forests by traditional Chagga homegardens or by commercial plantations of coffee, and e) effects of replacing savanna by corn fields. Overall, about 2000 species were recorded in all plots. In natural vegetation there were 55 species per 0.1 ha at lowest elevations, which increased to 60 species at $1300 \mathrm{~m}$ a.s.l., and decreased to about 10 above $4500 \mathrm{~m}$. Burned and natural Erica forests had about 20 species, but while the number decreased with altitude for natural ones, it increased for disturbed ones, and the number of species per burned plot depended on the time since fire. Logged camphor forests had less than a third of the species of natural ones and while species diversity decreased with altitude for natural ones it did not for logged ones. While plots in natural submontane forests harbored 60 species, plots in traditional Chagga home gardens at the same elevation 40 species and plots in coffee plantations 20 species. Savanna plots had 55 species, the diversity of current corn fields was very low and the diversity of fallow corn fields approached savanna diversity. Our data demonstrate that Kilimanjaro constitutes a hotspot of plant diversity, whose distribution largely depends on altitude. Moreover, disturbance by fire and logging and increased land use intensity generally affected diversity very negatively. A naive interpretation of altitudinal effects as proxy of climate change effects would lead to the prediction that increased temperatures could increase species diversity above $1300 \mathrm{~m}$, while they would decrease it at lower altitudes. However, a simultaneous general decline of precipitation, as currently discussed, would most likely more than offset any positive effects on species diversity also at higher altitudes. Also, our study suggests that disturbance and land use effects would override any climate effects of the strength of current altitudinal effects. Overall, we conclude that plant species diversity at Kilimanjaro is under pressure by direct land-use related anthropogenic effects and by indirect ones related to climate change.

Markus Fischer,markus.fischer@ips.unibe.ch 
Focus 1: Agroforestry management in an ecological and socio-economic context

\section{Norbert B. Binternagel}

University of Göttingen, Germany

Sunny Reets, University of Göttingen, Germany

Xenia van Edig, University of Göttingen, Germany

Stefan Schwarze, University of Göttingen, Germany

Heiko Faust, University of Göttingen, Germany

\section{Vulnerability and adaptability of rural households in face of ENSO-droughts - evidence from periphery regions of Central Sulawesi}

Climate change is increasing the risk of natural disasters. Adaptation to climate change takes place through adjustments to reduce vulnerability or enhance resilience in response to observed or expected changes in climate and associated extreme weather events (IPCC, 2007). This adaptation is already occurring at varying levels, and will occur with greater urgency in the future (Adger et al. 2005). Currently, adaptation to these impacts is increasingly being observed in physical and ecological systems as well as in human adjustments (see for example Kahn 2003, Yohe and Richard 2002, Haerlin and Heine 2007, Adger et al. 2004, Verchot et al. 2007, Füssel 2007). However, little is known on the very micro-level about the adaptive capacity of one of the most vulnerable groups and their strategies to cope with natural disasters: rural households in peripheral regions of developing countries.

This paper seeks to contribute to reduce the knowledge gap with a case study from a rainforest area in Central Sulawesi, Indonesia. Focus of the paper is the analysis of impacts and responses to ENSODroughts by different rural household types, which have been identified by applying cluster analysis. Its objectives are:

- To examine risk awareness and evaluate adaptability of households,

- To investigate if different households-types use different strategies of adaptation,

- To assess the adaptive capacity of different household-types in order to derive policy recommendations.

The article analyses adaptation strategies not just on a general household-level but allows a distinguished examination of strategies between different household-types and thus avoids rash generalizations. As the absolute assessment of successful adaptation is quite problematic (Adger et al., 2005) we estimate the degree of adaptation of households relative to each other, which leads to comparable conclusions about the adaptive capacity between household-types.

This paper employs an asset-based livelihood framework (Chambers and Conway, 1991) to analyse household risk management with regards to ENSO-Droughts. For the assessment of adaptive capacity emphasis is placed on the analysis of the households' endowment with social-, human, natural-, physical and financial capital, which is crucial to adapt to ENSO-Droughts. For data generation three waves of qualitative (semi-structured/in-depth) interviews were done. This data was complemented by quantitative household- and village-level data. To gain additional background information group discussions with participatory rural appraisals methods (PRA) like Venn- and Impact Diagrams, Timelines and Matrix Scoring were utilised.

The paper shows that ENSO-drought effects are found on micro level in peripheral regions of Sulawesi and that rural households have different adaptive capacities. For example ENSO-drought effects vary considerable between small and large specialised cacao farmers. Small specialised cacao farmers have a 
Focus 1: Agroforestry management in an ecological and socio-economic context

lower adaptive capacity to droughts than large specialised cacao farmers. They lack additional sources of income and can hardly absorb shocks. Further, their coping strategies are almost entirely based on the household's limited human capital itself (ability to work, knowledge, skills). By contrast, large specialised cacao farmers are the only households-type with more than one mitigation strategy which reduces vulnerability. The adaptations of strategies which reduce vulnerability to ENSO-Droughts are strongly influenced by social and personal capital. The knowledge transfer which promotes the adaptation is manly taking place within ethnic groups and local institutions. Thus, two possibilities to enhance the adaptive capacity could be:

- Strengthening local institutions and increased integration of migrants

- Direct support for the accumulation of human capital for the most vulnerable groups by capacity building measures like training courses, reduction of expenses for elementary and junior high schools and the improvement of medical services on village level to support personal skills, knowledge, ability to labour and good health.

Norbert B.Binternagel,norbert.binternagel@email.de 
Focus 1: Agroforestry management in an ecological and socio-economic context

\section{Oleg Panferov}

University of Göttingen, Germany

Stefan Erasmi, University of Göttingen, Germany

Pavel Propastin, University of Göttingen, Germany

Domenik Seidel, University of Göttingen, Germany

Heinrich Kreilein, University of Göttingen, Germany

Gode Gravenhorst, University of Göttingen, Germany

\section{How much shade the shade trees provide?}

Cacao, one of the world's most important perennial crops. It is cropped under the shade of forest trees or as a monocrop without shade. When growing under the shade trees the growth rates and yield of cacao depends stongly on light abvailability which in turn is controlled by number and structural parameters of shade trees (see e.g. de Almeide and Valle, 2007 on the review of abiotic factors influence on cacao). To quantify the actual amount of light intercepted by shading trees annualy and during different time periods the high resolution 3D model of raditive transfer (SPM-3D) developed in Department of Bioclimatology, University of Goettingen was implemented. The 3D structure of shade trees and its variations were retrieved from hemispherical photos made repeatedly above cacao stands at fixed points.

OlegPanferov,opanfyo@gwdg.de 
Focus 1: Agroforestry management in an ecological and socio-economic context

\section{Pavel Propastin}

University of Göttingen, Germany

Stefan Erasmi, University of Göttingen, Germany

Oleg Parfenov, University of Göttingen, Germany

Martin Kappas, University of Göttingen, Germany

\section{Patterns of vegetation response to ENSO warm events in Indonesia during the period 1982-2007}

El-Nino southern Oscillation (ENSO) is a widely acknowledged global climatic phenomenon caused by a rapid increase of sea surface temperature in the tropical Pacific. The ENSO phenomenon has effects throughout the world and one of these effects is redistribution of rainfall from Indonesia, New Guinea and Australia into the Pacific and to the pacific coast of South America. This redistribution leads to drought conditions in wide areas of South-East Asia. The goal of this study was to investigate and to quantify the relationship between variability of ENSO and drought events over Indonesian archipelago. We investigated the teleconnection effect between vegetation activity and ENSO by calculation of correlations between the Normalized Difference Vegetation Index (NDVI) and two ENSO indices, namely Sea Surface Temperature Anomalies (SSTA) and Southern Oscillation Index (SOI). The study examined month-to-month correlations between NDVI retrieved from the Advanced Very High Resolution Radiometer (AVHRR) and SPOT VGT sensor and the two ENSO proxies over the region for each ENSO warm event within the period from 1982 to 2007 at the scale of individual vegetation types and at the per-pixel basis. The results proved that the 1982-83 ENSO warm episode was rather short but the most intense one within the study period (1982-2007). The 1997-98 El Niño lasted longer but had a weaker influence on NDVI. However, compared to the 1982-83 El Niño the extent of the affected areas for the 1997-98 event is comparable to the 1982-83 period. Compared to these two major warm periods, the 1987-88 and 1991-94 periods had minor effect on vegetation productivity. Another aspect of the study was the investigation of land cover type specific sensitivity thresholds of vegetation cover to ENSO warm events. The results for the 1997-98 ENSO warm period confirmed the hypothesis that the vulnerability of vegetated tropical land surfaces to climate extremes like EL Nino caused precipitation decrease is considerably affected by land use intensity. In particular, it could be shown that natural forest areas are more reliable to drought stress than degraded or managed forest areas. Comparing all four El Nino phases, the spatial distribution of affected areas seems to be random over Indonesia, but there are distinct core regions of ENSO impact during all ENSO events.

Pavel Propastin,ppropas@uni-goettingen.de 
Focus 1: Agroforestry management in an ecological and socio-economic context

\section{Perdita Pohle}

University of Erlangen-Nuremberg, Germany

\section{Human ecological dimensions in sustainable utilization and conservation of tropical mountain forests in southern Ecuador}

Profound knowledge of region-specific human ecological parameters is crucial for the sustainable utilization and conservation of tropical mountain forests in southern Ecuador, a region with heterogenic ethnic, socio-cultural and socio-economic structures. In order to satisfy the objectives of environmental protection of tropical mountain forests on the one hand and the utilization claims of the local population on the other hand, an integrated concept of nature conservation and sustainable land use development is being sought. The DFG-research project presented here will figure out the extent to which traditional ecological knowledge and biodiversity management strategies can be made available for a long-term land use development. Investigations started in 2001 within the DFG-Research Unit FOR 402 "Tropical Mountain Rainforest" and are continuing until today within the DFG-Research Unit FOR 816 "Biodiversity and Sustainable Management of a Megadiverse Mountain Ecosystem in South Ecuador".

The tropical mountain rainforests of southern Ecuador: a "hot spot" of biodiversity

Given their location between the Andean highlands and the lowlands of the Amazon, the tropical mountain rainforests of the eastern Andean foothills in southern Ecuador have a proportionally rich biodiversity. The area under study, the region of the Podocarpus National Park, is especially noteworthy for its biodiversity. At the same time, these sensitive ecosystems have come under enormous pressure from the expansion of agricultural land (especially pastures), the extraction of timber, the mining of minerals, the tapping of water resources and other forms of human intervention.

Indigenous and local ethnic communities

Indigenous Shuar and Saraguro communities as well as local Mestizo communities are settling around Podocarpus National Park. Within the research project ethnicity is viewed as a driving factor in the relationship between man and his environment. Fundamental differences between the indigenous Shuar and Saraguro communities as well as the local Mestizo-Colonos occur not only in attitudes towards the tropical rainforest and the management of forest resources but also in wider economic and social activities, including all strategies for maintaining livelihood.

Ethnoecological studies among indigenous and local ethnic communities in southern Ecuador

Ethnospecific knowledge of the tropical rainforest ecosystem was determined in sample communities of the Shuar, the Saraguros and the Mestizo-Colonos - particularly with respect to the natural forest resources and their uses. Ethno-ecological and agro-geographical research methods were used to document the indigenous knowledge of traditionally utilized wild and domestic plants, to analyze current forms of land use (including the traditional cultivation of forest and home gardens), and to evaluate ethnospecific life-support strategies and strategies of biodiversity management.

The significance of forest products in the subsistence economy of indigenous and local groups

The Shuar of the Nangaritza valley have a comprehensive knowledge of plants and their utilization. All households make extensive use of forest products. According to the ethnobotanical survey, the actual 
Focus 1: Agroforestry management in an ecological and socio-economic context

inventory of traditionally used wild plants of the Shuar includes 211 species. Most of the plants are used to supplement the diet (74). Given the lack of state health care, medicinal plants also assume great significance (63). Many plants, too, are used as construction material (67) and have a cultural or ritual value. The Shuar use forest products exclusively for their own needs, there is no commercialization.

Agrobiodiversity in the Shuars' and Saraguros' tropical home gardens (huertas)

The tropical home gardens of indigenous communities are regarded as places of great agrobiodiversity and refuges of genetic resources. Furthermore, they contribute significantly to securing and diversifying food supplies. The forest gardens of the Shuar are characterized by an especially great diversity of species and breeds. In five huertas studied (size: approx. $600-1,000 \mathrm{~m} 2$ ), a total of 185 wild and cultivated plant species and breeds were registered. For the most part they serve as nutritional items (58\%) or medicines (22\%). The main products cultivated are starchy tubers like manioc (Manihot esculenta) and taro (Colocasia esculenta), along with various breeds of plantains (Musa sp.). Moreover, the planting of a large number of traditional local breeds was documented (e.g. 29 breeds of manioc, 21 breeds of Musa sp.). The huertas of the Saraguros likewise display a great diversity of useful plants. In one sample home garden studied in El Tibio, 51 species of cultivated plants were identified. Again, the majority are plants that supply nutritional value (41\%), followed by medicinal and ornamental plants (each 20\%). The most important cultivated products are plantains, tubers and various types of fruit.

Indigenous concepts of biodiversity management

The traditional way of biodiversity management among the Shuar is based on a sense of being closely bound culturally, spiritually and economically to the forest. The sustainability of their form of land use has long since been put to the test: one may mention in this context the regulated practice of shifting slashand-burn cultivation, which - given the correspondingly long time spent on the move - is thought to conserve the soil and vegetation; the system of exploiting forest gardens in keeping with principles of agroforestry; a humus form of cultivation featuring mulches; the use of digging sticks and dibbles as a suitable form of cultivating the soil, etc. While the Shuars' forest management can be evaluated as preserving biodiversity, the sustainability of the Saraguros' use of the environment has yet to be rated. Market-oriented stockbreeding has particularly led in recent decades to the rapid increase of pastures at the expense of forest. In spite of ecological conditions unfavourable to agricultural pursuits (steep Vshaped valleys, acidic soils, excessive precipitation), these Andean mountain farmers have at least, by means of their intensive form of pasture management, succeeded in generating a sufficiently stable agrarian and cultural landscape. In contrast to many completely deforested and ecologically devastated areas settled by Mestizo-Colonos, the richly chequered agrarian landscape of the Saraguros presents, not only aesthetically but also ecologically, a fundamentally more positive picture.

PerditaPoble,ppoble@geographie.uni-erlangen.de 
Focus 1: Agroforestry management in an ecological and socio-economic context

\section{Perdita Pohle}

University of Erlangen-Nuremberg, Germany

Andrés Gerique, University of Erlangen-Nuremberg, Germany

\section{Applied Ethnobotany in southern Ecuador: A key to sustainable land use and biodiversity conservation}

The tropical mountain forests of the eastern Andean slopes in southern Ecuador host an extraordinary rich biodiversity. Their conservation is directly linked to the use of plant resources by people: Three ethnic groups with diverse origin, knowledge, values and traditions - namely the Mestizo, the Saraguro and the Shuar - cohabit in the area and modify the local ecosystem by using local plant biodiversity in different ways. The development and implementation of alternative land use strategies that combine biodiversity conservation and rural development are destined to fail if they do not take these ethnic particularities and use claims into account.

Since 2004 applied ethnobotanical research on plant knowledge and on use of plant resources among the three mentioned ethnic groups has been conducted within the DFG-Research Unit 402 and 816. The poster presents the main results of the investigation, including the results of the ethnobotanical inventory and the local land use practices. It also includes plant species with potential for income generation. Finally it gives an overview of sustainable productive alternatives that could be implemented in the area in order to avoid further regional deforestation and biodiversity loss.

PerditaPoble,ppoble@geographie.uni-erlangen.de 
Focus 1: Agroforestry management in an ecological and socio-economic context

\section{Ramadanil Pitopang}

University of Palu, Indonesia

Ismet Khaeruddin, University of Palu, Indonesia

Achmad Rizal, University of Palu, Indonesia

\section{Biological Diversity of the Morowali Nature Reserve Central Sulawesi, Indonesia}

Morowali Nature Reserve is one of protected area in the Wallacea region which was established in 1980, to protect 525,500 acres of complex habitat types, including coral reefs, mangroves, rainforests, grasslands, swamps, and lakes. Morowali's mountain habitats include three peaks over 7,000 feet, including the majestic 7,946-foot Mt. Tambusisi. The reserve also contains a little-explored 980-foot deep cave. Morowali serves as a water catchment for five big rivers-Sumara, Morowali, Solato, Sobuko, and Bongka. These rivers provide essential environmental services to people in the surrounding areas, including water resources for irrigation, industries, and domestic use.

An initial survey on the biological diversity of the Morowali Nature Reserve has been done at three (3) sites namely Taronggo, Kea-kea and Uwata which were located arround the reserve from May-June 2007. The surveyed aimed to collect the biological diversity data including vegetation, avifauna and large mammals by using survey methods on transect along $3 \mathrm{~km}$ in each location.

It is more than 400 number of fertile herbarium specimens collected and deposited at the Herbarium Celebense (CEB) Universitas Tadulako. Structure and composition of vegetation in the studied area indicated a specific pattern. We recorded several unique and endemic plant to Sulawesi such as Macadamia bildebrandii (Proteaceae), Knema celebica (Myristicaceae), Gymnacranthera maliliensis, (Myristicaceae) Sarcotheca celebica (Oxalidaceae), Licuala celebica (Arecaceae), Gronophyllum macrospadix (Arecaceae), Korthalsia celebica (Arecaceae), Dinochloa barbata (Poaceae), Deplancea bencana (Bignoniaceae), Dillenia serrata and Dillenia celebica (Dilleniaceae) etc.

Although exact numbers are still not available, initial surveys show that Morowali is home to most of Sulawesi's endemic large mammals, including lowland anoa or dwarf buffalo, the pig-like babirusa, the Sulawesi pig, and a species of Sulawesi macaque. Morowali's mountain terrain provides habitat for the Sulawesi giant civet, one of the world's least-known carnivores, and the small nocturnal cuscus. For avifauna, latest survey recorded that of the 156 bird species, 49 of them are endemic. Notable species that endemic to Sulawesi include the maleo (Macrocephalon maleo), Yellow-crested cockatoo (Cacatua sulphurea), Ornate Lory (Trichoglossus ornatus), Snoring Rail (Aramidopsis plateni), Black Pigeon (Turacoena manadensis), and all five endemic kingfishers.

Numerous raptors, water birds including the Wooly-necked Stork (Ciconia episcopus), and nightjars are also found in Morowali Nature Reserve. Reptiles include the bizarre Sail-fin Lizard (Hydrosaurus amboinensis), and huge 12 meter-long Reticulated Pythons (Python reticulatus). In addition, a wealth of fascinating plants can also be seen in the reserve, ranging from massive Agathis (damar) trees to rare orchids and several species of pitcher plants (Nepenthes spp).

Morowali Nature Reserve is surrounded by 21 villages located along the boundary and also inhabited by the indigenous people of Wana, the majority of whom still practice their ancestral patterns of existence by moving house every few years to clear a new patch of forest and plant their crops. They hunt birds and other animals in the forest with blowpipes, snares, and spears, and fish in the rivers and lakes. Almost everything they use is made from the forest, including barkcloth clothes. The Wana people have communal rights to several areas in Tokala Mountain Ranges inside the nature reserve. 
Focus 1: Agroforestry management in an ecological and socio-economic context

Despite its important values for biodiversity conservation and economic development, Morowali faces serious threats for its long-term conservation, including illegal logging and hunting, agricultural encroachment, and road development. Although Morowali's biodiversity has not yet been definitively catalogued, scientists believe that the reserve's complex habitat types will yield undiscovered populations of Sulawesi's endemic flora and fauna species.

Based on the threats potentially affect Morowali Nature Reserve, The Nature Conservancy (based on Goal 2015 to establish one million hectares protected area in Sulawesi) has planned to take the reserve as a new conservation site. The target for MNR, based on 2007/2008 Work Plan, is to establish complete Management Plan which will be containing details activities and responsibility of every stakeholder in dealing with the reserve within the frame of conservation management plan. The first milestone therefore urgently needed is to formulate the conservation management by initiating coherent planning processes.

Ramadanil Pitopang,pitopang_64@yahoo.com 
Focus 1: Agroforestry management in an ecological and socio-economic context

\section{Robert Rudolf}

University of Göttingen, Germany

Jan Priebe, University of Göttingen, Germany

Julian Weisbrod, University of Göttingen, Germany

Stephan Klasen, University of Göttingen, Germany

Nunung Nuryartono, University of Bogor, Indonesia

Imam Sugema, University of Bogor, Indonesia

\section{Determinants of Rural Income Generation at the Rainforest Margin}

Indonesia is, what the World Development Report 2008 calls, a transforming country characterised by increasing rural-urban income disparities and high poverty rates. Bearing these facts in mind, it is striking how little is known about causes and mechanism of the underlying determinants of poverty in rural Indonesia.

In this study we aim to shed more light on the determinants of rural incomes and poverty in Indonesia. Drawing on a unique and highly detailed rural household panel data set for Central Sulawesi we investigate what are the drivers of rural income growth.

Moreover, exploiting the panel structure of our data set we are able to control explicitly for endogeneity issues in our estimations. In addition, in order to identify whether our findings might hold lessons for all of Indonesia, we upscale our analysis to the national level by comparing our results with the national household data survey SUSENAS.

Our results indicate that a sharp increase in rural incomes took place in the post-crisis period. Moreover, the ability to alleviate poverty and to enjoy income growth has been strongly associated with a household's ability to diversify into the non-farm sector of the economy and its capability to invest into new production techniques. These results seem to hold for all of rural Indonesia and are robust to various model specifications.

Robert Rudolf,rrudolf@uni-goettingen.de 
Focus 1: Agroforestry management in an ecological and socio-economic context

\section{Saharia Kassa}

University of Palu, Indonesia

Marhawati Mappatoba, University of Palu, Indonesia

\section{Analysing Stakeholders Needs at Community Conservation Agreement in Lore Lindu National Park}

This research has been conducted in the area of Lore Lindu National Park (LLNP) during October 2006 to April 2007. The aim of this research is to analyze the needs of integrated stakeholders regard to the park area which would be used to promote co-management pattern as an approach in LLNP management. The amount of respondents is 130, consists of 90 from local communities and 40 person from related stakeholders in Central Sulawesi Province. Two types of analyzis have been appled, the first is the need analysis (analisis kebutuhan) and the second is prosfektif analysis (analisis prospektif).

The research results show that the contradiction needs of different stakeholders particularly for forest dependent people such as local communities in the vicinity of park and local traders in gaining benefiction from illegal logging have directly influenced the degradation of the LLNP. Several point of conflicts arise: the need of agriculture land inside or in the border area, the un-clear border area of the park between the local communities' land and the park area, and illegal logging specially for the villiages which the community agreement on conservation (KKM) are on going (Group of Village B), and villiages which have no KKM (Group of Villiage C). By applying prospektif analysis, the result mention 8 (eight) strategic factors in determining the success of co-management in the future as solution of conflict management: the acknowledgemet of the customary area, the implementation of customary sanction, the clear status of the park border area, negotiation, equity situation among stakeholders, stakeholder participation, boundry of territory, and mutually agreements.

Saharia Kassa,saharia_kassa@yahoo.com 
Focus 1: Agroforestry management in an ecological and socio-economic context

\section{Stefan Erasmi}

University of Göttingen, Germany

Lilia Martin, University of Göttingen, Germany

Yann Clough, University of Göttingen, Germany

Michael Kessler, University of Göttingen, Germany

\section{Animal and plant diversity and its relationship to landscape structure along a tropical land-use intensity gradient}

It is evident from numerous studies that landscape patterns and land use intensity affect ecological services of tropical ecosystems. The rainforest margin along the Lore Lindu national park in Central Sulawesi comprises a buffer zone between natural forest and intensively managed land with a small scaled mosaic of land use patches of different cropping systems and land use intensities. A study within an interdisciplinary project team investigated the plant and animal species diversity along a land-use intensity gradient from natural forest to cacao dominated agroforestry systems. Plant groups that were sampled include trees $(>10 \mathrm{~cm})$, herbs and mooses, whereas animal groups include ants, bees, (canopy and dung) beetles, wasps and birds. The sampled data were compiled to abundance and species richness and were compared to a set of quantitative landscape indicators that were taken from a high resolution land cover map. Landscape effects were analysed within circular buffer zones of three different diameters $(500 \mathrm{~m}$, $1000 \mathrm{~m}, 2000 \mathrm{~m})$ corresponding to the centre coordinate of each sampling area $(\mathrm{n}=16)$. First results indicate that the relationships between landscape and biological diversity are not sufficiently described with a simple relation between forest distance and species richness but need a much more complex consideration of the habitat structure and diversity. On the other hand, landscape effects may be blurred by aggregation of groups (e.g. small and large bees, species assemblage of birds, etc.).

The presentation will summarize the results of the landscape structure analysis and will contribute to the debate on factors and processes affecting the stability of rainforest margins.

Stefan Erasmi,serasmi@uni-goettingen.de 
Focus 1: Agroforestry management in an ecological and socio-economic context

\author{
Stefan Erasmi \\ University of Göttingen, Germany \\ Dominik Seidel, University of Göttingen, Germany
}

Field based inventory of shadow in cacao agroforestry systems: an approach to model the horizontal and vertical structure at the plot level from hemispherical photography

Shadow is an important variable in cacao agroforestry management and a key factor to evaluate ecological services vs. economic benefits of agroforestry stands. It is assumed that the amount of shadow is correlated to the nature-oriented cultivation of land and hence may provide a surrogate for the biological diversity in cultivated land.

The present study investigated a sample of 44 cacao agroforestry areas that are subject to a natural scientific experiment within the STORMA project in Central Sulawesi. The aim of the study was to establish a robust data base of measures for the vertical and horizontal distribution of shadow in the plots. The measurement concept included 6 height levels at 10 systematically sampled positions within each plot and resulted in an overall amount of 2640 measurements. Measurements were based on a Nikon Coolpix S3 Digital Camera system with an EC- F8 Fisheye lens converter imbedded in a self-levelling device with remote control for the camera release that was mounted on a telescope tripod.

Processing of the hemispherical pictures included the calculation of openness and shadow values as well as the computation of biophysical variables (LAI effective, LAI true) within a field of view of $140^{\circ}$ (= zenith angle $70^{\circ}$ ) for each picture. The measurements were aggregated at the stratum and plot level. The results document the intensity gradient of the agroforestry systems with shadow values at the plot level ranging from 35.4 to $81.9 \%$ and at the highest stratum $(6 \mathrm{~m})$ from 5.0 to $73.8 \%$. The corresponding LAItrue values span ranges from 1.2 to 4.8 (plot level) and 0.1 to $4.4(6 \mathrm{~m})$ respectively.

Further investigations within the research team of STORMA now focus on the ecological functions and economic value of shadow in agroforestry systems to answer the question: What is the optimum combination of management practices to protect tropical rainforest margins and support biological conservation?

StefanErasmi,serasmi@uni-goettingen.de 
Focus 1: Agroforestry management in an ecological and socio-economic context

\section{Stefan Schwarze}

University of Göttingen, Germany

Stefan Erasmi, University of Göttingen, Germany

Manfred Zeller, University of Hohenheim, Germany

\section{Has the Lore Lindu National Park been working? An analysis of the effectiveness of the LLNP in protecting the forest}

Deforestation in the tropics has large scale consequences for carbon sequestration, biodiversity conservation, and ecosystem services. One way to protect the integrity of forests is to establish protected areas (PA) such as, for example, national parks. There is however little known whether PAs really reduced deforestation rates and by how much. Taking the case of the Lore Lindu National Park (LLNP) this study aims to quantify the effect of the establishment of the park on forest conversion using a combination of GIS and socio-economic data from before (1983) and after (2001) the establishment of the park.

The results show that deforestation rates differ between areas inside and outside the LLNP. Inside the LLNP the deforestation rate is $2.1 \%$, whereas $8.2 \%$ outside. If pixel inside and outside the park would have the same outcome in the absence of the establishment of the park, the impact can be simply calculated as the difference in deforestation rates. There exist, however, systematic differences between forested areas within and outside the park. On the average, the forested area within the park is characterised by higher elevations, more gentle slopes, higher population densities, and shorter distances to tarmac roads as well as village centres. To account for these systematic differences we will apply propensity score matching to estimate the unbiased effect of the LLNP.

Stefan Schwarze, s.schwarze@agr.uni-goettingen.de 
Focus 1: Agroforestry management in an ecological and socio-economic context

\section{Sumita Sen}

Jadavpur University, India

\section{Community based agro-forestry management in North-east India: Issues of its sustainabilty}

India's Northeastern side is rich in natural endowment. Its richness is more found in the dense forests, innumerable rivers and rivulets providing enough scope for the local communities to chalk out livelihood patterns accordingly. The natural endowment of the region made most the population worshippers of nature as well natural resource dependents. The continued social and community customs and practices provided typical patterns of forest and other natural resource based management. The practices still continue in the midst of changing global environment. An analysis of the same requires states to learn lessons from such practices for the ultimate cause of sustainabilty of both the practices and the forests in particular. The paper will throw light on this issue.

SumitaSen,senmita@yahoo.co.in 
Focus 1: Agroforestry management in an ecological and socio-economic context

\section{Triadiati}

University of Bogor, Indonesia

Sukisman Tjitrosemito, University of Bogor, Indonesia

Edi Guhardja, University of Bogor, Indonesia

Ibnul Qayim, University of Bogor, Indonesia

Christoph Leuschner, University of Göttingen, Germany

\section{Leaf-Litter Decomposition And Nutrient Released in Cacao Agroforestry Ssystem at Lore Lindu National Park, Central Sulawesi}

The effect of land use type on litter decomposition and nutrient released has been studied in the margin zone of the Lore Lindu National Park, Central Sulawesi. The aim of this experiment was to determine leaf-litter decomposition, nitrogen and carbon released in the natural forest and cacao agroforestry systems. Cacao agroforestry is a traditional form of agriculture by the people of Central Sulawesi. These agroforestry systems vary from a simple system, following selective cutting of forest trees, to a more sophisticated planting design. We studied 3 different agroforestry systems, i.e. cacao planted under the remaining forest cover (CF1), cacao planted in the garden under planted trees (CF2), cacao planted in between shade trees $(\mathrm{CP})$, and natural forest (NF - as an undisturbed ecosystems).

The rate of leaf-litter decomposition was done in two periods (March to June 2005 and September to December 2005), which revealed a different pattern. The rate of decomposition was determined with the percentage of mass remaining in the end of the litter incubation. The rate of decomposition since September until December revealed a same pattern, whereas since March until June revealed a different pattern, in all study sites.

Generally, the NF had the fastest rate of decomposition than those of cacao agroforestry systems. Based upon the content of nutrient (carbon and nitrogen) remaining in the litter, there was a release of carbon and nitrogen as decomposition proceeded in all study sites. The percent of carbon released in first period was significantly different between NF, CF1, CF2 and CP. The nitrogen released in first period was significantly different between NF and cacao agroforestry systems. The percent of carbon released in second period was significantly different between cacao agroforestry CF1 and CP. The percent of nitrogen released in second period was quite similar in the natural forest (NF) and cacao agroforestry systems.

Triadiati,tria_24@hotmail.com 
Focus 1: Agroforestry management in an ecological and socio-economic context

\section{Ulrich Schuler}

University of Hohenheim, Germany

Torsten Hüller, University of Hohenheim, Germany

Ludger Herrmann, University of Hohenheim, Germany

Karl Stahr, University of Hohenheim, Germany

\section{Towards agricultural sustainability in a limestone area in Northern Thailand by modeling different land-use-scenarios}

Population growth, migration and raising living standards are known factors for expediting the extension of arable land and forest loss. For the Black Lahu people in the mountainous areas of Northern Thailand, subsistence has still priority over production of fodder for life-stock and marketable crops. Therefore, stakeholders increasingly use steeper hillsides for agriculture.

Before the onset of rainy season clearing of the land and other agricultural practices such as slacken with a hoe take place not allowing biomass to return to the soil. Consequently, erosion has taken hundreds of tons of soil per hectare over the last decades already.

Due to these unsustainable practices farmer's yields decrease steadily and thus the strongly elevated use of fertilizer and pesticides will be an integral part of the future land use.

The investigation area of the present study is located in a limestone range with typical caves and sinkholes. Surface water runs off quickly into the aquifer system. Its specialized fauna might be endangered as applied toxic agents affect the organism directly causing still not assessable harm, besides the obvious health issues of poisoned groundwater.

The Uplands Program SFB564 collected data over the last couple of years comprising local knowledge of farmers' practices. This information is put into the EPIC model trying to predict yield, erosion, nutrient loss as well as the retention of agrochemicals.

The expected results show the consequences of farming under such conditions for the environment and the farmers' livelihoods. Planning alternative and more sustainable production methods using the outcome of this study might be feasible.

UlrichSchuler,uschuler@uni-hohenheim.de 
Focus 1: Agroforestry management in an ecological and socio-economic context

\section{Umrah}

University of Palu, Indonesia

Tjandra Anggraeni, Bandung Institute of Technology, Indonesia

Rizkita Rachmi Esyanti, Bandung Institute of Technology, Indonesia

I Nyoman P. Aryantha, Bandung Institute of Technology, Indonesia

\section{Preferences of Dolichoderus thoracicus to some nutrition source containing Trichoderma sp. and dispersion of Trichoderma on cocoa pod}

Application of biocontrol agent is an integral part of sustainable agriculture system and it has been widely accepted as one of the best solution for controlling plant pest and disease. Dolichoderus thoracicus has been known as a biocontrol agent for cocoa pod borer and a vector of $P$. palmivora but little is known about their potential as a vector of antagonist fungy such us Trichoderma sp. which has high potential for controlling cocoa pod diseases caused by $P$. palmivora.

This study aimed to know preferences of Dolichoderus thoracicus to cocoa pod place on different source of nutrition and potential of this ants for spreading Trichoderma sp. on cocoa pod. Research was set up following complete random design and consist of six treatment of medium as nutrition source as following; P0 (soil and water without Trichoderma sp), P1 (soil and water with Trichoderma sp), P2 (soil, potato sucrose solution and Trichoderma sp), P3 (soil, sucrose solution and Trichoderma sp), P4 (soil, honey and Trichoderma sp) and P5 (soil, coconut waste and Trichoderma sp).

The results demonstrated that $D$. thoracicus shows preferences to certain source of nutrition as indicated by their attendance at cocoa pod placed on different nutrition source. The higher percentage of $D$. thoracicus presence was found in P4 (5,139\%) followed by P5 (4,055\%), and P2 (3,250\%). However the higher number of Trichoderma sp. dispersed by D. thoracicus was recorded at treatment P2 (1,581x109 cfu / fruit) followed by P4 (1,579x109 cfu / fruit) and P5 (1,573x109 cfu / fruit) indicating that there is no correlation between the number of $D$. thoracicus presence on cocoa pod and the number of dispersed Trichoderma sp.

Umrah,umrah_2004@yahoo.com 
Focus 1: Agroforestry management in an ecological and socio-economic context

\section{Xenia van Edig}

University of Göttingen, Germany

Stefan Schwarze, University of Göttingen, Germany

Manfred Zeller, University of Hohenheim, Germany

\section{Poverty assessment for rural Central Sulawesi, Indonesia - A panel data analysis}

Eradicating poverty is one of the most urgent concerns of development policies. Organisations aiming at reducing poverty need simple and stable methods to detect poor households. To reliably distinguish poor people, tools for poverty assessment are needed that are easy to apply and robust in time.

Based on these constraints, in 2005 we conducted research in the vicinity of the Lore Lindu National Park in Central Sulawesi to obtain indicators of poverty. We surveyed 279 households using two questionnaires. One was used to derive the daily per capita consumption expenditures. With the second questionnaire we acquired poverty indicators of several dimensions. Two different multivariate regression models were fit to this data set. One model includes all sampled indicators and the other one contains just easily assessable indicators ranked previously by local staff. Each of the models yielded a different set of 15 indicators that predicted poverty best.

In 2007, we conducted an additional survey with the identical questionnaires in the same households. Furthermore, we will apply the same regression models again to test first of all whether the sets of indicators found are still capable in predicting absolute poverty and second, if the indicators remained robust over time.

First descriptive results show that in 2007 the poverty incident remains the same. Thus, almost $20 \%$ of the sampled households are identified as absolute poor, a similar result like in 2005.

Xeniavan Edig,xedig@agr.uni-goettingen.de 


\section{Focus 2:}

Climate change effects on tropical rainforests and agroforests 


\begin{abstract}
Abdul Rauf
University of Palu, Indonesia

H. Pawitan, University of Bogor, Indonesia

T. June, University of Bogor, Indonesia

C. Kusmana, University of Bogor, Indonesia
\end{abstract}

\title{
Dynamic of energy flow under different land use on Lore Lindu National Park
}

Case study of this research was conducted in tropical rainforest, Central Sulawesi Indonesia during two years (2005 - 2007). The objective was to know land use effect of energy dynamics and to calculate quantitative value of energy flux. Analysis was done with Bown ratio energy balance (BREB) method showing that latent heat vertical flux on the forest is dominant than sensible heat flux on rain season also dray season was reaching $67.57-73.32 \%$ of net radiation $(\mathrm{Rn})$. This condition is different on the grass land. On the last land use showing sensible heat vertical flux is dominant than latent heat flux at all seasons, was reaching $63.49-78.89 \% \mathrm{Rn}$.

The realty of energy dynamic, that is representing empirical fact of deforestation effects on local climate change for example increasing of air temperature, deficit waters vapour, etc. Later it would affect on stability of environmental biophysics.

Abdul Rauf,rauf_cca@yahoo.com 


\begin{abstract}
Abdul Rauf
University of Palu, Indonesia

H. Pawitan, University of Bogor, Indonesia

T. June, University of Bogor, Indonesia

\section{Rainfall properties and vegetation characters relationship with interception lost in Tropical rainforest}

This research was conducted during two years from June 2005 to May 2007 at natural tropical rainforest in Lore Lindu National Park. The objectives were :to know the effect of rainfall properties and vegetation characters on interception lost through mathematics model approach furthermore to calculate interception loss value and to determine dominant factors influences.

The Results of observation, showed that vegetation characters in this area seemed to be still good, according to vertical and horizontal structure, LAI $\left(4.8-6.43 \mathrm{~m}^{2} / \mathrm{m}^{2}\right)$, ground cover $(68.5-92.59 \%)$ and wide canopy $5.59\left(12.05-9.83 \mathrm{~m}^{2}\right)$. Total rainfall $(\mathrm{P})$ on the first phase measuring (June $2005-$ May 2006)) is $1888.9 \mathrm{~mm}$ for 200 events. Dominant of deep rainfall is $0.5-5 \mathrm{~mm}$ with 91 events and cumulative of rainfall is $213.4 \mathrm{~mm}$ or $11.3 \%$ of P. Rainfall intensity dominant is $1-20 \mathrm{~mm}$ per hour with 121 events and cumulative rainfall that is $633.3 \mathrm{~mm}$ or $33.53 \%$ of $\mathrm{P}$. The rainfall properties mentioned above would cause net rainfall decreased.

According to total rainfall and net rainfall, so rainfall interception (Ic) reached $686.35 \mathrm{~mm}$ or $36.33 \%$ of P. Relationship between rainfall properties and vegetation characters with throughfall, stemflow and interception lost showed that deep rainfall and LAI, were two factors strongly influences. Rainfall interception is formulated in mathematics equation as follows:

Ic $=0.980+0.239 * \mathrm{P}+0.035 * \mathrm{LAI} ; \mathrm{R}^{2}=77.53$.

Application of this equation and Gash model on the second phase (June 2006- May 2007) showed that result and sensitivity of this equation was relative same with Gas model. According to data requirement and procedure of calculation hence this equation is applicable at rainfall interception calculation .

AbdulRauf,rauf_cca@yahoo.com 


\author{
Aiyen Tjoa \\ University of Palu, Indonesia \\ Beate Michalzik, University of Jena, Germany
}

\title{
Nutrient leaching potential in Cacao Agroforestry of Central Sulawesi affected by Urea and Rainwater supply
}

Cacao (Theobroma cacao) is a crop of the humid lowland tropics produced largely by small-scale growers, as in Central Sulawesi-Indonesia, and often on farms with shade trees support higher levels of biological diversity than other tropical cropping system. Cacao farm is often a host of viral and fungal diseases, loss of soil fertility and numerous socioeconomic problems facing growers often makes cacao production locally unsustainable. In an attempt to maximise yields and optimise their profit margins, some growers appear to have been more liberal in the use of nitrogen fertilizer. However, due to the unreliable rainfall in tropics, cacao has not always been able to utilise the whole of applied N. Inaccurate estimation of any of $\mathrm{N}$ input may lead to excess $\mathrm{N}$ being present in the system, which then may be leached deeper into soil profile.

Most nitrogen fertiliser is very soluble and designed for lower rainfall areas or soils that can retain this nutrient. In the high rainfall areas may not only accelerate the leach out of $\mathrm{N}$ but also other nutrients as an effect of increasing $\mathrm{N}$ availability. Since available knowledge on the soil nutrient dynamic that influence by application of $\mathrm{N}$ in tropical country during wet and dry seasons is still inadequate particularly under cacaoagroforestry system. Thus, the main purpose of this experiment is to determine the impact of urea which is applied with combination of number of watering per week on $\mathrm{N}$ and other nutrients. It is envisage that this study may provide insights for the development of better cacao management system too.

A pre-experiment was conducted by using soil from cacao field in mesocosms system, which was treated by combining 2 factors; with or without urea and one or three times watering to the mesocoms in a week, respectively. In the collected soil solution, $\mathrm{pH}$ was reduced immediately in the urea treatment independently from number of watering per week, and higher NO3-N, NH4-N, Mg, Ca and Mn content were also found but not for $\mathrm{P}$ and $\mathrm{K}$. However, increasing of water supply would increase $\mathrm{Ca}$ and $\mathrm{Mg}$ content in the collected soil solution but not for NO3-N, NH4-N, K, P and Mn.

AiyenTjoa,aiyenb@yaboo.com 


\author{
Alexandra Zach \\ University of Göttingen, Germany \\ Viviana Horna, University of Göttingen, Germany \\ Christoph Leuschner, University of Göttingen, Germany
}

\title{
Wood CO2 efflux across an elevation transect in an Andean moist forest
}

Temperature has long been identified as the most important abiotic factor influencing plant $\mathrm{CO}_{2}$ efflux and hence the $\mathrm{CO}_{2}$ exchange between vegetation and the atmosphere. However, a strong relationship between temperature and plant $\mathrm{CO}_{2}$ release rates has only been proved and verified under controlled conditions, whereas in the field, a consistent relationship is often not found. Until now our understanding is still incomplete of how relevant environmental factors impact on plant $\mathrm{CO}_{2}$ release and how they interact. The picture gets more complicated on the ecosystem level due to the fact that co-occurring plants are responding individualistically to their specific environment and probably even more so to shifts in the environmental setting. A better understanding of the variability of $\mathrm{CO}_{2}$ release among different individuals in a population, different species in a stand, and different patches of the forest is therefore crucial to predict changes in the carbon dioxide exchange between forest and the atmosphere, in particular with respect to global climate change.

In this talk, we report on in situ-measurements of the diurnal stem $\mathrm{CO}_{2}$ efflux ( $\mathrm{Rs}$ ) of representative tree species in a tropical montane moist forest in southern Ecuador during two hydrologically contrasting seasons of the year. Under the prevailing moist conditions of the wet season, mean annual temperature is relatively low and diurnal temperature amplitudes are small. In contrast, the short dry season climate is characterized by exceptionally high day-time and low night-time temperatures. Trees of this ecosystem have to cope with constantly low temperatures, compared to lowland forests, while being exposed to unpredictable short-term microclimatic shifts.

Diurnal stem $\mathrm{CO}_{2}$ efflux $\left(\mathrm{Rs}_{\mathrm{s}}\right)$ was low and completely uncoupled from changes in the dial temperature regime under humid season conditions. In contrast, during a pronounced dry season, $\mathrm{R}_{\mathrm{S}}$ was generally higher and temperature sensitivity of $\mathrm{R}_{\mathrm{S}}$ differed greatly in degree and even in the direction of response, indicating that temperature might not be the only determinant of $\mathrm{CO}_{2}$ efflux variability. In an attempt to explain the large heterogeneity of $\mathrm{R}_{\mathrm{S}}$ we integrated vapour pressure deficit, wind speed and solar radiation as the main determinants of transpiration and xylem sap flow, which are well known to influence rates of stem $\mathrm{CO}_{2}$ release. Stepwise multiple regression analyses with these meteorological predictors were either biased by high collinearity of the independent variables or could not enhance the ability to explain the variability of $\mathrm{R}_{\mathrm{S}}$ under dry and humid conditions. The drier and hotter climate of the dry season period seemed to principally favour stem $\mathrm{CO}_{2}$ efflux, whereas under humid conditions $\mathrm{R}_{\mathrm{S}}$ seemed to be uncoupled from atmospheric parameters. We assumed maintenance respiration to dominate under conditions unfavourable for energy acquisition of the tree such as found during the cool and cloudy humid season, whereas an enhanced photosynthetic carbon gain during clear-sky conditions might have stimulated stem respiratory activity and hence stem $\mathrm{CO}_{2}$ release in most of the cases. 
Focus 2: Climate change effects on tropical rainforsts and agroforests

However, the response of adapted moist forest tree individuals to a drier climate was very plastic. Diverging patterns of stem $\mathrm{CO}_{2}$ efflux among tree individuals could also indicate differences in the climatic adaptation of species, which preferably occur at higher or lower elevations. Understanding the differences in the acclimation potential of the species of a mega-diverse plant community is especially crucial with respect to tropical montane forests, since the predicted warming by 2 to $4 \mathrm{~K}$ during this century will most likely force mesic lowland taxa to migrate upwards.

AlexandraZach,alzac@gmx.de 


\begin{abstract}
Alwin Keil
University of Hohenheim, Germany

Nils Teufel, International Livestock Research Institute, India

Dodo Gunawan, Research and Development Center, Meteorological and Geophysical Agency, Indonesia

Constanze Leemhuis, Center for Development Research, Germany
\end{abstract}

\title{
The impact of El Niño-related drought on smallholder farmers in Central Sulawesi, Indonesia: Who is most vulnerable?
}

Crop production in the tropics is subject to considerable climate variability caused by the El NiñoSouthern Oscillation (ENSO) phenomenon. In Southeast Asia, El Niño causes comparatively dry conditions leading to substantial declines of crop yields with severe consequences for the welfare of local farm households. In concert with global warming, the severity of ENSO events is forecast to increase in the future. In order to compensate drought-related agricultural income depressions households in forest margin areas may resort to coping strategies that threaten the remaining forest resources, such as the extraction of wood and non-timber forest products. The objectives of this paper are (1) to assess the impact of El Niño on agricultural incomes of different types of smallholder farmers in a rainforest margin area in Central Sulawesi, Indonesia, (2) to identify those groups that are particularly vulnerable, and (3) to derive suitable crop management strategies to mitigate these income depressions and, ultimately, to help avoid environmentally damaging coping mechanisms.

To reach these goals we use an interdisciplinary modelling approach that combines regression analysis with linear programming (LP) and stochastic simulation, and integrates climatic and hydrologic modelling results. We identify five farm classes by cluster analysis. Our LP model maximizes their cash balance at the end of the time period most severely affected by El Niño. Main activities are the cultivation of rice, maize, and cocoa. Accounting for water supply as an input factor, external Cobb-Douglas production functions generate output according to the level of production intensity and predicted weather patterns. A major limitation of LP models is that they produce deterministic estimates of the expected outcome under a given scenario, hence failing to incorporate the risky nature of agricultural production. In our modelling approach, stochastic simulation accounts for variations in crop yields due to factors not captured by the production functions. Iterative model runs produce probability distributions of the model outcomes for each household class, rather than point estimates, whereby the downside risk of failing to achieve a specified minimum level of income is a particularly policy-relevant measure of vulnerability against ENSO-related drought. The results can contribute to the formulation of enhanced development policies by illustrating that drought-related crop management recommendations must be tailored to farm households according to their location, farming system, and resource endowment.

AlwinKeil,alwin.keil@uni-hohenheim.de 


\section{Ashraf Salem \\ South Valley University, Egypt}

\section{Demographic Study on the Woody Vegetation in Wadi Allaqi, South Eastern Egypt}

One hundred and twelve stands were selected at the 19 locations within Wadi Allaqi Biosphere Reserve (South Eastern, Egypt) through demographic survey of these woody plants. The locations and stands were selected to represent a wide range of physiographic and environmental variation in each tributary. In each location, sampling stands were situated randomly. Soil samples representing each stand were collected to determine some physical and chemical characters. The volume of the individuals was determined as a cylinder and used to classify the woody population in each species into nine size classes. Annual rings, and human impacts and environmental constraints were recorded visually. Standing crop phytomass was estimated the stratified technique the regression technique. Analysis of variance, the regression, correlation, and confidence intervals were done. A perfect relationship between size and age of (Acacia eherenbergiana, Acacia tortilis subsp. raddiana, Tamarix nilotica). The size frequency of Acacia eherenbergiana, Tamarix nilotica are positively skewed on contrast Acacia raddiana was negatively skewed distribution. The application of regression analysis in the present study indicates that the volume of Acacia ehrenbergiana, Acacia raddiana and Tamarix nilotica is more closely fitted with the weight than diameter or height; and exhibted an insignificant variation between the actual and predicted weight of shoot and root systems thus, it can be considered as a good estimator for the phytomass of these plants. The overestimation or under of the phytomass applying the logarithmic equations may be related to an error resulting from antilog transformation. The three ivestigated species have the highest height: diameter ratio (e.g. the plant tends to expand more vertically than horizontally). The root: shoot ratio is within the range of woody plants. The decrease of this ratio with the size increase in may be due to the increase of nonharvestable parts of the root system with the size increase. It was a diagnostic study to evaluate the status of these plants. This study was of special importance for the populations of trees and shrubs that subjected to over uses (e.g. over-cutting and overgrazing).

AshrafSalem,Ashraf2404@yahoo.com 
Focus 2: Climate change effects on tropical rainforsts and agroforests

\section{Christina Seeberg-Elverfeldt}

University of Göttingen, Germany

Stefan Schwarze, University of Göttingen, Germany

Manfred Zeller, University of Hohenheim, Germany

\section{Carbon Finance - Impacts of Environmental Service Payments on Households in Central Sulawesi, Indonesia}

Up to 25 percent of all anthropogenic greenhouse gas emissions are caused by deforestation, and Indonesia is the third largest greenhouse gas emitter worldwide due to land use change and deforestation. On the island of Sulawesi in the vicinity of the Lore Lindu National Park (LLNP), many smallholders contribute to conversion processes at the forest margin as a result of their agricultural practices. Specifically the area dedicated to cocoa plantations has increased from zero (1979) to nearly 18,000 hectares (2001). A reasonable share of these plots have been established inside the 220,000 hectares of the LLNP. Moreover, an intensification process is observed with a consequent reduction of the shade tree density.

The research is motivated by the need to understand which level of incentives is needed to stimulate the farmers to desist from further forest conversion and land use intensification activities. Recently, "payments for environmental services" have been advocated as an approach to promote forest conservation initiatives. The purpose of this paper is to provide an insight into whether environmental service payment schemes for carbon sequestration could have an impact on land use changes. Specifically we assess which level of incentives would be necessary to reduce emissions from deforestation, and thus, contribute to the conservation of the rainforest.

We chose a comparative static linear programming model to analyse the behaviour of the households. These models simulate the farmers' reactions to interventions and the effect of technology changes on economic decisions concerning natural resource use management. To the extent that these models prove to be a reliable tool for policy analysis, the output can indicate the adjustments in resource allocation and land use shifts when introducing compensation payments. The objective function of the model is to achieve a maximum total gross margin of the farm by optimising the area shares of several crops. The model accounts for the resource constraints present in the research region, and also depicts forest conversion activities. Four cocoa agroforestry systems (AFS) can be distinguished whereby AFS I exhibits a high degree of shading and a low management intensity, while at the other hand of the spectrum AFS IV involves intensive management and fully sun grown cocoa. Cocoa gross margins increase when moving along the cocoa AFS intensification gradient from I towards IV.

The data was collected in a household survey in six villages in the surroundings of the National Park in 2006. We categorised the households according to the dominant AFS among their cocoa plots and identified four corresponding household types $\left(\mathrm{HH}_{\mathrm{I}}-\mathrm{HH}_{\mathrm{IV}}\right)$. A random sample of 46 households was drawn.

At the plot level, the payments required to induce the adoption of more sustainable land use practices are the highest for the full shade cocoa agroforestry system, but with low carbon prices of $5 € \mathrm{tCO}_{2}^{-1}$ these constitute less than 5 percent of the cocoa gross margin, and less than 1 percent of the fully sun grown AFS cocoa gross margin. At carbon credit prices of $25 € \mathrm{tCO}_{2}^{-1}$, the payments amount to 28 and 2 percent of the respective cocoa gross margins. The variation between the four AFS is not very pronounced.

However, the highest annuity payments from carbon sequestration are always obtained for the high shade AFS as it has the highest total carbon sequestration potential. 
Focusing on the household level, the baseline total gross margins (TGM) exhibit an increase from $\mathrm{HH}_{\mathrm{I}}$ towards $\mathrm{HH}_{\mathrm{IV}}$. With the introduction of the payments, the $\mathrm{HH}_{\mathrm{I}}$ experiences the most pronounced relative impact on its TGM, ranging from 4 percent with a low carbon credit price to 18 percent with a high price. The corresponding impacts for $\mathrm{HH}_{\mathrm{IV}}$ are extremely small. At this range of carbon prices, none of the households realises any shift in their land-use practices.

Economic incentives, such as price premiums offered through carbon certificates for shade intensive cocoa could be a solution to slow down the intensification process. With differentiated carbon prices of up to $32 € \mathrm{tCO}_{2} \mathrm{e}^{-1}$, an incentive is provided for the first three household types to either grow the full shade or slightly less shaded cocoa AFS. However, the household IV would need very high credit prices to induce it to adopt more of high shading cocoa production practices.

Avoided deforestation is increasingly being recognised as an important strategy for preventing greenhouse gas emissions in the first place. If the current LLNP deforestation rate of $0.4 \%$ is reduced to 0 and the prices paid for every ton of $\mathrm{CO}_{2} \mathrm{e}$ avoided are $€ 18$, the incentive is sufficiently high enough for the household types I, II and III to stop forest conversion activities. In comparison, the household type IV needs extremely high compensation payments.

The present study demonstrates the importance to include smallholders, when targeting the reduction of greenhouse gas emissions and searching for policy approaches. As discussed, it is the uncontrolled agricultural expansion at forest frontiers which undeniably contributes to its conversion and loss. Marketbased mechanisms and incentive schemes, such as carbon credits, can offer solutions for the sustainable management and conservation of forests. The results indicate that different household types have different opportunity costs. Thus, on the one hand, the prices of carbon certificates, which are currently traded on markets, could be sufficient to stimulate the adoption of sustainable land-use practices and for the households I-III in the research region. However, on the other hand, due to very high net-revenues in the intensive cocoa production, the current carbon prices are not high enough to stop the deforestation activities of the household IV. A solution could be to target payments only at the shaded and least intensively managed cocoa agroforestry systems.

Christina Seeberg-Elverfeldt, c.seeberg@agr.uni-goettingen.de 


\section{Daniele Cicuzza}

University of Göttingen, Germany

\section{Herbs composition and variation in a mountain forest of Central Sulawesi}

Herbs composition in tropical forests is little understood, only recently they have received considerable attention in efforts to classify tropical forest vegetation and to relate its variation to environmental factors. Several studies have been conducted in lowland tropical rain forest documented the effects of local-scale topographic variation on plant species distribution and abundance patterns. Many authors have suggested that topography and soil are the major determinants of species distributions and community patterns at small regional scales. Sulawesi remains among the island, in Indonesia, with the lowest herbarium collections, taxonomic study has been limited and focused especially on trees flora. Our study area was located in tropical mountain forest of Lore Lindu National Park, Central Sulawesi, Besoa valley; the area covers an extension superior of one square kilometer. We studied the herbs richness and community composition with a specific emphasis in terrestrial pteridophytes. Therefore we studied the correlations between distributional patterns of herbs community and their response to environmental predictors. Terrestrial herbs were sampled in 200 plots of $5 \times 5 \mathrm{~m}$, systematically distributed in the study area. Canonical correspondence analysis was carried out for vascular plant species composition versus soil and topographic information. For herbs community and terrestrial pterodophytes differences in topography within the plot were correlated with floristic distances. Furthermore, much of the variation in beta diversity could be explained by differences in elevation and soil properties within the plot, which indicates it was not caused by random variation.

Daniele Cicuzza, danielecicurza@yahoo.it 


\section{Ellyn Cook}

University of Göttingen, Germany

Torsten Haberzettl, University of Göttingen, Germany Sander van der Kaars, University of Göttingen, Germany

Wiebke Kirleis, University of Kiel, Germany

Benjamin Gutknecht, University of Göttingen, Germany

Ir Iskandar, University of Bogor, Indonesia

Hermann Behling, University of Göttingen, Germany

\section{High-resolution, multi-proxy records of palaeoenvironmental change through the last millennium from Lakes Lindu and Kalimpaa, Central Sulawesi, Indonesia}

Listed as a UNESCO Man and Biosphere Reserve in 1978 on the basis of its exceptional biodiversity and rich cultural heritage of ancient stone megaliths, the Lore Lindu National Park occupies an area of approximately 200,000 hectares in the province of Central Sulawesi. The park ranges in altitude from 200 $\mathrm{m}$ asl at Pakuli on the Gumbasa River to over $2300 \mathrm{~m}$ asl at the summit of Mt Nokilalaki in the northeast. Consequently, there exists a distinct vegetation gradient from diverse lowland rainforests below $1000 \mathrm{~m}$ to more uniform upper montane and Elfin forests above $2000 \mathrm{~m}$. This exceptional diversity has evolved over millions of years as a result of tectonic activity, long-term oscillations in climate and, in the most recent past, has been influenced by the migration of people onto the island. Our research focuses on reconstructing recent patterns of vegetation development, climate change and human impacts within this area. Here we present results from analyses of two lake sediment cores that provide detailed and valuable records of the ecological history of the area and of local climatic change throughout the last 1400 years. At an elevation of $960 \mathrm{~m}$ asl, average annual rainfall of $2400 \mathrm{~mm}$ and no pronounced wet or dry seasons, Lake Lindu lies just within the everwet tropical lowland vegetation zone. A $2.22 \mathrm{~m}$ core from the southern part of the lake is dated at the base by radiocarbon at around 1000 years and the sampling resolution averages around 70 years. Although only about $25 \mathrm{~km}$ to the east of Lake Lindu, Lake Kalimpaa is situated approximately $700 \mathrm{~m}$ higher, well within the lower montane vegetation belt. A $2.11 \mathrm{~m}$ core represents the last 1400 years and the sampling resolution averages around 100 years. In general, this lower montane forest is influenced to a much greater degree by changes in temperature parameters than the forest in the lowlands, whose composition is largely determined by changes in rainfall regime. The close proximity of the Lake Lindu site to the lower montane boundary, however, provides a way to measure small degrees of temperature lowering, in particular during the time period identified as 'The Little Ice Age', while comparison of changes in vegetation composition between records allows us to explore archaeological observations that past human impact on the landscape was more evident in lowland areas than in the highlands.

EllynCook,Ellyn.Cook@biologie.uni-goettingen.de 


\section{Erma Prihastanti}

Diponegoro University, Indonesia

Soekisman T, University of Bogor, Indonesia

Christoph Leuschner, University of Göttingen, Germany

\section{Hydraulic conductivity and percentage of embolism of cacao and gyricidia tree on drought experiment}

Cacao (Theobroma cacao L.) is one of the important crop in Indonesia. The current global warming is predicted to induce more frequent occurrance of droughts with an increasing severity and therefore, an increasing risk of yield loss in cacao farming. A typical cacao farming is established by planting cacao trees spaced at $3 \mathrm{~m}$ in rows with inter row distance of $6 \mathrm{~m}$. Shade trees mainly Gliricidia sepium are planted in between rows and spaced at $3 \mathrm{~m}$ also. A research was conducted to study responses of cacao farming in term of morphological, physiological and biochemical changes in both cacao and Gliricidia plants to drought using troughfall displacement experiment (TDE). The TDE design through installation of plastic roofing above the crop reduces water infiltration into the soil and thus generates artificial drought condition.

Published data on root water potential, hydraulic conductivity and embolism from tropical tree forest Indonesia is limited. This research was conducted in cacao argoforestry at Lore Lindu National Park Central Sulawesi Indonesia. Samples were collected on December 2006 - March 2008 from cultivated 5 years old plants of cacao and Gliricidia. Our main study objectives was to extend on water potential, TDR, hydraulic conductivity, percentage of embolism on cacao and gliricidia root before and during draught periode. Root water status was measures by using solander pressure bomb. We measures xylem hydraulic conductivity with Sperry system. The degree of embolism in a root segment is estimated by its initial conductivity as a percentage of the maximum obtained after removal of emboli.

The results showed that TDE design reduced root water potential and TDR on cacao and gliricidia. Directly, TDE did not affect on hydraulic conductivity and percentage of embolism of cacao and gliricidia root but the season did. Hydraulic conductivity and percentage of embolism both cacao and gliricidia root gave difference pattern in the whole experiment.

ErmaPrihastanti,eprihast@yahoo.co.id 


\section{Gerald Moser}

University of Göttingen, Germany

Henry Barus, University of Palu, Indonesia

Heike Culmsee, University of Göttingen, Germany

Stefan Erasmi, University of Göttingen, Germany

Dietrich Hertel, University of Göttingen, Germany

Dirk Hölscher, University of Göttingen, Germany

Viviana Horna, University of Göttingen, Germany

Michael Köhler, University of Göttingen, Germany

Daniela Leitner, University of Göttingen, Germany

Christoph Leuschner, University of Göttingen, Germany

Beate Michalzik, University of Jena, Germany

Johanis Mogea, University of Bogor, Indonesia

Ramadhanil Pitopang, University of Palu, Indonesia

Pavel Propastin, University of Göttingen, Germany

Bernhard Schuldt, University of Göttingen, Germany

Luitgard Schwendenmann, University of Göttingen, Germany

Kathrin Stenchly, University of Göttingen, Germany

Aiyen Tjoa, University of Palu, Indonesia

Teja Tscharntke, University of Göttingen, Germany

Oliver van Straaten, University of Göttingen, Germany

Edzo Veldkamp, University of Göttingen, Germany

\section{The Sulawesi Throughfall Displacement Experiment - Simulated ENSO Drought Effects on Primary Rainforest}

Most drought events in the non-seasonal rainforest region of Southeast Asia are related to the El Niño Southern Oscillation (ENSO) phenomenon. Climate scenarios predict more frequent occurrence of ENSO droughts with increasing severity induced by global warming. Detailed assessments of the ecological consequences of droughts in per-humid rainforests are scarce and knowledge of whether and how these ecosystems are adapted to severe droughts is limited. This is the first replicated experiment using roof constructions for throughfall displacement in natural forest to study the effects of nonpredictable ENSO drought periods on ecosystem functioning. During a simulated desiccation period the ecosystem water and nutrient flows, the activity of soil organisms and roots, and the physiological responses of plants have been studied. First results show decreasing volumetric water contents in the different soil depths of the desiccation plots. The first significant ecosystem response was a decrease of soil surface $\mathrm{CO}_{2}$ efflux starting immediately after roof closure. After one year of desiccation appeared first signs of increased leaf litter fall in the drought plots. After almost 8 months of experimental drought trees showed no response in xylem flux density. However, a strong dry period at the beginning of 2008 induced a noticeable decrease in xylem flux rates of several trees at control and experimental plots. Mainly air relative humidity remained low, even during night time. We deduced that at the experimental plots soil drought has not yet reached a critical value to induce permanent reduced tree water uptake.

GeraldMoser,gmoser@gwdg.de 


\section{Gerhard Gerold}

University of Göttingen, Germany

\section{Effects of "ENSO-events" and rainforest conversion on river discharge and nutrient output in Central Sulawesi (Indonesia)}

Natural interannual climate fluctuation as ENSO-events and forest conversion in the inner tropics play an important role for the water balance of tropical catchments. Distributed hydrological modelling that relate land cover changes and climate changes with river discharge changes for humid tropical catchment areas at the mesoscale level are rare. Sulawesi still has a forest cover of $48 \%$, but as population has been growing by $66 \%$ over the past two decades massive land cover transformations are going on $(-1.2 \%$ annual deforestation rate in Indonesia). Consequently soil and water resources of the region are altering as well. Since 2001, we investigate the impact of forest conversion on the water balance, on nutrient loss and soil erosion of a small mesoscalic tropical catchment within the long-term interdisciplinary collaborative project STORMA. Additionally since 2002 the hydrological modelling approach was upscaled for the mesoscale humid tropical Gumbasa catchment with special research on ENSO-events on the water resources (IMPENSO).

The study was conducted in a small mountainous catchment (Nopu $-2.6 \mathrm{~km} 2$, areal precipitation 1.850 mmy-1) and the Gumbasa River catchment which is located in Central Sulawesi, Indonesia $\left(1^{\circ} \mathrm{S}, 120^{\circ} \mathrm{E}\right)$. The Gumbasa River catchment has a total drainage area of $1275 \mathrm{~km}^{2}$ and is characterized by a gross annual areal precipitation of $2000 \mathrm{mmy}-1$ and a mean annual discharge of $22 \mathrm{~m}^{3} \mathrm{~s}-1$. - Since 2001 the Nopu-catchment is instrumented with three weirs (automatic stage recorder), one climate station and six rain gauges. Traditional slash\&burn cultivation is predominant and heavy machinery is not used. - In order to obtain a feasible temporal data set of meteorological forcing and hydrological calibration data for the performance of a distributed hydrological model the Gumbasa catchment was equipped with four automatic stage recorders and eight automatic climate stations monitoring precipitation, temperature and humidity. Additionally five automatic climate stations measure the complete meteorological parameters including wind speed and global radiation.

\section{Nopu-catchment:}

With two subcatchments (rainforest weir 3, slash\&burn weir 2) we compared the changes in soil moisture, river discharge and nutrient output. As indicators for land degradation we investigate the changes on infiltration rate, water flow path (increasing interflow and surface flow) and soil nutrient output with river discharge. Slash\&burn activities increased mainly since 2003/2004 with forest reduction until 2007 in the subcatchment weir 2 from $84 \%$ (2002) to $22 \%$ forest cover (2007). Consequently total runoff and peak discharges increased significantly. Despite decreasing annual rainfall the difference in runoff between weir 3 (natural submontane rainforest) and weir 2 increase to $179 \mathrm{~mm}(+40 \%)$ in 2006. Three scenarios (forest/cacao/slash\&burn (corn with cassava)) were simulated based on the main processes of land use change in the catchment and related to land use pattern of 2002. The application of the water balance model WASIM-ETH with simulation results for these scenarios support the experimental results and gives insight into the changing discharge components. Increase in overland flow leads to an increase in soil erosion from $0.5 \mathrm{t}$ ha-1 y-1 (natural forest) up to $11.3 \mathrm{t}$ ha- $1 \mathrm{y}-1$ (maize plot), also soluble nutrient output increase by factors of 4 to 6 in the slash\&burn subcatchment compared to the natural forest subcatchment. - The long experimental data on river discharge and soluted nutrient output (2001-2007) is used to set up a multiparameter regression model for the influence of forest conversion on river discharge and soluted nutrient output. 


\section{Gumbasa-catchment:}

The hydrological modelling approach with the soil hydrological parameter knowledge from Nopu catchment was used to analyse the impact of land cover changes and ENSO-events on the water resources of a mesoscale humid tropical catchment. Because of lacking detailed spatial soil information, a topographic based nested scale approach to parameterise soil physical properties was used for the hydrological model WASIM-ETH. The PHA approach produces reasonable results for the water balance components for the whole catchment.

Thereafter the distributed hydrological model WASIM-ETH was calibrated and validated for the current land use (2001/2002, Landsat/ETM+ scene). Model results were generally consistent with the observed discharge data and reproduced well the seasonal discharge dynamic. The implications of possible future climate and land use conditions on the water balance of the Gumbasa River sample catchment were assessed by a scenario analysis, which simulated a sequence of possible future events. The results of the hydrological model scenario application clearly demonstrate a strong relationship between deforestation rates and increasing discharge variability. Especially a significant increase of high water discharges was simulated for the applied land use scenarios. The main results of the scenario analysis are:

- that ENSO anomalies of precipitation lead to an increase of discharge variability.

- that strong ENSO-events (El Nino) lead to 30\% reduction of the water yield and annual crop scenarios up to $1,200 \mathrm{~m}$ a.s.l. showed a $42 \%$ and the perennial crop scenario (cacao) a $23 \%$ increase in river discharge with high increase in overland flow and flooding risks.

- that ENSO-events (El Nino) decrease the potential (flooding) area of paddy rice cultivation to one third in the second half of the year.

With regard to the high deforestation rates of the research catchment and increase of El Nino frequency with climate change in the future, one can expect further negative changes for the water resources in Central Sulawesi.

\section{Gerbard Gerold,ggerold@gwdg.de}




\section{Heike Culmsee}

University of Göttingen, Germany

\section{Diversity and productivity of primary pre- to upper montane forests in Central Sulawesi}

The analysis of primary forest tree community diversity and productivity is based on tree inventories in Sulawesi, Indonesia, and compared to other studies from the Malesian region.

The study sites are situated in Lore Lindu National Park, Central Sulawesi. Four sites are investigated along an altitudinal gradient ranging from $1050 \mathrm{~m}$ to $2400 \mathrm{~m}$ a.s.l. and covering wet tropical forests of the pre-montane to upper montane vegetation belts.

Tree species richness is decreasing with altitude. While the Fagaceae and the Myrtaceae are important families over the whole altitudinal range, the importance of other families is limited to the pre-montane and lower montane forests (e.g. Lauraceae, Sapotaceae, Euphorbiaceae, Burseraceae) respectively to the mid and upper montane forests (e.g. Podocarpaceae, Escalloniaceae). The biogeographical relationship of the different tree communities is each analyzed in the Malesian context.

Productivity is estimated by above-ground biomass (AGB). Total AGB is decreasing with altitude from 306 to $286 \mathrm{t} / \mathrm{ha}$ considering trees of diameter breast height $(\mathrm{DBH}$, at $1.3 \mathrm{~m})>=10 \mathrm{~cm}$. The stand structure and AGB partitioning among the different taxa are investigated and compared to other available data from tropical SE Asia.

Heike Culmsee, beike.culmsee@bio.uni-goettingen.de 


\section{Henry Barus}

University of Palu, Indonesia

Iskandar Lapanjang, University of Palu, Indonesia

Christoph Leuschner, University of Göttingen, Germany

\section{Arbuscular Mycorrhizal Preliminary Study in Natural Forest and Cacao Agroforestry of Central Sulawesi}

The composition of arbuscular mycorrhizal fungi (AMF) communities and their relationship to environmental gradients has been investigated in different ecology systems, but information from tropical forest and agroforestry are scarce particularly from Central Sulawesi-Indonesia. In fact, mycorrhiza has been recognized to have important roles for sustainable forest ecology, especially for nutrient uptake of the plants. Therefore, the AMF status of primary forest and cacao agroforestry in the vicinity of national park Lore-Lindu, Central Sulawesi, has been investigated recently. A total of 80 soil samples were collected from the rhizospheres of 50 trees species (from 34 Family) and 30 cacao trees. AM fungal structures were observed in $40(80 \%)$ of 50 primary forest tree species. Different type, size and color of AMF spores were found constantly in primary forest and cacao agroforest. The result also showed that spore density in $25 \mathrm{~g}$ rhizosphere soil of primary forest plant was quite similar to the cacao; it was laid between 12 to 92 spores of primary forest rhizosphere trees and 8 to 100 spores in cacao, respectively.

Experimental drought on the trees by put plastic roof underneath the tree canopy increased significantly spore density in both primary forest tree rhizosphere and cacao in comparison to the trees from the non roof plots. This result indicates an important ecological impact of drought to spore density. However, no difference was found in spore density between the primary forest and cacao agroforestry.

HenryBarus,henbarus@hotmail.com 


\section{Hermann Behling}

University of Göttingen, Germany

\section{Vegetation, climate dynamics and human impact in neotropical mountain ecosystems during the late Quaternary}

The tropical mountain ecosystems harbor the most biodiverse ecosystems on planet earth. We know only little about the reasons for this biodiversity. We are especially ignorant of the role that history has played in the development of these hotspots of species endemism and richness. Despite the importance to understand the landscape dynamics, in particular in hotspots of biodiversity, for management and conservation only little is known on its environmental history. Palaeoecological studies provide interesting insights on vegetation, plant diversity, fire and climate dynamics and the role of human impact during the late Quaternary. New results from different mountain ecosystems of the neotropics will be presented.

Hermann Bebling, bbebling@online.de 
Focus 2: Climate change effects on tropical rainforsts and agroforests

\section{Jan Barkmann}

University of Göttingen, Germany

Sebastian Gessert, University of Göttingen, Germany

\section{Socio-economic Resilience to Enso Droughts by Intensified Paddy Rice Production in Central Sulawesi (Indonesia)?}

One of the most severe effects of prediced climate change in some parts of south-east Asia are more frequent ENSO-related (El Niño Southern Oscillation) droughts. From Java, substandial production losses were reported for the last severe ENSO-drought event in irrigated paddy rice prouction. The main effect was due to the need to postpone the planing of the new crop due to water shortage. For the northern part of the Lore Lindu National Park area (LLNP; Palu river catchment), Keil (2004) reports that rice production dropped by $37 \%$ on average ( $n=123$ rice farmers). For one village at the downstrem end of a main irrigation channel, a decline of more than $53 \%$ was recorded. Gross margins dropped by about $1,000,000 \mathrm{IDR} / \mathrm{ha}$. Still, paddy rice delivered lower yield reductions compared with other crops of the same farm in comparison with maize, cocoa and coffee. These data stemming from recall surveys indicate the potential for severe ENSO-related drought effects around LLNP but also hint at a surprising resilience in paddy rice yields. In this contribution, we compare the recall data results from Keil will the modelled paddy rice yield response of farms from two villages in the same region. Based farm management data, detailed records of local hydrology including the irrigation pattern of several hundred paddy rice fields, and a simplified ENSO-scenario analysis, we explore to which degree income losses due to more frequent ENSO-related droughts could be offset by more intensified paddy rice production.

A detailed rice farming survey was carried out at the villages of Maranatha and Rejeki ( $\mathrm{n}=79$ households) in the Palu river catchment at the northern tip of the LLNP area in Central Sulawesi for the growing season 2006/07. During this time, no water shortages occurred.A Cobb-Douglas production function (CDPF) for paddy rice was estimated A continuous area of 476 rice plots ( 20 ha) in Rejeki mostly belonging to the surveyed farmers $(91 \%)$ was mapped, and the individual plots geo-referenced. Based on spatial design of the irrigation scheme and interview results on irrigation management, a water distribution algorithm was generated. In the 2002 ENSO drought, local water availability for paddy rice production was reduced from $1260 \mathrm{~mm}$ to $560 \mathrm{~mm}$ from July to November. Yield reactions due to water scarcity are modelled according to physiological rice demand. In a simplified climate change scenario, we assume that ENSO-realated droughts occur in one out of three years instead in one out of four years.

Average rice yield was $4.8 \mathrm{t} / \mathrm{ha} /$ harvest at two harvests/year. In the CDPF (adj. R2: 61.9\%; $\mathrm{p}<0.001$ ), rice field size (-0.370; standardised coefficient), labour for puddling $(+0.109)$, amount of seeds $(+0.231)$, and material input costs (fertilisers, pesticides, herbicides; +0.305 ) were used to predict rice yield. A dummy variable testing for yield differences between the two villages was not significant. For the rice crop during the 2002 drought period, we calculate a yield reduction of $40 \%-49 \%$ depdending on details of the calculation. This result supports the range of yield decreases reported by local farmers at the recall survey conducted by Keil.

A yield reduction of $49 \%$ in one harvest every three years instead of every four years (i.e., at higher ENSO frequency) requires a productivity rise of $2.1 \%$ to compensate yield losses. This could be achieved by a rather modest increase of material costs by 48,600 IDR (3-4 EUR; +7.7\%) per hectare and harvest. To completely offset drought effects during a three-year ENSO cycle demands an increase of $8.2 \%$ in material inputs equivalent to 207,000 IDR (15-17 EUR; +35\%) per hectare and harvest. Valuated at local market prices, this represents $1 \%$ of revenue from rice harvest per hectare. While these preliminary 
Focus 2: Climate change effects on tropical rainforsts and agroforests

calculations do not make full use of the spatial and temporal resolution of the production data - and do not account for potnentiall negative environmental long-term effects of intensification -, they still suggest that more intensified paddy rice production could play an important role for an increased socio-economic resilience of the local communities to ENSO droughts.

Jan Barkmann, jbarkma@gwdg.de 


\section{Kurniatun Hairiah}

University of Brawijaya, Malang, Indonesia, and World Agroforestry Centre ICRAF, Bogor, Indonesia

Widianto, World Agroforestry Centre ICRAF, Bogor, Indonesia

Syahrul Kurniawan, World Agroforestry Centre ICRAF, Bogor, Indonesia

Cahyo Prayogo, World Agroforestry Centre ICRAF, Bogor, Indonesia

Fitri Khusyu Aini, World Agroforestry Centre ICRAF, Bogor, Indonesia

Degi Harja, World Agroforestry Centre ICRAF, Bogor, Indonesia

Ni'matul Khasanah, World Agroforestry Centre ICRAF, Bogor, Indonesia

Meine van Noordwijk, World Agroforestry Centre ICRAF, Bogor, Indonesia

\section{Tree roots anchoring soil and reducing landslide risk during high rainfall episodes as basis for adaptation and mitigation to climate change through agroforestry}

Landslides killing hundreds of people have become an almost yearly phenomenon in SE Asia and have a high profile in the public debate. High rainfall events on wet soil generate shallow slope failures by elevating pore pressures, but site-specific factors, such as preferential hydrologic flowpaths, slope steepness, soil thickness, and existing plants root systems influence the potential for slope instability. Tree roots plays an important role for 'anchoring' as a component of overall shear strength, while the 'binding' in the topsoil can prevent the more disruptive types of landslides and replace them by 'landslips'. Trees, however, add weight and the positive or negative net effect on landslide risk depends on root strength and weight. As there is a need for a generic rapid appraisal tool for site-specific assessment of impacts of trees and tree management on landslide risk, we tested methods for

- Rapid survey of tree species and population density in the landscape in relation to signs of preceding landslides,

- Inventory of proximal tree root architecture to assess binding and anchoring,

- Standardized strength measurement of tree roots in relation to their lignin content,

- Estimation of dynamic root pattern at hillslope scale using the 'spatially explicit individual tree-based forest simulator' (SEXI FS) model

Case studies in West Lampung, West and East Java suggested a number of options for 'right tree in right place' management in mixed agroforestry systems to reduce landslide risk on slopes, in the context of adaptation strategies to climate change, combined with biomass carbon storage as contribution to mitigation.

Kurniatun Hairiah, K.Hairiab@cgiar.org 


\section{Luitgard Schwendenmann}

University of Göttingen, Germany

Iswandi Anas, University of Bogor, Indonesia

Aiyen Tjoa, University of Palu, Indonesia

Gunawan Djajakirana, University of Bogor, Indonesia

Stefan Erasmi, University of Göttingen, Germany

Uswah Hasanah, University of Palu, Indonesia

Hendrayanto, University of Bogor, Indonesia

Dietrich Hertel, University of Göttingen, Germany

Dirk Hölscher, University of Göttingen, Germany

Abdul Kadir, University of Palu, Indonesia

Michael Kappas, University of Göttingen, Germany

Michael Köhler, University of Göttingen, Germany

Daniela Leitner, University of Göttingen, Germany

Christoph Leuschner, University of Göttingen, Germany

Beate Michalzik, University of Jena, Germany

Gerald Moser, University of Göttingen, Germany

Erma Prihastani, University of Bogor, Indonesia

Pavel Propastin, University of Göttingen, Germany

Carsten Schmidt, University of Göttingen, Germany

Kathrin Stenchly, University of Göttingen, Germany

Efi Toding Tondok, University of Bogor, Indonesia

Teja Tscharntke, University of Göttingen, Germany

Oliver van Straaten, University of Göttingen, Germany

Edzo Veldkamp, University of Göttingen, Germany

Stefan Vidal, University of Göttingen, Germany

\section{Effects of an experimental drought on a cacao agroforestry, Sulawesi, Indonesia}

Climate scenarios predict for tropical humid regions a higher frequency of droughts. In Southeast Asia drought periods are often related with the El Nino Southern Oscillation (ENSO) phenomenon. Socioeconomic surveys revealed that strong droughts in 1997 and 2002 led to a considerable reduction in cacao yield. However, detailed experimental studies on the ecological consequences of droughts on agroforests are still limited. The objective of this study was to assess the impact of an experimental drought on ecosystem properties and dynamics such as soil water content, tree sap flux, litter fall, water and nutrient fluxes, root distribution, soil respiration and cacao yield.

The research was conducted in a 6-year-old Theobroma cacao plantation shaded by Gliricidia sepium trees in Central Sulawesi. The plantation was divided into six plots; three study plots were equipped with a roof underneath the cacao canopy and three plots were left without roof (control plots). The roofs covered a ground area of about $80 \%$ and were closed for 13 months. Soil water content in the roof plots decreased considerably at all measured depth (of 10, 20, 40, 75, 150 and $250 \mathrm{~cm}$ ), and sap flux of cacao and Gliricidia declined by $10 \%$ and $20 \%$, respectively. Soil respiration in the roof plots tended to be lower as compared to the control plots. However, cacao litter fall and yield showed no significant differences between control and roof plots. This finding suggests that this cacao agroforestry may cope quite well with reduced water availability.

LuitgardSchwendenmann, Ischwen@gwdg.de 


\section{Oleg Panferov}

University of Göttingen, Germany

Andrey Sogachev, Wind Energy Department, Denmark

Heinrich Kreilein, University of Göttingen, Germany

Andreas Ibrom, Biosciences department, Denmark

Gode Gravenhorst, University of Göttingen, Germany

\section{Effects of complex landscape on fluxes between atmosphere and rainforest in Central Sulawesi, Indonesia}

In Central Sulawesi the closed-canopy rainforest is located at higher elevations. The assessment of turbulent fluxes above the rainforest by means of tower measurements are complicated by a heterogeneous terrain. The tower measurements are point based and to interprete them correctly additional information on airflow structure over the complex terrain is required. The 3D atmospheric boundary layer model SCADIS employing a two equation closure approach (E- $\omega$ closure) and taking into account the flow dynamics within a plant canopy (Sogachev and Panferov, 2006) was used to describe the airflow over heterogeneous topography. To discriminate the vegetation influence, horizontal homogeneity of both, plant cover and of flux source strength was assumed. The vertical distribution of leaf area density was taken from measurements. Neutral atmospheric stratification was investigated in details for 8 main wind directions. The comparison between results of numeric experiments for idealized flat terrain and for the real one allowed to obtain the $3 \mathrm{~d}$ distributions of "correction factors" for the main wind directions. It is shown that due to relief induced distortion of air flow the flux measured above the forest could differ the real one up to 1.5 times depending on wind direction.

OlegPanferov,opanfyo@gwdg.de 


\section{Oliver van Straaten}

University of Göttingen

Edzo Veldkamp, University of Göttingen, Germany

Iswandi Anas, University of Bogor, Indonesia

Nia Megasari, University of Bogor, Indonesia

\section{The effect of a simulated ENSO drought on soil $\mathrm{CO} 2$ production and $\mathrm{CO} 2$ efflux in cacao agroforestry plantation in Central Sulawesi, Indonesia}

Global warming trends are known to intensify El Niño Southern Oscillation (ENSO) droughts in Indonesia. This paper discusses the measured impacts and the implications of a simulated ENSO drought on carbon dioxide (CO2) efflux and $\mathrm{CO} 2$ production from soils in a cacao agroforestry system in central Sulawesi, Indonesia. A through-fall exclusion roof was built to simulate this ENSO drought condition wherein ecosystem impacts were closely monitored and compared with adjacent control plots. The desiccation period lasted for a period of 13 months, preceded by a two months baseline assessment phase and followed by a two months rewetting phase. In this experiment, the carbon dioxide efflux from the soil to atmosphere interface remained relatively comparable between the treatments although the drought plots maintained a slightly lower respiration rate indicating a small decline in soil biological activity in the soil. Identifying the mechanisms that affect soil respiration is challenging as environmental controls often have co-varying effects. In this study we observed a parabolic relationship between soil moisture and soil respiration. Soil respiration rates were low when soils were either extremely wet or dry and highest when soils were neither too wet nor too dry. A strong decline in CO2 concentrations in the soil profile to 2.5 meters in depth was measured as the soil dried out. The drier soil having more open pore space and less water facilitated the transport of $\mathrm{CO} 2$ along the concentration gradient from the high build up in the soil to the atmosphere where concentrations of $\mathrm{CO} 2$ are far lower. Over the period of the simulated drought soil $\mathrm{CO} 2$ production shifted to deeper soil depths. Initially $\mathrm{CO} 2$ production was highest at the soil surface, but as the soil dried out trees sent new roots to find available water resources at deeper soil depths; correspondingly $\mathrm{CO} 2$ production increased in these zones. As this drought experiment failed to induce any significant stress in the cocoa trees or the Gliricidia overstory, and our soil respiration rates remained relatively comparable we could conclude that this ecosystem is relatively drought resistant.

Oliver vanStraaten, ostraat@gwdg.de 


\section{Rütger Rollenbeck}

University of Marburg, Germany

\section{Climatic variability and impact of landuse change in south Ecuador}

Long and short term climatic oscillations like El Niño and the ongoing global change attributed mainly to human activity have a potentially high impact on natural and anthropogenic ecosystems. The interaction between land cover changes and climate may lead to a permanent and irreversible alteration of these ecosystems, impairing their capacity of ecosystem services and causing a permanent loss of natural richness, especially biodiversity. The long-term investigations of the mountain ecosystem of south-ecuador shows indicators for these type of tendencies. The combination of remote sensing data and point observations enabled a deep insight into atmospheric processes of the study site. There are drastic variations in rain fall from year to year, which can not be explained by the well known ENSO-cycle, but are controlled by interaction of local topography and mesoscale processes, which are especially prone to changes in land cover characteristics. Furthermore longterm observations of atmospheric nutrient input show, that biomass-burning activities in the amazon basin may have an impact on the local nutrient balance, which consequently may lead to changes in species composition. These observed processes and trends are now examined with advanced tools of Soil-vegetation-atmosphere transfer models and associated climate models, forming a nested cascade of different simulation tools, to understand current observations and simulate potential scenarios of future changes.

Rütger Rollenbeck, rollenbeck@lcrs.de 


\author{
Samuel Agele \\ University of Akure, Nigeria
}

\title{
Environmental and physiological regulations of productivity in tropical fruit tree species under variable climate and extreme weather events: case of the humid south of Nigeria
}

Worldwide, there has been a range of changes in climate overtime, and such variabilities could constitute profound problems for agriculture (food supply and livelihoods) and water resources management. Agricultural systems have to be made responsive to changing climatic and weather patterns, there is therefore urgent need to study adaptation strategy in tropical crops and to improve understanding of what may be required to adapt to significant changes in climate and their impacts on tropical agriculture. Changes in climate and weather scenarios could elicit various responses in crops and competition and stresses on water resources, water stress situations and marginal growing environments. In plants, the changing growing environmental conditions will cause shift and plasticities of physiological function, and may obliterate negative effects of environmental stresses or increase species adaptation to stressful growing environments. Changes in climate and weather scenarios could regulate seasonal periodicity, water use, flowering and fruiting characteristics and hence productivity in tropical crop species and overall ecosystem/catchment water balance (hydrological cycle).

The plasticity of physiological functions may enhance the resilience of cacao agroforests and landscapes to impacts of weather variability. The humid tropics is especially characterised by wet and dry season transitions, biotic and abiotic stresses and rainfed agriculture, and since tropical fruit trees in plantation (especially cacao,coffee, citrus, cashew etc) are seldom irrigated, under the prolonged summer drought of the wet and dry season transitions, they undergo severe water stress during this period. These abiotic stresses would implicate adjustment in plant water relations and water use in order to maintain the integrity of physiological functions and productivity. In the tropics. the production of fruit trees is characterised by co-occurring fruit trees in plantations such as mixture of cacao, kola, coffee, cashew, citrus etc) and growth under variable agroforestry practices and agroecologies or landscapes.

There is inadequate physiological insights on the responses of fruit trees to seasonal trends in weather especially water shortage and silvicultural practices (mixed stands of fruit trees and agroforest tree species in plantation) in different ecologies/landscapes, cropping systems, soil types. Significant tropical advances have been made in the use of soil, plant and meteorological tools for assessing plant physiological functions and productivity. These advances have rarely been applied to tree crops under rainfed agriculture, and variable growing environmental conditions.

It is important to strengthen knowledge through SPAC and water ecophysiology research, such understanding may contribute to improved management of tropical fruit trees in a changing climatic condition (agroforestry practices, landscapes and climate) and for reliable agricultural and water resources planning.

SamuelAgele, obiagele@yahoo.com 
Focus 2: Climate change effects on tropical rainforsts and agroforests

\author{
Stefan Köhler \\ University of Göttingen, Germany \\ Carsten Gutzler, University of Göttingen, Germany \\ Jürgen Groteer, University of Göttingen, Germany \\ Gerard Gerold, University of Göttingen, Germany
}

\title{
The use of passive collector method to measure the input of mineral nutrients from precipation and dust in the vicinity of Lore Lindu National Park
}

Both nutrient and contaminant which brought during wet and dry season would be added to ecosystem while it is an open system. And the input onto ecosystem and agricultural system would change the system thus research is needed in order to understand the balancing of nutrients in the system. Increase of material adding to the system because of anthropogenic emission in the rural area as well as caused by fire clearing of the field often proved. Naturally material can be transported in long distance for instance dust from Sahara to Amazon area and rainforest ecosystem could be influenced by sea shell deposits.

Therefore to measure nutrient balances in the ecosystem in the tropics that added by precipitation is challenging while the transport of collected precipitation to analytic laboratory often faces both long distance and in particular the attack of algae and fungi, will finally reduce the quality of the collected precipitation. An automatic water collector is often not possible to employ due to lack of electricity where the research are often placed in the remote areas. Besides the problem to maintenance laboratory equipment or tool regularly in the research areas, the lost of data due to damage of the collected solution is also difficult to be avoid. Often found too that the laboratory equipment could not analyze well while the nutrients in the collected solution is low with the bulk collection system.

At the presented work here was aimed to improve the method of precipitation collection and as well the analytical method, and the developed method has been tested in the areas of STORMA (Stability of Rain Forest Margin) research, the precipitation was collected using a water "in situ" trapper that not only simple but also cheap, called as a passive tank collector (IER collector). The device was developed by integrated mineral material that functioned basically as ion exchange in a tube and in which the concentration of the precipitation quality can be maintained over long period after collection. This IER collector is expected to reduce obstacle due to strong climate change in the area of research too e.g. when there is a strong monsoon storm and wind and can overcome the low concentration of element in the precipitation, it is because the element concentration in the precipitation is different from place to place.

There were 12 locations have been chosen and spread in the climate research station in the vicinity of Lore Lindu National Park areas. The IER collector was established at 01.01.2007 and the ion exchange substrate in the tube was changed every two weeks. After several laboratory testes (reproduce ability and freight of the solution) showed that the estimation of the mineral input from the atmosphere was accurately measured by the new method. Also, the mineral concentration that collected by bulk deposit method fitted quite well to the new method. The small difference was mainly caused by the low concentration of the mineral in the precipitation which could not well fixed by the ion exchange substrate and caused by high flow velocities of the precipitation too.

The results clearly showed that $\mathrm{Ca}$ and $\mathrm{Na}$ were the highest content of the precipitation in all 12 climate stations in the vicinity of the national park but partly of the concentration showed strong different between stations even collected at similar month. However, P and Fe were found at much lower level but with steady level. Thus, it is suggested to consider the regional variability while different location in 
Focus 2: Climate change effects on tropical rainforsts and agroforests

rainforest ecosystem and Cacao-agroforestsystem showed high variability of the concentration of the nutrients input from the precipitation.

StefanKöhler,skoeble2@gwdg.de 


\section{Stefan Köhler}

University of Göttingen, Germany

Henry Barus, University of Palu, Indonesia

Jürgen Grotheer, University of Göttingen, Germany

Gerhard Gerold, University of Göttingen, Germany

\section{Central Laboratory Unit of Stability of Rain Forest Margins (STORMA) project - A Laboratory in tropic}

In 2000, a well equipped laboratory for soil, plant, and water samples was launched in Palu, Central Sulawesi, Indonesia. The laboratory was set up within the framework of a longterm research sponsored by the Deutsche Forschungsgemeinschaft (DFG)-Germany, identified as SFB 552.

The overall objective of the Laboratory is to analyze macro and micro nutrient content in the soil, plant, and water samples, besides to deliver knowledge on laboratory management to the Indonesian partners, especially Tadulako University staff and alumni. The quality assurance is regularly ensured in the partner laboratory in Göttingen University-Germany as well as in Palu.

The laboratory is equipped with an ICP-OES (Optima 2000 DV, Perkin Elmer) for cation analysis, a Continuous Flow-Analyzer (AA3, Bran \& Lübbe) for determination of nitrate, ammonium, phosphate and chloride, an elementary analyzer (Elementar) to perform carbon and nitrogen in solid samples and a TOC analyzer (Dimatoc 100, Dimatec) for determination of dissolved organic and inorganic carbon and total bound nitrogen in aqueous samples. Continuous electricity supply is independently from PLN (Perusahaan Listrik Negara) while supported by a $100 \mathrm{kVA}$ diesel generator and a $40 \mathrm{kVA}$ USV installation.

The laboratory staff have successful support hundreds of the researchers since it was established, for example, from 2004 to today; nearly 45,000 samples have been analyzed, those samples were belong to more than 1000 orders. Samples receipt, login and storage were controlled by a well developed database system.

Besides laboratory routines, the staff was also able to map and later characterize the soils in the laboratory. The laboratory staff is not only capable to analyze samples that order by the researchers and students, but also conducting own experiments e.g. in Nopu; a catchments area, and in Bariri, where a micrometerological tower has been set up, in order to carry out longterm the nutrient leaching and fluxes.

Stefan Köbler, skoeble2@gwdg.de 
Focus 2: Climate change effects on tropical rainforsts and agroforests

\author{
Victor Timmer \\ University of Toronto, Canada \\ Deborah Kimaro, University of Toronto, Canada
}

\title{
Carbon sequestration potential of planted tree fallows in semi-arid eastern Tanzania
}

The Kyoto protocol recognizes agroforestry as one of the strategies for mitigating the effects greenhouse gas emission. To the best of our knowledge, there is limited information regarding carbon sequestration potential of agroforestry systems in semiarid areas, particularly in the natural Miombo (Zambezian savanna) ecozone. To address this problem, the present study evaluated carbon stocks in wood and soils after 5year tree fallows versus natural grass fallows under rotational woodlot systems and in continuous cropping culture in semiarid Morogoro, Tanzania. The rotational woodlot system consists of three interrelated management phases of trees and crops grown sequentially on the same land for on-farm fuelwood supply and soil fertility improvement (Kimaro et al. 2007; Agrofor Syst 71:175-184). The experiment was established in a randomized complete block design to evaluate effects of tree species on carbon accumulation in wood and soils, and to assess carbon sequestration potential of tree fallows relative to a continuous cropping treatment. Carbon in wood was determined as $50 \%$ of the oven dry weight of wood from stem and branches of destructively sampled trees from each plot. A composite soil sample was collected from five randomly selected points at $0-15 \mathrm{~cm}$ depth in each plot for organic carbon determination by the Walkley and Black method.

After a 5-year fallow period, wood carbon accumulation varied significantly among trees fallows. Carbon sequestered in wood of Acacia crassicarpa (25.5 $\mathrm{Mg} \mathrm{C} \mathrm{ha}^{-1}$ ), and Acacia mangium and Acacia polyacantha (18.018.9 $\mathrm{Mg} \mathrm{C} \mathrm{ha-1)} \mathrm{were} \mathrm{respectively} \mathrm{higher} \mathrm{and} \mathrm{similar} \mathrm{to} \mathrm{wood} \mathrm{carbon}\left(19 \mathrm{Mg} \mathrm{C} \mathrm{ha}^{-1}\right.$ ) reported from protected Miombo forests (Williams et al. 2008; For Ecol Manage 254: 145-155). These results demonstrate the high capacity of planted tree fallows to sequester atmospheric carbon compared to native forests in semiarid areas presumably due to faster growth, larger tree size, and more intensive management. Carbon accumulation in dry Miombo vegetation is usually suppressed by drought and frequent severe bush fires. Annual carbon accumulation rates of planted tree fallows ranged from 2.3-5.1 $\mathrm{Mg} \mathrm{C} \mathrm{ha-1} \mathrm{yr}^{-1}$. Based on this rate, it takes approximately 4-10 years for the tree fallows to recover wood carbon lost by converting native forest reserves $\left(19 \mathrm{Mg} \mathrm{C} \mathrm{ha}^{-1}\right)$ to agriculture. This period is considerable shorter compared to 2-3 decades reported for re-growing Miombo woodland after cultivation (Williams et al. 2008; For Ecol Manage 254: 145-155); thus demonstrating the important role that rotational woodlot systems may play in sequestering carbon.

Soil organic carbon after tree fallowing $\left(15.8-25.6 \mathrm{Mg} \mathrm{C} \mathrm{ha}^{-1}\right)$ was significantly higher than organic carbon $\left(13 \mathrm{Mg} \mathrm{C} \mathrm{ha}^{-1}\right)$ in the continuously cropped soils. This improvement was attributed to soil organic matter addition from litter and root turnover during the fallow period. However, except for A. mangium, tree fallows did not enhance soil carbon relative the natural fallow treatment presumably due to prolific rooting of grasses (Hyperthelia dissolute) dominating this treatment. Overall, carbon replenishment rates in soils by tree fallows were lower than corresponding carbon accumulation rates in wood, consistent with other studies in semiarid areas (Takimoto et al. 2008; Agric Ecosyt Environ 125: 159-166). Presumably, a large proportion of carbohydrate is allocated to biomass increase in early tree growth. Tree fallowing raised soil carbon above levels obtained in surface soils $(0-30 \mathrm{~cm})$ of the Miombo vegetation re-grown after cultivation (9-15 $\mathrm{Mg} \mathrm{C} \mathrm{ha}^{-1}$ ). Soil carbon pools under our tree fallows were also close to levels (14-27 Mg $\mathrm{C} \mathrm{ha}{ }^{-1}$ ) obtained in forest reserves of the Miombo woodland (Walker and Desanker, 2004; For Ecol Manage 203: 345-360). Although labile fractions of soil carbon under rotational woodlot systems may be lost after clearing tree fallows for crop production, it has been shown that stable fractions of soil organic 
matter are unaffected by cultivation during the first three years (Solomon et al. 2000; Agric Ecosyt Environ 78: 203-213). This trend suggests that rotational woodlot systems do not adversely affect soil carbon pools because the recommended length of the post-fallow cropping phase is usually no longer than three years.

Our study suggests that rotational woodlot systems utilizing fast growing tree species may rapidly (less than 10 years) sequester atmospheric carbon to levels of the natural Miombo forest reserves in semiarid areas. Although wood carbon can be released after fuelwood harvesting, it represents amounts that counter increased carbon dioxide emissions from clearing local forests for wood fuel supply or from using fossil fuels. The rotational woodlot system holds promise to sustain soil organic carbon because stable fractions of soil organic matter are generally unaffected by the short (3-year) post-fallow cropping period. Of the tested tree species, $A$. mangium, $A$. crassicarpa and $A$. polyacantha showed the highest capacity to sequester carbon. These species may be useful for mitigating carbon dioxide emission through on-farm wood supply and build up of soil organic matter.

VictorTimmer,vic.timmer@utoronto.ca 


\author{
Viviana Horna \\ University of Göttingen, Germany \\ Reiner Zimmermann, University of Hohenheim, Germany \\ Pedro Vasquez, Agricultural University of Lima, Peru
}

\title{
Interannual variabibility in water use of a neotropical equatorial dry forests
}

The natural vegetation of the dry southern equatorial coastal region is strongly affected by intra- and interannual varying precipitation regimes with a dry season having up to 8 months duration. Multi-annual cycles of ENSO events are superimposed to the annual regime bringing within a short time, torrential rains with a ten fold increase in precipitation.

At the Game Reserve of El Angolo in northern Peru, we conducted continuous measurements of xylem flux density over a 2.5 year period on 30 trees of the most common tree species. Four evergreens and 6 deciduous species were included for comparison of contrasting functional plant types. Measurements of microclimate were conducted in parallel as well soil humidity.

Mean radiation load and air temperature were stable all year round and showed little annual variation. Mean vapor pressure difference (VPD) was around $1 \mathrm{kPa}$, maximum VPD was high and occasionally exceeded $3 \mathrm{kPa}$. Night VPD typically did not reach zero and fog or condensation were then absent. Night VPD at the end of the dry season may not drop below $0.5 \mathrm{kPa}$, enough to drive significant transpiration. Soil volumetric water content in $10 \mathrm{~cm}$ depth saturated after significant rains within $24 \mathrm{~h}$, but soil water was depleted within few weeks. The soil within $20 \mathrm{~cm}$ depth needed one month con continuous rainfall to saturate but retained plant available water for several months thereafter.

Surprisingly, daily patterns of tree xylem flux varied widely and were often completely decoupled from the usual driving factors such as atmospheric vapor pressure deficit and solar radiation. These species seem to have extensive root systems for continuous water extraction. Even though most species in the dry forest are deciduous, water loss is not reduced to zero during the leafless period. During many dry months of the year, tree species have flux peaks during late evenings or early night. This is indicating switching from C3 to CAM in drier periods and strong stomatal control of transpiration.

The tree species which dominate the dry forests of El Angolo seem to have a variety of adaptations and strategies to cope with the highly variable and seasonal water availability of their habitat. Woody organ transpiration and CAM-induced night transpiration contribute to the "hydraulic" diversity of the dry forest.

Viviana Horna, vhorna@gwdg.de 


\section{Focus 3:}

Integrated concepts of land use in tropical landscapes 


\begin{abstract}
Alfredo R. Huete
University of Arizona, USA

Piyachat Ratana, Khon Kaen University, Thailand

\section{Satellite measurements of dynamic human- environment and climate interactions in tropical Monsoon Asia}

Following decades of war, conflict and isolation, large areas of tropical forested ecosystems, rich in natural resources and biodiversity, have remained relatively intact or have regenerated, in the lower Mekong Region (Thailand, Cambodia, Laos, Vietnam). However, this region has become a new frontier for economic growth with open markets, borders, and economic corridor developments. The transport corridors will traverse preserved tropical forest areas, intersect important biodiversity corridors, and facilitate greater access and regional vulnerability, with threats of destructive land conversion, unsustainable exploitation of resources, population pressures, and poverty. Little is known regarding the resilience of Monsoon Asia tropical ecosystems to increasing human pressures and climate variability, despite the large consequences to carbon cycling, fires, ecosystem services, and the socioeconomic welfare of the region.

In this study, we used eight years of satellite observations from the NASA- Moderate Resolution Imaging Spectroradiometer (MODIS), at high temporal frequency, to evaluate and better understand the seasonal functioning and health of these tropical forests. We explored the utility of landscape seasonal profiles as integrators of various ecosystem processes with observed shifts serving as indicators of environmental change resulting from climate and/or human influences. We found the time series based seasonal and phenology profiles varied across and within land cover classes (montane, lowland, and swamp tropical forests), in accordance with land use pressures, climate variability, forest degradation, soils, past disturbance, and stages of regeneration and provided good measures of ecosystem functionality.

Most of the preserved and healthy landscapes remained green and moist through all or a part of the dry season, i.e., they were resilient to short-term seasonal and interannual drought events. Meanwhile the more degraded forests and younger forests were more water-limited and browned down during drought seasonal periods. In the more degraded tropical forest areas, land use pressures have greatly altered seasonal greening and drying patterns with important consequences to the carbon, water, and energy cycles. The enhanced drying patterns observed in the degraded environments have greatly increased landscape vulnerability to human-made fires. Land degradation combined with more intense drought periods, as predicted with climate models, will most likely stress these ecosystems beyond their threshold, which will result in widespread forest drying and wildfires becoming a more dominant force with large impacts and consequences to the social and economic welfare of the region (erosion, landslides and other natural disasters). We conclude that satellite temporal datasets offer great potential to the integrative understanding of ecosystem functioning, the impacts of human activities and climate on altered functioning of landscapes, and in the monitoring and assessments of shifts in biome seasonality and function.

Alfredo R.Huete,abuete@cals.arizona.edu 


\author{
Alfredo R. Huete \\ University of Arizona, USA \\ Piyachat Ratana, Khon Kaen University, Thailand \\ Nagon Wattanakij, Khon Kaen University, Thailand \\ Chanada Ratana, Rajapat Burirum, Thailand \\ Charat Mongkolsawat, Khon Kaen University, Thailand
}

\title{
Satellite Time-Series Vegetation Seasonal and Temporal Variations of Human Savannah and Forests in Northeast Thailand
}

Northeast Thailand, representing one-third the area and population of the country, is the driest region in Southeast Asia and has the greatest extent of land disturbance, with more than $70 \%$ of the land converted into agricultural uses, such as rice and cash crops. The region now comprises savannah-like agricultural areas (a continuum of rice or crop understory and a sparse cover of overstory trees), and remnant dry tropical deciduous and evergreen forests. This large-scale land conversion from forest to man-made savannah has had significant impacts on ecosystem functioning. Moreover, with recent climate variability due to climate change and a severe drought problem persisting for more than a decade, an improved understanding of landscape mechanisms and dynamics is needed for effective mitigation planning and decision making. Therefore, the focus of this study was to investigate the seasonal and temporal characteristics and variations of natural forests and human savannah ecosystems in NE Thailand. We utilized eight years (2000-07) of NASA Moderate Resolution Imaging Spectroradiometer vegetation index data (VI) to monitor the changes in vegetation seasonal dynamics at local and regional scales. We also analyzed the relationships between meteorological/climate factors and vegetation dynamics in both natural and human-made systems. Our results showed significant differences in the seasonal dynamics and functioning between human savannah and tropical evergreen forests with important consequences to landscape health. We found well-pronounced dry-wet season, vegetation seasonal dynamics strongly coupled with rainfall over savannah-like areas and deciduous forests with greening up occurring in the rainy season (May-Oct). This suggests that changes from drought and climate variability impacts on vegetation can be observed and monitored in satellite observations. On the other hand, the tropical evergreen forests showed the least seasonal contrast and variations with peak greenness in the dry season (Jan-Feb) and low correlations between VI and rainfall. We noted that the savannah-like agricultural areas exhibited strong seasonal dynamics with large spatial variations due to land use management practices. Therefore, it is suggested that land use practices be taken into account in future studies and assessments of ecosystem functioning and dynamics.

Alfredo R.Huete,abuete@cals.arizona.edu 
Focus 3: Integrated concepts of land use in tropical landscapes

\begin{abstract}
Alwin Keil
University of Hohenheim, Germany

Camille Saint-Macary, University of Hohenheim, Germany

Manfred Zeller, University of Hohenheim, Germany

\section{Maize boom in the uplands of Northern Vietnam: What are the socio-economic and environmental implications?}

Maize production in Vietnam has increased sharply since the government began to strongly support and promote maize hybrid technology in 1990. Maize has become the second most important crop after rice, and it is the primary source of feed for Vietnam's livestock and poultry industry. Due to rapid economic growth and accelerated urbanisation, the demand for meat products and, hence, maize has grown dramatically and is expected to further increase in the future. While this development has the potential to reduce rural poverty by offering attractive income opportunities to smallholder farmers, it promotes the expansion of agricultural cultivation into fragile agro-ecological zones, often leading to deforestation and subsequent soil degradation, especially in the uplands. Vietnam's challenge, thus, is to supply maize for an expanding market, while ensuring environmental sustainability of maize production through appropriate agricultural and rural development policy. Using empirical evidence from a random sample of 300 households in Yen Chau district in north-western Vietnam, the objective of this paper is to investigate the socio-economic and environmental implications of maize production in an agro-ecologically fragile mountainous environment that is characterised by rapid population growth and a high incidence of poverty. Apart from providing descriptive empirical ground-truthing, the paper investigates determinants of farmers' engagement in maize production with the aim of deriving policy recommendations.

In Yen Chau only patches of natural forest remain, mostly on mountain tops above 1,000 $\mathrm{m}$ a.s.l.. Due to population pressure even steep slopes have been taken into cultivation, which, together with intensive ploughing, shortened fallow periods, and a lack of soil conservation measures, has led to massive erosion and declining soil fertility. Maize is by far the most important cash crop in the area: ninety-six percent of farm households earn income from maize production, which accounts for $76 \%$ of total agricultural household income on the average. In the main cropping season in 2007 farmers devoted on average $71 \%$ of their cultivatable area to maize, mainly on erosion-prone upland plots. While substantial efforts have been made since the mid 1990s to promote soil conservation technologies in the area, adoption rates have remained extremely low; major reasons are adverse short-term effects on maize production in terms of area loss and yield, for example through the planting of contour hedgerows using trees, shrubs, or grasses on sloping land.

While maize is the dominant cash crop in Yen Chau, our data exhibit a high degree of variation in terms of input use for its cultivation, yields, and farm area share devoted to the crop. The latter ranges from zero to $100 \%$ (3\% of sample households each). This allows to apply a Tobit regression model to identify influencing factors of the degree to which farmers engage in maize production. These may be related to households' resource endowment, access to services, such as credit and agricultural extension, and infrastructural conditions; moreover, farmers' crop management skills as reflected by their degree of technical efficiency in maize cultivation may influence the scale of the practice. The findings will be discussed with policy-makers at different administrative levels and can thus aid the formulation of policies aimed at a balance between sufficient maize supply on the one hand and environmental sustainability on the other.

AlwinKeil, alwin.keil@uni-hohenheim.de 


\author{
Andreas Neef \\ University of Hohenheim, Germany
}

\title{
Towards Incentive-Based Policies for Protecting Watersheds in Southeast Asian Uplands
}

Policies and programs towards sustainable upland development and integrated watershed management in Southeast Asia have produced mixed results since concerns for upland areas have moved from the fringes of public interest to the center of national and international policy agendas. This paper attempts to identify the major factors associated with some of the failures and successes of integrated watershed management polices and projects with a particular emphasis on the uplands of mainland Southeast Asia. It sets out by describing the uncertainties of knowledge under which upland watersheds are managed and the strategic simplifications that characterize government policies and project agendas. The paper argues that many policy measures have been misguided by (1) failing to acknowledge the multi-functional character of mountain watersheds, (2) putting too much emphasis on one-size-fits-all conservation models, technology-driven solutions and command-and-control approaches, and (3) neglecting the various institutional dimensions of resource conservation and integrated watershed management. The latter is particularly evident in the failure of most Southeast Asian governments to legalize communal forms of resource tenure and to monitor more closely the differential impacts of private and state property regimes and of enhanced market integration on resource conservation and adoption of sustainable and less sustainable agricultural practices in the uplands.

Co-management approaches to natural resource conservation or multi-stakeholder platforms in combination with Payment for Environmental Services (PES) schemes have been widely proposed to break the deadlock in upland conservation policies, and pilot projects in Indonesia and the Philippines have shown encouraging results at some locations. Yet, they still have to prove their viability on a broader scale and whether they can combine pro-poor and pro-environment. Drawing on recent initiatives in one of the study areas of a long-term collaborative research program in Thailand (The Uplands Program - SFB 564) this paper will present evidence how a socially, institutionally and ecologically optimal mix of agricultural production, ecological services and rural livelihood opportunities can be achieved.

The paper concludes that future policies and approaches towards integrated watershed management need to overcome the (perceived) antagonism between conservation and development in upland areas of Southeast Asia and to determine the socially, institutionally and ecologically optimal mix of agricultural production, ecological services and rural livelihood opportunities.

AndreasNeef,neef@uni-hobenheim.de 


\section{Bernhard Schuldt}

University of Göttingen, Germany

Viviana Horna, University of Göttingen, Germany

Christoph Leuschner, University of Göttingen, Germany

\section{Seasonal response of tree xylem flux to climatic variation and experimental drought in Central Sulawesi}

Seasonality of water flux was investigated for common tree species of a Central Sulawesi submontane forest located in the Lore Lindu National Park. Trees were exposed to reduced precipitation levels to simulated Enso effects. Since June 2007 we monitored 90 trees from 8 common tree species. Half of the trees were located under the rainfall displacement experiment of the STORMA Project and the other half in the control areas. We used the constant heated method to monitor stem xylem flux density. Observations started between May and July 2007 and are still going on.

After almost 7 months of experimental drought, trees did not show effects of water stress. Only at the end of 2007, between December and January 2008 there was a strong dry event with high radiation levels and air humidity not reaching saturation at night time. Vapor pressure deficit (VPD) values remained above zero during several consecutive nights. Xylem flux density of several species decreased during this period. For instance Castanopsis acuminatissima (Blume) Rheder, a very common tree species, showed a mean decrease in maximum xylem flux density from 31.5 to $19.1 \mathrm{~g} \mathrm{H}_{2} \mathrm{O} \mathrm{m}^{-2} \mathrm{~s}^{-1}$. After rains resumed, xylem flux rates raised again at control and experimental plots.

Parallel measurements of xylem anatomy and hydraulic architecture revealed a good adaptation of the tree species water conducting system with tree height. These features together with the overall high precipitation in the area may explain the lack of response to the experimental drought. Critical soil water content levels have not yet been reached. Reduced xylem flux in December was mainly due to low air humidity but provide a clear evidence for tree sensitivity to drought. We expect that once critical soil humidity has been reached under the experimental roofs, the effects of VPD on tree xylem density would be dramatically intensified.

BernhardSchuldt, bschuld2@gwdg.de 


\section{Camille Saint-Macary}

University of Hohenheim, Germany

Alwin Keil, University of Hohenheim, Germany

Manfred Zeller, University of Hohenheim, Germany

\section{Does rice self-sufficiency foster environmental sustainability in the uplands of Northern Vietnam?}

The short planning horizon of poor farmers in developing countries and the pressure to fulfill basic consumption necessities have been identified as important causes for the intensification of agriculture and the resulting destruction of natural resources, especially in mountainous areas. In the uplands of Northern Vietnam, rapid population growth in the past decades has pushed farmers to expand cultivation into the mountains, destroying large tracts of natural forest. Despite the ecological fragility of the area, upland households still largely depend on crop production to meet their basic needs.

In Yen Chau district farmers are usually engaged in the cultivation of two main crops: irrigated rice grown in low-lying and flat areas and maize cultivated on sloping upland plots. While maize is the primary source of cash income for most farmers, rice, as in most of Asia, is by far the most important food staple.

Based on existing theoretical and empirical literature, we hypothesize that a higher degree of rice selfsufficiency will reduce the pressure on households to engage in intensive and potentially environmentally damaging upland cultivation. Therefore, we address the following research questions: (1) What determines farmers' rice production efficiency and their capacity to fulfill their consumption needs? (2) Does the degree of self-sufficiency in rice production affect farmers' behavior with respect to resource use in the uplands?

We use data collected in a random sample of 300 farm households in Yen Chau district, among which $80 \%$ grow irrigated rice. Forty percent of these households met their consumption needs in 2006-2007, and $12 \%$ derived cash income from this activity; however, this accounted for less than $1 \%$ of cash income on the average. Rice production is therefore mainly a subsistence-oriented activity in the study area. The degree of rice self-sufficiency, i.e. the share of home produced rice in a household's total rice consumption, varies widely between households, even within villages, indicating that variation is not only due to geographical characteristics.

The empirical analysis is built on two steps: (1) Assessment of farmers' technical efficiency in rice production and the determinants of the degree of rice self-sufficiency. In particular, we investigate how access to credit and tenure security affect farmers' capacity in this regard. (2) In a second step, we estimate the effect that the degree of rice self-sufficiency has on natural resource management indicators, such as intensification, expansion of cultivation, and use of soil conservation technologies. From our results we deduce policy recommendations that could enhance sustainable rural development in the area. 


\section{Carsten Gutzler}

University of Göttingen, Germany

\section{Effects of rainforest conversion on throughfall}

The progressive conversion of natural forests into arable land, especially into cacao agroforest, can be witnessed at variable rates throughout whole the STORM research area.

In order to predict the effects this change has on the water- and nutrient cycle, comparative site experiments in natural forest and agroforest are crucial. On plot-level it is necessary to assess the differences within the key processes: throughfall, litterfall and soil-water drainage.

To measure differences in throughfall rate and composition three experimental plots (plot size 100m2 ) were set up within the STORMA research area, Central Sulawesi, Indonesia $\left(1^{\circ} \mathrm{S} ; 120^{\circ} \mathrm{E}\right)$ near the village Bulili. Two cacao plots of different age ( 7 and 18 years) and management intensity were set against one natural forest plot. To allow the calculation of throughfall rate and nutrient enrichment during canopy passage a number of open area plots near to the research plots were also set up.

All research plots were equipped with 20 bulk deposition samplers. Read out and sampling was carried out twice a week.

Over a 12 month measurement period we found a significant difference in the median throughfall rate (based on single event throughfall rates) of the cacao plots on the one hand $(85 \%)$ and $(87 \%)$ and the natural forest on the other hand $(77 \%)$.

This implies an increase of water input with the conversion of natural forests to cacao plantations, leading to higher runoff and increased flood risk.

Chemical analysis of water samples showed that the input of nutrients into the plots with throughfall was significantly lower in the cacao plots than in the natural forest plot.

The findings on plot level were compared to those from an experimental meso-scale catchment to evaluate the quality of upscaling from plot level-data to catchments-level.

Carsten Gutzler,.gutzler@web.de 


\section{Carsten Gutzler}

University of Göttingen, Germany

Stefan Köhler, University of Göttingen, Germany

Gerhard Gerold, University of Göttingen, Germany

\section{Plot level measurements of water- and nutrient-cycle}

The progressive conversion of natural forests into arable land, especially into cacao agroforest, can be witnessed at variable rates throughout whole the STORM research area.

In order to predict the effects this change has on the water- and nutrient cycle, comparative site experiments in natural forest and agroforest are crucial to assess the differences within the key processes: throughfall, litterfall and soil-water drainage.

Although a number of plot-level studies in the inner tropics do already exist, a lack of standardisation and documentation makes it difficult to compare the widely varying results. For this reason exact documentation of the applied methodology and data treatment is at the core of our research.

Three experimental plots (plot size $100 \mathrm{~m} 2$ ) were set up within the STORMA research area, Central Sulawesi, Indonesia $\left(1^{\circ} \mathrm{S} ; 120^{\circ} \mathrm{E}\right)$ near the village Bulili. Two cacao plots of different age $(7$ and 18 years) and management intensity were set against one natural forest plot. To allow the calculation of throughfall rate and nutrient enrichment during canopy passage a number of open area plots near to the research plots were also set up.

All research plots were equipped with 20 bulk deposition samplers (BDS). Read out and sampling was carried out twice a week. Litter was collected on 1x1 meter nets and analysed every two weeks. Soil water was sampled by means of ceramic candles in different depth levels down to $190 \mathrm{~cm}$.

Data from throughfall, litterfall and soil-water were used to create water- and nutrient balances for the natural forest plot and the cacao plot.

The poster concentrates on showing the techniques applied to realise the research objective, advocating a higher degree of standardisation in ecosystem research.

Carsten Gutzler,.gutzler@web.de 
Focus 3: Integrated concepts of land use in tropical landscapes

\section{Chapika Sangkapitux}

University of Chiang Mai, Thailand

Andreas Neef, University of Hohenheim, Germany

Ke Nanthasen, University of Chiang Mai, Thailand

Nongkran Pramoon, University of Chiang Mai, Thailand

\section{Willingness of upstream and downstream resource managers to engage in reward schemes for environmental services}

Providing compensation for agricultural conservation practices adopted by upstream farmers is still an alien concept in the Thai political context. The governance of natural resources, such as forest and water, has traditionally been under the control of powerful government line agencies, while the contributions of local communities to natural resource conservation have been largely ignored by policy-makers. One of the focal points of command-and-control environmental policies has been the northwestern part of the kingdom where more than 50 percent of the country's total forest area and the major head watersheds feeding the Chao Praya river, the lifeline of Thailand's rice bowl, are located. Drawing on a case study in Mae Sa watershed, Chiang Mai province, northern Thailand, this paper discusses the potential of compensation schemes in a socio-political context where upland farmers - mostly belonging to ethnic minority groups - tend to be considered as a threat to the natural resource base rather than providers of environmental services. Based on data obtained from 166 households in the upstream communities and 151 households in the downstream communities of the watershed, we aim to identify factors determining the potential of developing a payment scheme for environmental services. Upstream resource managers' willingness to accept compensation for the conservation measures and downstream residents' willingness to pay for water resource improvements were estimated through the use of choice experiments (CE).

Results from the study suggest that upstream resource managers who had experienced problems of soil erosion and water scarcity in the past, had a higher probability to adopt "downstream friendly" practices. Strikingly we found a higher probability to adopt soil and water conservation practices among farmers with low tenure security. In addition, a higher level of reliance on agricultural income increased the probability to accept compensation to shift towards more environmentally friendly practices. Among, three selected conservation practices, namely (1) installing water saving technology, (2) planting grass strips for erosion control and (3) application of bio-insecticides, the latter two significantly determined the farmers' willingness-to-accept-compensation. For downstream communities, a high probability to pay for water resource improvement was found among the farmers who had experienced drought conditions in the past and who were actively engaged in environmental conservation activities. On the other hand, a decrease of the dependency on water resources from the Mae Sa river, reflected in the diversification of both water sources and income opportunities towards non-agricultural sources, resulted in a lower probability to pay for water resource improvement. The estimated marginal willingness-to-pay turned out to be highest for the attribute 'water quality improvement' followed by 'water quantity for cultivation'. 
Focus 3: Integrated concepts of land use in tropical landscapes

The paper concludes that there is a clear potential for establishing compensation schemes for provision of environmental services in northern Thai watersheds. The important policy implication is to move from ineffective command-and-control towards incentive-based approaches in order to preserve vital watershed functions. Both upstream and downstream resource managers should get involved in the compensation schemes. This requires that policy-makers revise their exclusive focus on 'fixing uplanders' resource management practices'. Finally, a specific regulatory framework in support of compensation measures needs to be put in place to bring service providers and beneficiaries together and to facilitate the implementation of such schemes on a broader scale.

ChapikaSangkapitux, chapika@chiangmai.ac.th 
Focus 3: Integrated concepts of land use in tropical landscapes

\section{Christina Seeberg-Elverfeldt}

University of Göttingen, Germany

Stefan Schwarze, University of Göttingen, Germany

\section{Institutions for Payments for Environmental Service programmes - Evidence from community resource management arrangements in Indonesia}

Payments for Environmental Service (PES) schemes have been increasingly discussed among scientists, donors and policy makers during the past few years. They are regarded as a possibility to promote the conservation of natural resources, whereby the providers of the environmental service should receive compensation payments from the external beneficiaries on the basis of a negotiated framework agreement. The local landowners and land users in turn have to adopt land use practices which secure the conservation or restoration of the environmental service. Some donors and policy makers regard these schemes as the solution to natural resource management problems. However, the experience derived by PES projects in various countries indicate mixed results. These pilot schemes are frequently very small in size and face high transaction costs which lead to the exclusion of smallholders. A solution could be collectively bundled contracts which are currently being tested in Costa Rica. In addition, an interesting option is to use the existing community resource management arrangement structures and build upon those in order to enhance cost effectiveness and allow the participation of smallholders in these programmes. Using present institutional arrangements has, furthermore, the advantage that the participants are familiar with them and trust them. The purpose of this paper is, therefore, to assess on the basis of the example of the institution of the community conservation agreements in Central Sulawesi whether a community arrangement can provide the framework to implement a PES project.

Community conservation agreements (CCA) were established in 60 villages in the surroundings of the Lore Lindu National Park in Central Sulawesi as a co-management strategy. The local communities entered a negotiated arrangement with the national park authority as a strategy to resolve conflicts between the peoples' needs and conservation demands. For this study, we assessed whether the CCA can provide an institutional platform for a carbon sequestration project. This implies an organisational structure representing the village households as well as the community being involved in the resource management process. This considerably increases the legitimacy of regulatory interventions when the resource users participate in its design and implementation. Furthermore, this institution needs to monitor and enforce the forest usage regulations and, finally, to also be able to administer funds from potential carbon payments and channel them towards the individual recipients.

We chose a qualitative research design and conducted focus group discussions in four villages with a CCA. In each village, one focus group discussion was carried out with the village authorities and a second one with farmers who had been randomly selected. The groups usually consisted of five participants. As we wanted to obtain information about various people's attitudes, awareness and values pertaining to a defined topic and why they are as they are, the focus groups were considered especially relevant to this research. They allow the organiser to gain an insight into the participants' opinions by observing the structured discussion of an interactive group in a permissive, non-threatening environment. Thus, a focus group can be considered a combination of a focused interview and a discussion group. The discussions were assessed with the content analysis, and a systematic text retrieval was carried out using a methodologically controlled assignment of categories.

Our findings show that the CCAs are backed up by an organisational structure which is usually the village conservation council. The community is familiar with this organisation, and aware of its activities. 
However, in most villages, the community members were not very involved in the agreement negotiation and sometimes did not even know of the existence of the agreement. The traditional customary institution is present in all of the villages and provides a good foundation for the regulatory framework of the conservation agreement. It can be built upon in order to improve the local population's acceptance of the new regulations. A monitoring entity has also been constituted and is, with the limitations its faces, relatively active. Several cases of law enforcement were recorded; however, limited funds constrain the entity's activities considerably, and the monitoring is adjusted according to personal time schedules. Thus, a good basis is given for the monitoring and enforcement structures, but the entity needs to be financially supported and improved to be more effective. The awareness with respect to nature conservation has become more widespread only in the recent past, but considerable resource extraction has left its marks, and the perception prevails among the participants that environmental problems such as flooding and erosion are increasing. Finally, compensation payments are regarded on the one hand as a good reimbursement for desisting from using the forest resources. On the other hand, due to the negative experience with corruption and the embezzlement of funds, a very clear organisational structure for the administration of such a project is needed, and this does not seem to be given with the current community conservation agreements and the associated village conservation councils.

Therefore, based on this study, we recommend using existing community arrangements because that entails the advantage of using already established structures such as, in this case, the regulatory framework. However, these need to be frequently enriched and built upon in order to fulfil all the requirements of a PES project. It is of major importance to include the community members in the management of natural resource projects in order for those to function. Compliance with regulations increases when they are acceptable and considered legitimate by those whose interests are regulated.

Christina Seeberg-Elverfeldt, c.seeberg@agr.uni-goettingen.de 


\title{
Cindy Hugenschmidt
}

\author{
University of Hohenheim, Germany \\ Walaya Sangchan, University of Hohenheim, Germany \\ Joachim Ingwersen, University of Hohenheim, Germany \\ Yongyuth Sukvanachaikul, University of Chiang Mai, Thailand \\ Stefan Uhlenbrook, Delft University of Technology, The Netherlands \\ Thilo Streck, University of Hohenheim, Germany
}

\section{A model approach using the SWAT model to assess rainfall-runoff relations under different land use conditions in Northern Thailand}

The growth of population and the intensification of land use in the mountainous regions of Northern Thailand lead to an urgent reclamation of natural forests. The expansion of arable land is accompanied by an increasing input of agrochemicals, which poses the risk of environmental pollution. To study the impact of different land use types and of the shift of land use on the fate of agrochemicals we used the SWAT (Soil and Water Assessment Tool) model. The focus of the present work is on model calibration and application in a subcatchment of the Mae Sa watershed. The watershed is located close to Chiang Mai. It has a total area of $77 \mathrm{~km}^{2}$ with a subcatchment of $7 \mathrm{~km}^{2}$. It is dominated by steep slopes and narrow valleys. The cultivated area is mainly used for flower and vegetable productions. The forests are mixed evergreen and deciduous forests. Rainfall and runoff data in the subcatchment have been recorded for several years. Two additional discharge gauges and 12 rain gauges were installed in the beginning of the rainy season 2007. Soil physical properties and land use maps are at hand. Two rain gauges were set up in the subcatchment. They show a high spatial and temporal variability of rainfall. High variability was also observed in the whole watershed which points to difficulties in model calibration especially according to the simulations in the subcatchment. Runoff coefficients for the different years vary from 0.3 to 0.4 . The model will be validated with data from the last rainy season and up-scaled to the watershed scale. In the near future the results from pesticide analyses of water samples taken at the three discharge gauging stations are going to be implemented into the model to simulate the transport of agrochemicals in the watershed under different land use conditions.

Cindy Hugenschmidt, cindy.hugenschmidt@uni-hohenheim.de 


\section{Damayanti Buchori}

University of Bogor, Indonesia

Bandung Sahari, Indonesia Nature Conservation Foundation

Akhmad Rizali, Indonesia Nature Conservation Foundation

\section{Insect Pollinator Community in Brassicaceae Plantations at the Southern Margin of Halimun Salak National Park, Indonesia}

Insect pollinators in brassicaceae plantations at the southern margin of Halimun Salak National Park was studied between November 2006 and Oktober 2007. Insect samplings were conducted in 15 plots of brassicaceae (Brassica rapa) plantations situated in different distances from the nearest forest (between 0 and $2000 \mathrm{~m}$ ). Insects were sampled during 45 days of flowering season. In total, approximatelly 1029 individual insects belonging to 39 morphospecies and eight families of Hymenoptera were collected from brasicaceae plantations. Apidae was found to dominate the community with species richness and abundance covered about $42 \%$ and $49 \%$ of the total collected specimens respectively. Several species that were recorded to cover large number of individual specimens were (1) Colletidae sp. 002 (356 individual, or $34.6 \%$ of total collected), (2) Ceratini (Tribe) sp. 007 (192 individual, approximately amounted to 18.6\%), and (3) Trigona sp (record sp. 001) with 124 individual (12.05\%). The result of the study showed that species diversity decreased with increasing distance of plots to the nearest forest. Our preliminary data indicates that there is a site-specific species composition of insect pollinator communities and habitat isolation may contribute significantly to the presence of species. Implications of these findings toward conservation of pollinator insects are discussed.

DamayantiBuchori,dami@indo.net.id 


\section{Dirk Hölscher}

University of Göttingen, Germany

Diego Dierick, University of Göttingen, Germany

Michael Köhler, University of Göttingen, Germany

Luitgard Schwendenmann, University of Göttingen, Germany

\section{Sap flux of tropical trees: a model based analysis of species-specific responses to environmental variables}

Tree sap flux and water use is usually controlled by a suite of partly correlated environmental variables and their response to fluctuating conditions is often non-linear. Consequently, it is not always obvious which variable actually induced observed changes in water use and how variables interact. A model may help to overcome such difficulties. We used data of ten tree species of plantations in Leyte, Philippines (humid tropical climate) and two species of an agroforestry system in Sulawesi, Indonesia, which underwent an experimental drought. A combination of a relatively simple Jarvis type model and a statistical, multivariate approach as based on previous work by O'Brien et al. (2004) was applied. Objectives were: (1) to identify species-specific differences in sap flux response to environmental variables, and (2) to provide reference sap flux for trees under soil drought. A model based on meteorological variables alone explained between $86 \%$ and $96 \%$ of observed sap flux variability per species in the Filipino plantations using 30 min average sap flux data. Model parameters suggested significant differences among species including maxima of sap flux density, daily onset of sap flux, and influences of air humidity and radiation. Also for the agroforestry system in Indonesia the model predicted $30 \mathrm{~min}$ sap flux in control plots under moist soil conditions quite well (observed variability explained: $90 \%$ for Gliricidia and $92 \%$ for cacao), and again suggested some species-specific differences in model parameters. With the prediction of sap flux, the model also improved comparison between roof and control plots during a period with little rain when soil water reduction was assumed to influence sap flux in control plots too. We conclude that the applied, relatively simple model helped to reveal differences among species under relatively moist soil conditions and provided valuable insights into tree species' response to soil drought.

Dirk.Hölscher,dhoelsc@gwdg.de 


\section{Eleanor Milne}

Colorado State University, USA

Carlos Eduardo P. Cerri, CENA, Brazil

João Luis Nunes Carvalho, CENA, Brazil

\section{Observations on agricultural expansion in the Sinop area of Mato Grosso state, Brazil}

The states of Rondonia and Mato Grosso in Brazil, make up the world's largest agricultural frontier, with deforestation occurring at an increasing rate. The environmental consequences of this include loss of biodiversity (the Amazon Basin is believed to embody approximately $25 \%$ of the world's biodiversity), soil degradation and increased greenhouse gas (GHG) emissions from above and below ground sources. In this frontier area, where agriculture is a relatively new activity, land use and management practices change rapidly as farmers react to market pressures but also use trial and error to increase productivity/reduce losses. The fact that systems are in a state of flux has implications for sustainability and the ability of scientists to produce local and national GHG inventories and project future GHG emissions. Farmers routinely make use of the latest technologies available e.g. farm machinery, applications using Geographical Information Systems (GIS) and remote sensing, making agricultural expansion in this area very different from historical examples.

As a preliminary activity, we considered five farms in the area surrounding Sinop, a town on the edge of the agricultural expansion zone which has one of the highest grain productivity rates in the world. Farms were considered in terms of crop choice, crop rotations and cropping practices from the time of farm establishment (the mid 1980's onwards) through to anticipated activities for the future. Farms varied in size, from large (20 thousand ha) to relatively small (200 ha). We found that all farms were initially set up to repeatedly grow a monoculture, generally soybean, with corn or millet as a second crop. The larger farms are moving away from this system towards crop-livestock integration systems involving different crops. Farmers see integrated systems as a means of increasing productivity, protecting themselves from changes in the market, reducing soil degradation, increasing carbon stocks and decreasing pest infestation. However, the smaller farms lack the capital needed to change to an integrated production system. The case of each farm is discussed, as is the need for a comprehensive study of changing cropping practices across the agricultural frontier area of the Brazilian Amazon.

EleanorMilne,e.milne@macaulay.ac.uk 


\section{Fadly Y. Tantu}

University of Palu, Indonesia

Hagi Yulia Sugeha, LIPI, Indonesia

Jusri Nilawati, University of Palu, Indonesia

\section{Fish Juvenile Diversity migrated inshore in River Palu Estuary: Implications for Conservation}

River Palu is formed by four rivers in the upper land: Rivers Rawa (outlet of Lake Lindu), Sopu, Gumbasa, and Miu. A study on fish juvenile diversity migrated inshore to River Palu estuary was conducted in the periods of June-October 2005 and May 2006-April 2007. The study was part of comprehensive study on fish diversity in Rivers Palu, Miu, Gumbasa, Sopu, Rawa, and Lake Lindu. Fish collections were accomplished monthly during new moon. Fish sampling were established in 12 hours from $0600 \mathrm{pm}$ until $0600 \mathrm{am}$ at hourly interval. We collected 2507 juveniles during the period of June October 2005 (79.9\% of which are Anguilla spp. in glass eel stage), and 1534 juveniles during the period of May 2006 - April 2007 (61.95\% of which are Anguilla spp. in glass eel stage). The others are groups of other fish species. Fish caught in 12 hours sampling time increased in the evening, then decreased two hours towards and two hours after mid night and again increased in the early dawn. Shannon-Wiener $\left(\mathrm{H}^{\prime}\right)$, similarity (E) and dominancy (D) indices for each sampling period were analyzed. Environmental parameters including water $\mathrm{pH}$, temperature, salinity and weather conditions were recorded. Global climate during sampling periods was studied further to describe variation of species number and each species density caught during those periods. It is required to manage fish habitat conservation from the upland (Lake Lindu) to the downland (River Palu estuary).

Fadly Y.Tantu,ftantu@yahoo.com 
Focus 3: Integrated concepts of land use in tropical landscapes

\section{Frank von Walter}

University of Göttingen, Germany

Jan Barkmann, University of Göttingen, Germany

\section{Integrated Modelling of Smallholder Land-use Decisions on the Availability of Rattan}

The margins of national parks belong officially to the protected areas of the parks. However, they are used for the livelihood of smallholders in the park's vicinity. Conflicts and continued poverty around protected areas suggest that existing approaches to conservation lack understanding of links between maintenance of diversity and human well-being. To mitigate between the needs of ecosystem conservation and economic development of a region, sustainable management options have to be found.

Integrated Assessment Models (IAM) are one tool to analyse the economic and ecological impact of landuse change. They combine economic reasoning with ecological. We will extend spatially explicit modelling by a multi-agent component. Agent-based modelling allows to differentiate between the perception of an individual agent and the system functioning with "full" information. With the SIEHL-framework (Spatially and Institutionally Explicit Household decision-making and Land use model) we apply this rationale to the margins of tropical rainforests in Indonesia (Lore Lindu National Park); In-SIEHL and later to Ecuador (Podocarpus National Park; Ec-SIEHL).

Lore Lindu National Park (LLNP) is situated in Central Sulawesi, Indonesia and is a core area of the Wallacea biodiversity hotspot, harbouring many endemic plant and animal species. The park covers an area of about 217,000 ha, which consists mainly of lower montane forest. Annual rainfall ranges from 2000 to $4000 \mathrm{~mm}$. Especially the margins of the national park are encroached by smallhold farmers and the natural land cover is changed. This encroachment includes logging, planting of cash-crops (mostly cacoa) and is accompained by the extraction of wood and non-timber forest products (NTFP) such as rattan. Rattan plays an important role in the smallhold economy. With the depletion of Calamus mannan as priority rattan species, Calamus. zollingeri has become the most important furniture cane. Around 150 canes (ca $12 \mathrm{~m}$ in length) can be harvested per ha (Siebert 2004). In the villages of Au and Moa in the vicinity of LLNP rattan is a major source of income.

We chose this area to carry out our first case-study of the SIEHL-framework. There the abundance and distribution of rattan (Calamus zollingeri) was measured along 5 transects in the years 1996 and 2000 and a strong decline in abundance was observed (Siebert 2004). The transects were located along a heightgradient with those of Moa located within the National Park and those of Au just outside the park's borders. A third visit to the transects is planned for fall 2008.

The sources of the spatially explicit landscape model are a digital elevation map, with a resolution of $30 \mathrm{x}$ $30 \mathrm{~m}$ (LandSat) and digital land-use and land-cover maps (data source: STORMA). With these digital maps we identify potential rattan sites (below $1500 \sim \mathrm{m}$ and within the forest as land-cover type). Then we compute the relative movement costs concerning the slope and the distance to the closest village. These two maps juxtaposed give us an idea about the areas where rattan harvest can take place. With the easier accessible areas (low movement costs) harvested earlier. With these data we can simulate the growth and harvest of rattan in the area. As part of the In-SIEHL framework, the Agent-Based Modelling component will simulate the smallholders in their plight to collect rattan. For initialisation purposes we will adjust the harvesting rate, that it matches the observed data.

FrankvvonWalter, fwalter2@gwdg.de 
Focus 3: Integrated concepts of land use in tropical landscapes

\section{Frank von Walter}

University of Göttingen, Germany

Jan Barkmann, University of Göttingen, Germany

\section{Ex-ante Analysis of an Agroforestry Land-use option in Southern Ecuador}

In Southern Ecuador there is an accelerated land use change from fragmented forest to crop and cattle farming. This is also true for "Biosphere Reserve Podocarpus - El Cóndor" (BRPC), where the principal economic activity is livestock farming west of the park and timber extraction in the eastern part.One option to mitigate the negative effects of cattle farming is the introduction of agroforestry management systems (AFMS). In AFMS crop plants are planted along the boarders or within differently used land (e.g. pastures or natural forest). The crop plants can have a beneficial effect on the land (e.g. leguminous plants improve nitrogen fixation), enhance the land-use (e.g. shade trees for livestock on pastures) and provide an extra source of income (e.g. fodder or marketable products).

Especially for Latin-American countries AFMS are considered to be an attractive alternative. However, financial benefits can only be reaped after an establishment period of, at times several years. We exemplify this by exploring AFMS with Tara (Caesalpinia spinosa; Fabaceae) as the tree component. The Tara is a leguminous shrub or small tree. It reaches about $5 \mathrm{~m}$ in height and is common in the Andes and grows in altitudes ranging from 50 - $2800 \mathrm{~m}$. Adult trees bear $20-40 \mathrm{~kg}$ of fruit annually. Commercially it is used for dying, tanning and as a food additive (E 417 - Tara Gum).

Successful planting projects have already been concluded in Northern Peru and a Tara planting project is on its way in other parts of the Loja province. These planting projects will show, whether Tara can be planted and harvested at acceptable yields in the BRPC-region.

Since cattle ranching is the main livelihood we assess the applicability of AFMS on pastures. We do so under the assumption that the pasture is split and areas are dedicated exclusively for Tara, because livestock might feed on Tara, which is supposedly more profitable. Therefore we apply the analyses on a sparse AFMS with fruit trees (400 Tara-trees/ha).

Before the local data are at hand, we will use the Peruvian cost and yield data for Tara plantations to estimate a production model.

With the assumptions on the market prices and opportunity costs we will implement the economic module of the spatially explicit Ec-SIEHL framework. Census data of the region gives us the number of households and their cultivated plots in this area. We will compare different scenarios of smallholders adopting to two different land-use innovations (Tara-AFMS and Alnus-plantations). After a modelling period of 30 years, we can compare the impact on the environment and the average income from both land-uses. Data from Peru indicate that Tara can be planted at densities ranging from 400 to 1000 trees/ha, depending on other land-uses in the AFMS. At a low density other crops can be planted between the trees (e.g. Alfalfa, Medicago sativa as fodder plant).

After the establishment period of three years harvesting can begin. Preliminary analysis suggests that even with tentative assumptions on market prices and conservative interest rates $(8 \%)$, Tara seeds are far more profitable than Alnus-Plantations (a 20-year reforestation programme) or cattle ranching (the current most profitable land-use type). After four to five years break-even is reached. Beyond that point an income from harvesting could be gained.

Tara has a high economic potential. In Peru alone, the production has increased almost ten-fold in the last six years. However, for the BRPC region there is a considerable risk component involved. Firstly, for this 
Focus 3: Integrated concepts of land use in tropical landscapes

region there is a lack of knowledge both scientific on the performance of Tara in this environment and among the smallholders about this agroforestry innovation. For modelling purposes, we will therefore only focus on the profits of an already established innovation. Marketing and production risks will be implemented in the model, as soon as new data is available. Socio-economic surveys, which are part of the FOR 816 program, evaluate the knowledge and opinions of smallholders about the Tara. The results from these surveys will help to further scrutinize the adoption process. Aided by our models we can do an economic ex-ante analysis and we can give recommendations for funding programs as well as contract and credit design.

Frank.vonWalter, fwalter2@gwdg.de 


\section{Hendrik Freitag}

State Collections of Natural History Dresden, Germany

\section{Aqua Palawana - The Aquatic Biodiversity Research and Conservation Project on the Philippine Island of Palawan}

AQUA Palawana is a joint initiative of the Western Philippines University and the International Research Institute of Entomology at the Museum of Natural History Vienna. The poster aims to introduce this program to the audience. Its strategies and its scientific foci, which include ecological studies and taxonomic works on Coleoptera, Ephemeroptera, Heteroptera (Insecta) and Decapoda (Crustacea) are presented. The data obtained during related projects are supportive of the Protected Area Suitability Assessment for priority areas of conservation. The program follows a multi-track strategy. A communitybased approach focuses on raising of people's awareness and on knowledge-transfer to the local communities. It is particularly aimed at promoting sustainable land use practices such as "Rainforestation Farming", an evaluated long-term strategy aimed to increase both, livelihood standards of rural communities and ecosystem conditions. The second, scientific-driven approach concentrates on biodiversity research into the freshwater macroinvertebrate fauna of Palawan and biodiversity key areas, in particular. Third of all, junior scientists and conservationists are trained by field courses, lectures and workshops to enable their independent work and forthcoming monitoring activities. Recent activities focus on the "Lake Manguao Aquatic Biodiversity Research and Conservation Project" which is supported by the Rufford Small Grants Foundation.

Hendrik.Freitag, hendrik.freitag@gmx.de 


\section{Jusri Nilawati}

University of Palu, Indonesia

Fadly Y. Tantu, University of Palu, Indonesia

\section{Diversity of Endemic Fish in Sulawesi Lakes and Threats of Habitat Loss due to Global Climate Change}

Lakes in the Central Sulawesi Island become a hotspot for endemic freshwater fishes in Wallace. There are three main lake systems that receive major interest from world biologists and conservationists: Malili Lakes Complex (Lakes Matano, Towuti, Mahalona, Lantoa, and Masapi), Lake Poso, and Lake Lindu. The lakes harbor a highly diverse endemic fish. Recently, we noted 41 endemic fish from those lakes; 32 species in Malili Lakes Complex, 7 species in Lake Poso, and only one species in Lake Lindu. Three of those endemic species were already extinct: Adrianichtys kruyti and Xenopoecilus poptae from Lake Poso, and Xenopoecilus sarasinorum from Lake Lindu. Reasons for the fish extinction are introduction of foreign fish species, overexploitation of the endemic fish, and destruction of native fish habitat. In the future, global climate change scenario accumulated in a variety use of the lakes, rivers and stream drainages, and surround terrestrial areas is predicted to enhance the loss rates of species diversity in this region. Ex-situ conservation and other management strategies to support the sustainable use of the lakes are urgently needed. Information should be disseminated to local community, government office and other stakeholders.

Jusri Nilawati,jnilawati_98@yahoo.com 


\section{Kerstin Wiegand}

University of Jena, Germany

Thorsten Wiegand, Helmholtz Centre for Environmental Research - UFZ Leipzig, Germany

\section{The effects of species and landscape properties on extinction thresholds in fragmented landscapes}

Land conversion is known to have a significant impact on biodiversity. A spatial version of Levins' (1969) metapopulation model has been used to show that, as the amount of habitat destroyed increases, the structural properties of the resulting landscape change in a non-linear way (Bascompte and Sole 1996). Most notably, there is critical amount of habitat ('extinction threshold') below which the metapopulation becomes extinct, despite the fact that there is still available habitat (Lande 1987).

For an application of the Levins model to real species, a critical assessment of the model assumptions is needed. Taking the ecological properties of some carabid beetle species as a basis, we relax assumptions pertaining to the number of colonization events, short- and long-range dispersal, and the spatial structure of the fragmented landscape. We individually analyze the effect of each of these assumptions on the extinction threshold and show that some assumptions enhance extinction while others have a delaying effect. We conclude by showing how to generalize the original equation model by Levins (1969) to a simple, yet more realistic model.

More generally, our results show that metapopulation survival depends on a combination of effects (assumptions) of both species and landscape properties. With respect to landscape properties, metapopulation survival is affected by both the amount of habitat destroyed and the spatial arrangement of the remaining habitat.

KerstinWiegand, kerstin.wiegand@uni-jena.de 


\section{Laurène Feintrenie}

French Research Institute for Development, France

Clara Therville, University Montpellier II, France

Wim Ikbal Nursal, CIFOR, France

Gen Takao, CIFOR, France

Patrice Levang, French Research Institute for Development, France

\section{Combining spatial analysis and perception surveys to understand the dynamic of rubber agroforests conversion in Muara Bungo district (Jambi, Indonesia)}

Located on the fringe of the last tropical rainforests of Sumatra, rubber agroforests are known to conserve approximately $50 \%$ of the biodiversity of the primary forest, and its main ecological functions. Presently these smallholder plantations are under threat. Because of the harsh increase of rubber and oil palm prices, many smallholders are incited to convert their agroforests into clonal rubber and oil palm plantations. However, some resist the change and prefer rejuvenating their agroforests.

In order to better understand the dynamic of conversion and the most determining factors of change, investigations were conducted at the household, village and landscape level. Our methodology combined spatial analyses and perception studies. A spatial analysis of SPOT images from years 1973 to 2005 , allowed us to quantify the conversion dynamic and to classify villages according to their conversion rates. A landscape analysis allowed us to assess present trends. In a second time, a survey of local peoples' perceptions of agroforest conservation and conversion was carried out in twelve villages of the district. This dual approach enabled us to elaborate the most likely scenarios of landscape evolution for the area.

Laurène Feintrenie, l.feintrenie@cgiar.org 


\section{Marion Mehring}

University of Greifswald, Germany

Susanne Stoll-Kleemann, University of Greifswald, Germany

\section{Sustainable Land Use in the Buffer Zone - The Villagers' Perspective}

The presented paper focuses on local people's perspectives on sustainable land use and its challenge in the context of rainforest margins at Lore Lindu National Park in Sulawesi, Indonesia.

Land conversion, such as deforestation, with resulting degradation threaten the integrity of forested ecosystems worldwide with South-East Asia showing the highest rates of deforestation of any major tropical forest region. One effective means to address this trend is the establishment of buffer zones as part of protected areas - PAs (e.g. national parks), where sustainable resource use is fostered to meet both human needs and conservation objectives. However, buffer zone implementation is a challenging task, which often raises difficult local problems. In order to address these and to better understand the dynamics of land use change a sound understanding of local people's ways of thinking is needed.

In this context, the paper considers two main research questions: (1) From the farmer's point of view, what hinders sustainable land use at rainforest margins in the case of Lore Lindu National Park and (2) what kind of management activities would make sense in the buffer zone to improve the establishment process? The overall aim is to identify and formulate strategies to foster adequate, locally specific activities towards the implementation of sustainable land use in PAs buffer zones.

A case study was performed to evaluate the effectiveness of the buffer zone in the forest National Park Lore Lindu. In an integrated approach ecological and socio-economic data were combined. Satellite images were used to track the landscape dimension of forest-cover change as a response to changing management regimes (before and after establishment as national park in the 90s) and political contexts over time. The attitudes and perceptions of local farmers towards the national park were examined using participatory rural appraisal (PRA) methods such as resource mapping. For this purpose 2 villages in the buffer zone and 2 villages in the park (one village inside the park, one village inside enclave) were chosen.

Our analysis revealed two different major aspects that prevent successful implementation of sustainable land use. First, traditional knowledge about land use systems within the forest was not considered during the establishment process of the National Park. Second, unclear responsibilities and uncoordinated sustainable development activities by various actors and stakeholders led to confusion among local people.

Taking these findings into account we conclude that a good organisation and communication across all levels of protected area management is of high priority in achieving the target of sustainable land use.

Marion Mehring, marion.mehring@uni-greifswald.de 


\section{Michael Köhler}

University of Göttingen, Germany

Luitgard Schwendenmann, University of Göttingen, Germany

Dirk Hölscher, University of Göttingen, Germany

\section{Soil water dynamics and tree water use in a cacao agroforest under experimental drought, Sulawesi, Indonesia}

A recent physiological production model suggested that cacao agroforests are quite sensitive to periodic drought but evidence from field data is scarce. The objectives of our experimental field study were (1) to analyze rates and depths of soil moisture depletion and (2) to assess tree water use rates under reduced rainfall conditions. In a cacao agroforest in Central Sulawesi, Indonesia (annual rainfall $2789 \mathrm{~mm}$ yr-1), three study plots were equipped with a roof extending underneath the canopy to reduce throughfall and compared with three control plots. The roofs, which were closed for 13 months, covered a ground area of about $80 \%$ each. Soil moisture was monitored in depths of 10, 20, 40, 75, 150 and $250 \mathrm{~cm}$ by TDR technique. Xylem sap flux in two tree species (Gliricidia sepium and Theobroma cacao) was measured using the heat dissipation method after Granier. Immediately after roof closure, soil water content in the roof plots decreased almost simultaneously in all depths. Four to five months after roof closure, soil water content decrease levelled off and reached a minimum of $45 \%$ lower than the control. At greater depths it showed only minor further changes and remained close to the permanent wilting point as determined in the laboratory. On control plots, average rates of tree water use were $10 \mathrm{~L}$ per tree and day for cacao and $14 \mathrm{~L}$ per tree and day for Gliricidia resulting in an average stand transpiration rate of $1.4 \mathrm{~mm} \mathrm{~d}-1$. About two months after roof closure, sap flux rates of cacao and Gliricidia in roof plots declined by $10 \%$ to $20 \%$ and remained almost constant at that level for another nine months. Lower sap flux rates, about $30 \%$ reduction on experimental plots compared with the control, were monitored in a period of two months with very little rain at the end of our experiment. However, the soil moisture depletion down to $250 \mathrm{~cm}$ depth and the maintenance of a comparatively high tree sap flux over an extended period of time suggest that the cacao agroforest at our site can cope quite well with reduced water availability. A possible mechanism would be water uptake from greater soil depths, which will be tested during further analyses.

MichaelKöhler,mikoe1@gmx.net 


\section{Muhammad Ardiansyah}

University of Bogor, Indonesia

Stefan Erasmi, University of Göttingen, Germany

\section{Crop type mapping in small scaled tropical land-use patterns from multitemporal TerraSar-X data}

TerraSAR-X was launched in Juli 2007 and is the first earth observation satellite that delivers a continuous global coverage of X-band radar data. The system operates in three modi (ScanSar, Stripmap, Spotlight) with a ground resolution between 16 and $1 \mathrm{~m}$. For the present study, TerraSAR-X Stripmap $(5 \mathrm{~m})$ and Spotlight $(1 \mathrm{~m})$ data acquired from February to July 2008 and ground data measured on fields taken as a reference were used to investigate the potential of high resolution time series of X-band SAR data for agricultural crop type mapping and for determining the rice growth stages in a small-scaled tropical environment at Palolo valley, Central Sulawesi. A stepwise process and a hierarchical image segmentation was implemented for mapping agricultural crop in order to monitor the rice growth stages based on multitemporal, dual-polarimetric TerraSar- $\mathrm{X}$ data. Imagery analysis indicates that the backscattering value differences from the different growth stages of rice fields and other crop covers. This allowed the use of a hierarchical image segmentation to generate crop type maps with high accuracy. Moreover, at the rice growth stages with high water level the backscattering value of TerraSar-X band data is the lowest and as the water level decrease or the rice cover raise the backscattering value more high. Hence, it is possible to determine rice growth stages on rice fields region and thus supply timely information on production estimates which could yield valuable information for food security matters.

Mubammad Ardiansyah,ardysaja@yahoo.com 


\section{Nunik S. Ariyanti}

University of Bogor, Indonesia

Merijn M. Bos, University of Bogor, Indonesia

Kuswata Kartawinata, University of Bogor, Indonesia

Sri S. Tjitrosoedirdjo, University of Bogor Indonesia

E. Guhardja, University of Bogor, Indonesia

S. Robbert Gradstein, University of Göttingen, Germany

\section{Bryophytes on Tree Trunks in Natural Forests, Selectively Logged Forests and Cacao Agroforests in Central Sulawesi, Indonesia}

Forest disturbance and transformation into agricultural land alter tropical landscapes at drastic rates. We investigate bryophyte assemblages on trunk bases in natural forest, selectively logged forest and cacao agroforests that are shaded by remnants of natural forest in Central Sulawesi, Indonesia. Overall, bryophyte richness per site did not differ between the forest types. However, mosses and liverworts reacted differently in that moss richness was lowest in cacao agroforests, whereas liverwort communities were equally rich in all forest types. In terms of cover, mosses remained unaffected while liverwort cover decreased significantly in the disturbed forest. Floristic composition of bryophytes clearly changed in cacao agroforests as compared to natural forests and selectively logged forests. In particular some drought-sensitive species were rare or absent in cacao agroforests and were replaced by drought-tolerant ones, thus underlining the importance of microclimatic changes. Moreover, floristic differences between large and small trees were only pronounced in the cacao agroforests, presumably due to concomitant changes in stemflow of precipitation water. In conclusion, the bryophyte floras of selectively logged forests and cacao agroforests were as rich as in natural forest, but species turn-over was particularly high towards cacao agroforests probably due to pronounced microclimatic changes.

Nunik.S.Ariyanti,nuniksa@yahoo.com 


\section{Pavel Propastin}

University of Göttingen, Germany

Stefan Erasmi, University of Göttingen, Germany

\section{Derivation and validation of temporal LAI and fPAR data sets for Central Sulawesi: integration of medium- und fine-resolution satellite data with in situ measurements}

Leaf area index (LAI) and teh fraction of photosynthetically active radiation (fPAR) are two biophysical variables that have importance in climate, weather and ecological studies. LAI and FPAR have been effectively estimated from remote sensing measurements. This paper reports about the retrieval of temporal data sets of LAI and fPAR over teh central part of Sulawesi (Idonesia) using time-series of the normalized difference vegetation index (NDVI) from Moderate Resolution Imaging Spectroradiometer (MODIS) and SPOT VGT sensor. The retrieval algorithms used in this study based on the physical radiative transfer model which establishes relationships between LAI, IPAR and given patterns of surface reflectance, view-illumination conditions, optical properties of vegetation and other parameters. Patterns of surface reflectance were represented by fractional vegetation cover Fc that was modelled from NDVI. In situ measurements of Fc served for calibration of model parameters. Optical properties of vegetation cover were represented by a number of factors including the extinction coefficient, the canopy projection coefficient, and the clumping index, which are strongly dependent on vegetation type. The canopy projection coefficient and the clumping index were computed from the measurements of crown architecture and hemispherical photographs during field surveys. Influence of view-illumination conditions on optical properties of canopy was simulated by a view angle geometry model incorporated the solar zenith angle and the sensor viewing angle as input variables. Validation of LAI and fPAR modelling results included two steps: (1) development of trancfer function between the ground measurements of LAI and PPAR and fine-resolution satellite data (Landsat ETM+ image) to generate reference maps; (2) comparison of MODIS aand SPOT VGT LAI and fPAR products with aggregated reference maps and assessment of accuracy.

The time-series of LAI and PPAR retrieved in this study can serve as basis input variables for modelling net primary production and its variability at the regional scale. Finally, they can be used for validation and improvement of teh global MODIS LAI and fPAR products for Indonesia.

PavelPropastin,ppropas@uni-goettingen.de 


\title{
Pepijn Schreinemachers
}

\author{
University of Hohenheim, Germany \\ Sithidech Roygrong, University of Hohenheim, Germany \\ Chakrit Potchanasin, University of Hohenheim, Germany \\ Thomas Berger, University of Hohenheim, Germany \\ Walaya Sangchan, University of Hohenheim, Germany
}

\section{An integrated assessment of four innovations to maintain the litchi orchards in northern Thailand}

The profitability of litchi growing in northern Thailand has declined during the last 15 years. The potential substitution of seasonal field crops for litchi trees has created concerns about increased levels of erosion, pesticide use, and irrigation water demands. In response, researchers have been developing various technical innovations that could make litchi growing more profitable again.

The objective of this paper is to ex-ante evaluate four of these innovations: artificial flower induction to produce off-season fruits, village level fruit drying, improved shelf-life and fruit quality, and greater irrigation efficiency. These innovations were evaluated in terms of five indicators: profitability of litchi growing, farm household incomes, area under litchi orchards, irrigation water use, and the environmental impact of pesticides. As some innovations (artificial flowering and improved self-life) are only at a research stage, assumptions were made about their likely costs and benefits.

The profitability of litchi growing and the four innovations was assessed through financial analysis. Although the results show that each innovation could increase profits of litchi growing, this is no guarantee for farm level adoption. For this, opportunity costs, resource constraints, risk aversion, and knowledge need to be taken into account. To do this, an integrated land use model was developed that used an agent-based modeling approach to capture the heterogeneity in opportunity costs between households and to capture the dynamics of innovation diffusion.

The model was calibrated to the Mae Sa watershed area in Chiang Mai province. Located about $40 \mathrm{~km}$ northwest of the rapidly expanding town of Chiang Mai, the watershed has seen rapid economic development which has created various farm and non-farm alternatives to litchi growing. Farmers have increasingly left their litchi orchards unmanaged or have cut down trees to replace them with more profitable crops. Although the Mae Sa watershed is not representative for northern Thailand, it could be a prospect for other areas in northern Thailand. Using scenario analysis, each innovation was separately introduced into the model allowing a comparison of their separate effects. The innovations are then introduced simultaneously to analyze their combined effects. The results show under what conditions the area under litchi orchards would be maintained and what would be consequences on irrigation water use and pesticide loads.

PepijnSchreinemachers, pepijn@uni-hohenheim.de 


\section{Piyachat Ratana}

Khon Kaen University, Thailand

Nagon Wattanakij, Khon Kaen University, Thailand Chanada Ratana, Rajapat Burirum University, Thailand

Charat Mongkolsawat, Khon Kaen University, Thailand

Alfredo R. Huete, University of Arizona, USA

\section{Satellite Time-Series Vegetation Seasonal and Temporal Variations of Human Savannah and Forests in Northeast Thailand}

Northeast Thailand, representing one-third the area and population of the country, is the driest region in Southeast Asia and has the greatest extent of land disturbance, with more than $70 \%$ of the land converted into agricultural uses, such as rice and cash crops. The region now comprises savannah-like agricultural areas (a continuum of rice or crop understory and a sparse cover of overstory trees), and remnant dry tropical deciduous and evergreen forests. This large-scale land conversion from forest to man-made savannah has had significant impacts on ecosystem functioning. Moreover, with recent climate variability due to climate change and a severe drought problem persisting for more than a decade, an improved understanding of landscape mechanisms and dynamics is needed for effective mitigation planning and decision making. Therefore, the focus of this study was to investigate the seasonal and temporal characteristics and variations of natural forests and human savannah ecosystems in NE Thailand. We utilized eight years (2000-07) of NASA Moderate Resolution Imaging Spectroradiometer vegetation index data (VI) to monitor the changes in vegetation seasonal dynamics at local and regional scales. We also analyzed the relationships between meteorological/climate factors and vegetation dynamics in both natural and human-made systems. Our results showed significant differences in the seasonal dynamics and functioning between human savannah and tropical evergreen forests with important consequences to landscape health. We found well-pronounced dry-wet season, vegetation seasonal dynamics strongly coupled with rainfall over savannah-like areas and deciduous forests with greening up occurring in the rainy season (May-Oct). This suggests that changes from drought and climate variability impacts on vegetation can be observed and monitored in satellite observations. On the other hand, the tropical evergreen forests showed the least seasonal contrast and variations with peak greenness in the dry season (Jan-Feb) and low correlations between VI and rainfall. We noted that the savannah-like agricultural areas exhibited strong seasonal dynamics with large spatial variations due to land use management practices. Therefore, it is suggested that land use practices be taken into account in future studies and assessments of ecosystem functioning and dynamics.

Piyachat Ratana, piyachat_ratana@mac.com 


\section{Ramadanil Pitopang}

University of Palu, Indonesia

Heike Culmsee, University of Göttingen, Germany Hardianto Mangopo, University of Palu, Indonesia Michael Kessler, University of Göttingen, Germany Stephan Robbert Gradstein, University of Göttingen, Germany

\section{Structure and Floristic Composition of old Growth Secondary Forest in Lore Lindu National Park, Central Sulawesi, Indonesia}

Tropical deforestation has become a major concern for the world community. Several recent studies have documented the impact of forest disturbance on biological diversity Sulawesi Indonesia (e.g. Walter et al. 2003 ; Schulze et al. 2004 ; Aryanti et al. 2005 ; Kessler et al. 2005; Gradstein et al. 2007; Pitopang et al. 2002, 2004, Pitopang 2006). Some studies reveal conspicuously reduced species richness in secondary or degraded rainforests (Brearley et al. 2004 ; Pitopang et al. 2002). Increasing attention is now being paid to tropical secondary forest, sustainable use of the resources of these forests is essential for the continued protection of undisturbed primary forest areas. Secondary forests may act as buffer zones and serve as a habitat for forest plants and animals displaced from the disturbed or destroyed primary forest. They may also act as reservoirs for recolonization and as corridors between remaining primary forest fragments.

We present the preliminary result of a study on vegetation structure and floristic composition of a 35-40 year old secondary rainforest at the Lore Lindu National Park, in Central Sulawesi, Indonesia. Four 0.25 ha plots were established in the Toro village, at the westernmost border of the National Park at elevation $950 \mathrm{~m}$. All big trees $(\mathrm{dbh} \geq 10 \mathrm{~cm})$ were numbered with tree tags and their position in the plot mapped, crown diameter and dbh measured, and trunk height as well as total height determined by Vertex.

We recorded 482 individuals of trees and 2408 saplings $(\mathrm{dbh} 2-9.9 \mathrm{~cm})$ per ha. Tree species included Dracontamelon dao Merr. (Anacardiaceae), Cyathocalyx acuminatus R.C. Rob. (Annonaceae), Lithocarpus induta Blume (Fagaceae), Pangium edule Reinw. (Flacourtiaceae), Alstonia scholaris R.Br. (Apocynaceae), Arenga pinnata (Wurb) Merr. (Arecaceae), Elaeocarpus macropus Warb., Elacocarpus octopetalus Merr. (both Elaeocarpaceae), Palaquium luzoniense (Fern-Vaill.) Vidal (Sapotaceae), Drypetes minahassae (Boerl. \& Koord.) Pax. \& K. Hoffm. (Euphorbiaceae), Aporosa lucida (Miq.) Airy Shaw etc. The sapling layer mainly consisted of Osmoxylon massarangense Phillipson (Araliaceae), Cyathocalyx acuminatus R.C. Rob. (Annonaceae), Ilex cymosa Blume (Aquifoliaceae), Pometia pinnata (Sapindaceae), Areca vestiaria Giseke, Pinanga caesea Blume, Arenga undulatifolia Becc. (Arecaceae). The structure and floristic diversity of the plot are still being analyzed quantitatively.

Ramadanil Pitopang, pitopang_64@yahoo.com 


\section{Reiner Finkeldey}

University of Göttingen, Germany

Abayneh Derero, University of Göttingen, Germany

Taye Bekele, University of Göttingen, Germany

Akindele Akinnagbe, University of Göttingen, Germany

Marius R.M. Ekué, University of Göttingen, Germany

Oliver Gailing, University of Göttingen, Germany

\section{Human impact on intraspecific diversity of tropical trees: Case studies from Africa}

The spatial dynamics of genetic structures of plant populations is the result of their evolutionary past. Recent evidence suggests a strong influence of natural processes such as postglacial remigration and rare long-distance dispersal on genetic variation patterns of trees not only in the temperate zone, but also in the tropics. In addition, human impacts such as forest destruction, fragmentation, and seed transfer caused irreversible changes of genetic structures. Marker-based studies help to elucidate the role of natural and anthropogenic influences on intraspecific diversity of selected African tree species. Postglacial remigration and rare long-distance dispersal shaped genetic variation patterns of Hagenia abyssinica in Ethiopia, but seem to have much less influence on Cordia africana in the same region. Uncontrolled seed transfer is a main factor contributing to poor phylogeographic clustering in particular for intensively used multipurpose tree species such as the West-African tree Blighia sapida. Effects of forest disturbance and fragmentation on intraspecific diversity depend on numerous factors including pre-existing variation levels, life-history traits, and successional status of target species. In conclusion, alterations of the land use and other types of human impact seem to have limited immediate effects on intraspecific diversity of 'wild' plant populations in most cases. However, disruptions of evolutionary processes in human-altered environments, in particular the disturbance of gene flow and migration patterns, are likely to compromise the adaptive potential of tropical trees.

Reiner Finkeldey,rfinkel@gwdg.de 
Focus 3: Integrated concepts of land use in tropical landscapes

\section{Retno I Pujaningsih}

University of Diponegoro, Indonesia

Adam Malik, University of Palu, Indonesia

Satyawan Pudyatmoko, University of Gadjah Mada, Indonesia

Muhammad Amran Amir, University of Gadjah Mada, Indonesia

\section{Management of Anoa conservation for the seek of socio-economic improvement for the indigenous people arround Lore Lindu National Park}

Our research is standing on two primary different background of study. Agricultural and Forestry background of science. Each has their different mission though the target is the same: Human societies live in harmony with nature. Pressure on biodiversity are severe and increasing. Because the fact we live in a human dominated planet. And during the course of the 20th century the global human population increased from 1.65 billion to 6 billion. Large population means large demand on food. Over the past 50 years, humans have changed these ecosystems more rapidly and more extensively than in any other comparable period of time in human history, largely to meet rapidly growing demands for food, fuel, timber, fiber and fresh water.

Indonesia's forest are among the world's most diverse and biologically rich. Although the country comprises only 1.3 percent of the Earth's land surface, it holds a disproportionately high share of its biodiversity. These make Indonesia as one of 10 Mega Biodiversity country in the world. And the greatest resources of Indonesia's biodiversities collection was found in Sulawesi island. A unique region in the world that has mixed type of plant and animal species from Asia and Australia. Some of endemic fauna species are anoa (Bubalus sp.), deer (Cervus timorensis), Babyrousa, Macaca tonkeana and Macrocephalon maleo. Then, Anoa came as the main topic of this research with its potential aspects: (1)Acquaintable with local resources, (2)Climate tolerance, (3)Relatively high resistance on disease, (4)The horn and cranium is believed as traditional medicine, (5)The pelt has a high economic value and (6)The meat consumes as high protein low fat resource. The last three potencies were related on the local wisdom. So, it is hard to stop the hunting for the seek of conservation. It is needed to find the justification among conservation on biodiversity, local wisdom and agriculture aspect.The last aspect refers to the effort of domesticating this endemic animal. The concept of conservation is by now not only to maintain the sustain but also to utilize it.

Some strategic was offered to find the justification from the three point of view concerning with the sustainability of anoa; (1)Socialization and publication about the status and potencies of anoa especially for the people arround Lore Lindu National Park, (2)Developing research to find the precisely way of anoa's conservation. Once again - it is because research's mission is to conserve the Earth's living heritage \& demonstrate that human societies are able to live harmoniously with nature, the research mainly seeks to maintain the inherent value of biodiversity and its value to humankind everywhere.

RetnoI Pujaningsib, retnoip@telkom.net 


\section{Robin Matthews}

Macaulay Institute, Aberdeen, UK

Iain Brown, Macaulay Institute, Aberdeen, UK

Innocent Bakam, Macaulay Institute, Aberdeen, UK

Shibu Muhammed, Macaulay Institute, Aberdeen, UK

\section{Balancing ecosystem services: analysing tradeoffs between food production, carbon storage, and fuel production in tropical forests}

With increasing demand for biofuels in the US and Europe, many tropical countries see the growing of biofuel crops such as maize and sugarcane as opportunities to kick-start their economies. However, there are growing concerns that this may not only divert crop production away from use as food, but also increase pressure to convert tropical forests to agriculture. As it is, an estimated 13 million hectares of tropical forest are already destroyed each year, resulting in the emission of $2 \mathrm{Gt}$ of carbon, about $20 \%$ of total anthropogenic emissions of GHGs.

Currently this $20 \%$ is outside the Clean Development Mechanism of the Kyoto Protocol. While there have been valid reasons for this, there are now discussions within the UN Framework Convention on Climate Change to try and develop mechanisms to reduce emissions from deforestation and degradation (REDD). One mechanism suggested is that of 'Compensated Reduction' which would reward countries that demonstrate a decrease in deforestation rate below a baseline based on average historical deforestation rates. Such countries would be allocated emissions allowances tradable in the global carbon market, thereby creating a monetary value to carbon stored in trees and increasing the likelihood that they will be protected. However, it is unclear whether this approach would be sufficient to overcome the many pressures at the local level leading to deforestation, including the need to produce food, and the economic opportunities afforded by growing biofuel crops.

Previous work by this group has identified agent-based modelling (ABM) as a promising approach to study individual decision-makers within coupled human-environmental systems. In this poster, we use an ABM approach to explore some of the drivers and processes involved in land use change in tropical forests, with particular emphasis on the tradeoffs and synergies between the three ecosystem services of food production, fuel production and carbon storage.

RobinMatthews,r.matthews@macaulay.ac.uk 


\section{Shahabuddin}

University of Palu, Indonesia

Sjafrida Manuwoto, University of Bogor, Indonesia

Purnama Hidayat, University of Bogor, Indonesia

Woro A. Noerdjito, Muzeum of Zoology Bogor, Indonesia

Teja Tscharntke, University of Göttingen, Germany

Christian H. Schulze, University of Vienna, Austria

\section{Tropical land-use changes affect diversity, mean body size and ecosystem functioning of dung beetles}

Dung beetles (Coleoptera: Scarabaeidae) are an important component of most terrestrial ecosystems and were widely used to assess effects of habitat disturbance and deforestation. This study aimed to evaluate effects of land use on their diversity as well as their ecosystem function (dung decomposition) at the forest margin of Lore Lindu National Park (LLNP), Central Sulawesi. Samples were collected from March to November 2005 in six habitat types ranging from natural forest to three types of cacao agroforestry (with remaining natural forest shade trees, planted shade trees and without shade trees) and open areas. The study area was located around the village Toro in Kulawi Valley at the western margin of LLNP. The research focused on four main aspects: (1) effects of land-use and dung type on species richness and species composition; (2) relative contribution of land-use systems to regional diversity; (3) dung decomposition rates at different land-use types and (4) the role of species richness, species composition and body size of coprophagous beetles for dung decomposition.

Beetles were collected with a total of ten pitfall traps per site, five baited with cattle and five with anoa dung. To quantify dung decomposition rate, additionally twelve dung patches of the same fresh weight (ca. $260 \mathrm{~g}$ ) were exposed at each site. To study the role of coprophagous beetles for dung decomposition and enhancing soil fertility also laboratory experiments were conducted. The total content of nitrogen, phosphor, potassium, and organic matter as well as $\mathrm{C} / \mathrm{N}$ ratio of soil were measured to analyzed effects of dung decomposition on soil fertility.

A total of 1,429 dung beetle specimens representing 28 species of five genera (dominated by the genus Onthophagus) were trapped at Toro village. Twenty six species (93\% of recorded total) and $24(86 \%)$ were collected in pitfall traps baited with cattle and anoa dung, respectively, indicating no distinct food preferences. Species richness and composition were significantly affected by land-use type. Species richness, abundance, biomass and the ratio of large to small species decreased from natural forest towards cacao agroforestry systems and open area. However a highly significant effect of habitat type was only detected between natural forest and open area. The closer relationship between dung beetle assemblages recorded at forest and agroforestry sites most likely is caused by a higher similarity of habitat parameters such as microclimate and vegetation structure between these habitats compared to open areas. Species composition at open areas differed significantly from that of any other habitat type. Few species showed clear preferences for a certain habitat or dung type, indicating that the majority of recorded species appears to represent generalists capable of colonizing a large variety of habitats and feeding on dung of different species of herbivorous mammals.

The decomposition rate of exposed dung differed significantly between land-use systems, and decreased with increasing habitat disturbance from natural forest to open area. Body size of dung beetles was a better predictor for decomposition rate than biomass or species numbers of beetles. The laboratory experiments showed that dung decomposition by coprophagous beetles significantly increased soil fertility. In conclusion, land-use changes affected important ecosystem services such as dung 
Focus 3: Integrated concepts of land use in tropical landscapes

decomposition and soil fertility with changes in body size rather than dung beetle diversity as a main driver.

Shahabuddin,shahabuddin_slb@yahoo.com 


\section{Shahabuddin}

University of Palu, Indonesia

Sjafrida Manuwoto, University of Bogor, Indonesia

Purnama Hidayat, University of Bogor, Indonesia

Woro A. Noerdjito, Muzeum of Zoology Bogor, Indonesia

Teja Tscharntke, University of Göttingen, Germany

Christian H. Schulze, University of Vienna, Austria

\section{Regional differences in the decay of the dung beetle communities along land-use gradients in Central Sulawesi, Indonesia}

Agricultural expansion increasingly homogenizes landscapes, which poses a potential threat to biodiversity at local and regional scales due to the decline of $\beta$ diversity and $\gamma$ diversity, respectively. Here we evaluated the importance of "biotic homogenization" as result of forest destruction and agricultural intensification for the dung beetle fauna of Central Sulawesi, Indonesia.

Dung beetles (Coleoptera: Scarabaeidae) were sampled using pitfall traps baited with cattle dung. Study sites were located in two different regions at the western and eastern margin of Lore Lindu National Park, respectively. In both study areas dung beetles were sampled in natural forest, agroforestry systems and open areas.

In an additive partitioning approach we quantified local and regional $\alpha$ and $\beta$ diversity of the dung beetle fauna in natural rainforests, adjacent cacao agroforests and annual crops in two study regions. Our data showed that land-use changes had a significant effect on diversity of dung beetle assembles in both regions. Species richness and abundance decreased from forest and cacao agroforests to open cultivated areas, thereby promoting local homogenization. Dung beetle communities differed greatly between the two regions independent of habitat type. Twenty three percent of the estimated species richness depended on regional differences, while the factor habitat type contributed $28 \%$ to the dung beetle species richness. These findings illustrated that land-use changes contribute to local but not regional homogenization of the dung beetle fauna. However, it is unclear whether biotic homogenization may become more important on a regional scale in the long run.

Shahabuddin,shahabuddin_slb@yahoo.com 


\title{
Soekisman Tjitrosoedirdjo
}

\author{
Seameo Biotrop Bogor, Indonesia
}

A. Subiakto, Forest and Nature Conservation Research and Development Centre

\section{Mikania Micrantha: an invasive alien plant species threatens the rehabilitation of logged over natural forestsin Indonesia}

A program on the rehabilitation of logged over natural forests, Intensive Silviculture was launched in 2001, In Indonesia. The program's activities were based on 3 integrated concepts, i.e. the use of selected high yielding species, manipulation of environment to support an optimum growth, and integrated pest management. The selected species were mainly Dipterocarps and others that were previously dominant in the rehabilitated areas and proven to grow fast. The seedlings of selected species were prepared in the green house for about 8 months to reach a height of about $30 \mathrm{~cm}$. hardened and planted in the fields in cleared strips of $3 \mathrm{~m}$ wide and spaced at $2.5 \mathrm{~m}$ distance. The strips were made by clearing most vegetation along the way, at an interval of $20 \mathrm{~m}$ wide. The seedlings were planted in holes measuring $30 \times 30 \times 40$ $\mathrm{cm} 3$ which were filled with forest litter before being planted with the selected seedlings. The design proved to be excellent, with a mortality of about $10 \%$. The loggings and the constructions og strips facilitated the invasion of Mikania micrantha, an invasive alien plant species native to American tropics. There also growing liana which were also posting problems the planted seedlings. The invasion of liana and particularly M.micrantha molested, the planted seedlings, breaking and killing them, thus threatening the rehabilitation. The use of existing herbicides also damaged the planted seedling. Currently controlling M.micrantha before planting, help to reduce the invasion.

Soekisman Tjitrosoedirdjo,sukisman@indo.net.id 


\section{Sri S. Tjitrosoedirdjo}

Seameo Biotrop Bogor, Indonesia

S. Tjitrosoedirdjo, Seameo Biotrop Bogor, Indonesia

N. Suminah, Seameo Biotrop Bogor, Indonesia

Setiabudi, Seameo Biotrop Bogor, Indonesia

Pujantoro, Seameo Biotrop Bogor, Indonesia

\section{Data Base Development on Invasive Alien Plant Species in Indonesia}

SEAMEO BIOTROP has been working on weeds since the beginning of their establishment. At present, not only weeds but also IAPS (Invasive Alien Plant Species) are included in the data base. The development of the IAPS database have been conducted in 2006-2007. BIOTROP in cooperation with the Ministry of Environment conducted an inventory of the alien plant species in Indonesia and the results were published in 2003 and it was revised in 2006. Based on that records there were 339 species of invasive alien plant in Indonesia and it is expexted that a prototype of interactive weeds and IAPS database will be available at the web-site of BIOTROP in the late 2008.

Sris. Tjitrosoedirdjo, sudarmiyati@biotrop.org 


\section{Stefan Köhler}

University of Göttingen, Germany

Thomas Duwe, University of Brunswick, Germany Jana Juhrbandt, University of Göttingen, Germany

Gerhard Gerold, University of Göttingen, Germany

\section{Effects of soil fertility on cocoa yields in agroforestry plantations in central Sulawesi}

In the inner tropics soil fertility often is an important parameter for sustainable agriculture. In Central Sulawesi cocoa smallholder plantations have increased in the last ten years by forest conversion. Within the multidisciplinary STORMA project ecolocigal and socio-economic conditions of cocoa plantations in different villages are in investigation (twelve villages). Additionally to the inventory of management and socio-economic parameters for the twelve villages (in each village four plots) a study on soil types and soil fertility was launched. The soil inventory covers altitudes from 50 to $1200 \mathrm{~m}$ a.s.l.

For each plantation a representive soil profile was chosen from Pürckhauer auger samples. Samples were taken by horizon. Within a $20 \times 20 \mathrm{~m}$ plot three subplots werde chosen $(5 \times 5 \mathrm{~m})$ for depth sampling $(0$ $10 \mathrm{~cm}, 10-30 \mathrm{~cm}, 30-50 \mathrm{~cm}$ ). In addition leaf samples were taken from lower and higher canopy (the first 4 fully developed leaves on a branch from 5 randomly selected trees). In the STORMA laboratory the following variables are being analysed: for mineral soil analysis: CECeff, P-Bray, ph- $\mathrm{H} 2 \mathrm{O}, \mathrm{pH}-\mathrm{KCl}, \mathrm{C} / \mathrm{N}$, total amount $\mathrm{K}, \mathrm{P}, \mathrm{Mg}, \mathrm{Ca}$, bulk density, texture; for leaf analysis: $\mathrm{C} / \mathrm{N}$ and total amount $\mathrm{K}, \mathrm{P}, \mathrm{Mg}, \mathrm{Ca}$.

The soils showed high variability due to the intensive geological and morphological situation in Sulawesi. We found that Cambisols, Gleysols and Pseudogleysols dominate. In part soils were anthropogenically modified. Soil differentiation depends on the relief-substratum situation and varies between villages and also within the village plots. Therefore the hypothesis that the high variability of cocoa yields at the village level and between villages can be explained for by the main soil parameters. Fertility is limited due to acid substratum and high ground water level and Stauwasser.

Yields and soil analysis data will be compared via multivariate analysis.

StefanKöbler, skoeble2@gwdg.de 


\section{Tanty S. Thamrin}

International Fellowship Program

\section{Community coping mechanism in dealing with scarcity of food in NTT}

This paper presents the empirical experiences of the community efforts in NTT in coping with the long drought period that caused direct food supply in the area. Changes in weather conditions due to global warming have a detrimental influence on agricultural production. Due to the "normal drought," for several years, NTT faced the season called "hungry period." Communities in the province faced longer dry-seasons than usual. This caused planting and harvest failures especially for dry-land commodities that caused "abnormal hungry period." The paper is based on data collected through mass-media, discussions and interviews with local authorities, communities, non governmental organizations, community based organizations, research centres, and local news-papers in NTT. It is very essential for the main actors and stakeholders to understand local hazards, vulnerabilities, and capacities as part of the community capacity building and coping strategy. There are several points to consider toward community resilience to the long drought disaster risk i.e. right to sustainable livelihood and security, livelihood in the area of long-term decline, emergency food security, and climate change adaptation and mitigation. The local government suggested to the farmers to plant various types of beans (green beans and soybeans) or tuber (cassava) towards the end of the rainy season. Farmers of different communities in NTT had developed land-use diversification strategies to cope with the long drought period. The land-use diversification strategy developed by the local communities is valuable in coping with food deficits after long drought periods. The community efforts has started but needed to be supported, monitored, and assessed whether the community's coping strategy can deal with the disaster risk of long drought hazard. As conclusion, efforts are needed to be undertaken by considering the underlying causes, dynamic pressures, and unsafe conditions behind the "abnormal hungry period".

TantyS.Thamrin, thamrintantys@yahoo.de 
Focus 3: Integrated concepts of land use in tropical landscapes

\section{Ulrich Schuler}

University of Hohenheim, Germany

Ludger Herrmann, University of Hohenheim, Germany

Karl Stahr, University of Hohenheim, Germany

\section{SOTER based soil mapping in NW-Thailand}

Millions of people in Northern Thailand rely on vulnerable steep highland areas to sustain their livelihoods. A major issue here is the quality and characteristics of the available soils. Despite this obvious importance of these regions, information on highland soils of NW Thailand is still sparse. This low data density is mainly due to terrain inaccessibility, steep slopes, remoteness from research centers and political reasons like declaration of conservation areas and use by ethnic minorities. Population growth and soil degradation entailed an extension of arable land along with mostly highly unsustainable agricultural practices comprising the intensification of land use and the increased application of fertilizers and pesticides in the highlands causing intensified flooding and water pollution in the lowlands. Besides the inherent environmental problems for both parties, this leads to social conflicts between the lowland "Thai-majority" and the ethnic minorities in the highlands. Landscape and watershed modeling can provide knowledge to enhance agricultural sustainability and help to resolve misunderstandings or conflicts between different stakeholders and authorities. Detailed information on soils and their properties are required therefore, but intensive soil mapping of whole NW Thailand is very costly and time consuming. A less expensive and quicker alternative is given by the SOTER (SOilTERrain) approach, which combines soil and terrain information through a so called SOTER map. SOTER maps use hierarchical map units, which are linked with a database. The highest level consists of terrain units representing major landforms, while the lowest level is represented by soils and their properties. In order to map the soils within the different landforms of NW Thailand in an efficient way, three different petrographic areas were chosen and intensively investigated. Each investigation area stands for a small, but representative section of their respective landform, dominated by a certain petrography. Soils of the respective areas were mostly investigated along transects. In zones of expected high soil variability additional investigations were carried out. The investigations resulted in reference soil maps, representing a best guess of the actual pedology. In addition local soil knowledge was elicited in each area. Subsequently, soil mapping based on the maximum likelihood (ML) approach was carried out and compared with the respective reference maps.

The reference soil maps showed the highest accuracy. Even minor soil types were detected. However, the compilation of the reference soil map was the highly time consuming and costly.

The elicitation of local knowledge revealed the farmers' profound knowledge of their respective land. In all three areas, soils were mainly differentiated according to soil color. Further criteria for local soil classification were bulk density, stone content and topsoil thickness. All elicitated local soil maps provided an overview about the main soil types of the respective area. Additionally, background information like crop suitability, water infiltration, erosion hazard was provided for each local soil type by the farmers. Mapping of local soils and their properties was comparably the cheapest and rapidest method in this study. The degree and kind of local knowledge varied among the villages. Furthermore, the respective local soil knowledge is restricted to village areas and therefore mapping at larger scales is not possible.

The ML approach was carried out according to the following procedure: First, soil types were sorted according to their abundance within an area. Soil types occurring in more than 15\% of all samples build up the group "major soil types". The less frequent soil types, representing between 2 and 15\% of all samples were grouped as "minor soil types". Exceptional soil types representing less than 2\% of all 
samples were excluded from the maximum likelihood mapping, because their abundance is not sufficient to calculate the covariance matrix (therefore at least 5 different sampling points are required). The second step comprised a factor analysis of both groups using the software PAST 1.69. The aim of the factor analysis was to select the raster data with the highest explanation value for the given soil data. In a next step the maximum likelihood approach was applied for all sampling points of the major soil types within the area. This step was implemented using the ArcGIS 9.1 software. Several results of the factor analysis consisting of different shares of the respective raster data were compared with the reference soil map. The variation with the highest accordance was selected. The same approach was applied for all sampling points of the minor soil types. The final maximum likelihood map was compiled by overlaying the maximum likelihood map of the major soils with the map of the areas, where the minor soil types show a probability of more than $90 \%$. Once a useful solution is found, the maximum likelihood approach can be extended to larger areas, exceeding the size of the respective reference map several times. Therefore the conditions are merely comparable elevation ranges and petrography. The soil maps based on the maximum likelihood approach delivered information about the distribution of the main soil properties and the probability of their occurrence. For all three investigated areas a correspondence of $\geq 58 \%$ with the reference soil map was achieved. An essential contribution to the maximum likelihood classifications came from bands of SPOT and LANDSAT images indicating vegetation and drought stress. All used SPOT and LANDSAT images were taken during dry season. Therefore, it is assumable that the response of vegetation to drought correlates with soil moisture and with the major soil types. The effort for the initial investigation of the calibration area for the ML approach is high, but using this method also the mapping of areas exceeding the size of the calibration area at 15 times seems to be feasible. Despite the restriction to village areas local knowledge is very helpful to make soil mapping of the calibration area more efficient by providing information on key sites and soils.

Summarizing, the present study allowed concluding that the combination of the SOTER concept with the ML approach along with the investigation of local soil knowledge can create synergy effects, which enable an efficient soil mapping of whole NW Thailand.

UlrichSchuler,uschuler@uni-bohenheim.de 


\section{Wolfram Lorenz}

University of Göttingen, Germany

\section{The impact of decentralization on natural resource management in Indonesia. Does the concept of 'conservation districts' contribute to stability of rainforest margins at protected areas?}

In Post-Soeharto Indonesia decentralization measures led to a power shift from central to regional governments and weakened central control over natural resources. These resources became an important incoming factor for a growing number of regional leaders who gained power by renegotiation process of administrative boundaries under decentralization law. Between 1999 and 2004 the number of districts in Indonesia increased from 300 to 440 by almost $50 \%$.The formation of new districts is not an evenly distributed phenomenon of decentralization in Indonesia. In provinces like Bali the forming of new district was not an issue, while for instance Central Sulawesi has shown an interestingly high dynamic in forming new districts. As newest critical analyses have shown, a major driver behind this dynamic territorial reorganization process seems to be gaining personal power to get access to income generating resources. Protected areas like National Parks are in Indonesia under responsibility of the central government but the management of the parks heavily depend on politicians and elites of regional and local level demanding access to the resources of the park. With an increasing number of districts the park management has to deal with an increasing number of institutions weakening the park management. At the end of 2007 the Indonesian government announced a draft law regulating the formation of „conservation districts“. The main idea is it to provide district governments with incentives in order to preserve their natural resources instead of exploiting them. For certain reasons these new regulations raised much attention by local elites even due to lack of available funds and further regulations from central government, non of those new formed districts was fully granted the status of a „conservation district" yet. At first glance "conservation districts" could be promising for nature conservation and exemplary in improving management of protected areas. No analyses exist yet evaluating the impacts of a "conservation district". This paper will deal with the formation process of new districts attached to the National Park Lore Lindu in Central Sulawesi. On example of the process of the formation of the "Conservation District Tampo Lore“, covering a third of the territory of the National Park Lore Lindu, it will be analysed if the concept could have positive impact to reduce deforestation and stabilize rainforest margins. Further, the paper will deal with motives of actors behind and give a better understanding of decision-making processes in relation with natural resource management in settlements in margins of protected areas.

WolframLoren₹,wlorenz@gwdg.de 


\author{
Karl Stahr \\ University of Hohenheim, Germany \\ Gerhard Clemens, University of Hohenheim, Germany \\ Ulrich Schuler, University of Hohenheim, Germany \\ Niwat Anongrak, University of Hohenheim, Germany \\ Wanida Rangubpit, Chiang Mai University, Thailand
}

\title{
Innovative soil mapping methods for land evaluation
}

Different soil mapping approaches were performed for different petrographic areas of northern Vietnam and Thailand. These approaches are based on transects grid based randomization, maximum likelihood. Validation was performed using reference soil maps and independent sampling points. In addition local knowledge based soil maps were created. The mapping approaches based on transects and grid based randomization showed a very high correspondence with the respective soil map and a very high degree of matching with independent sampling points. Both methods are only suitable for small areas. Another problem concerning these two approaches is that in the case of unknown ex-ante soil variability for a specific area, the choice of the distance for transects, grid cell size and amount of sampling points is difficult. The soil maps based on maximum likelihood showed a high match with the respective reference soil maps and the independent sampling points. The effort to compile the maximum likelihood based soil map was higher than for those based on transects and randomization. However, only the maximum likelihood approach is applicable to upscaling procedures, by far compensating the higher effort. Local knowledge based soil mapping is very cheap and fast. However, it is restricted to village areas and classification often varies even within a village. Despite this, local knowledge is highly useful for soil reconnaissance surveys, as well as to acquire an overview of the major distribution of soils and their properties. In one pilot study local knowledge based soil sampling could reduce the amount of sampling points to less than the half used for transect and randomized mapping and still provide an accuracy of at least $70 \%$. A further new attempt to correlate soil units with airborne radiometric data will be shortly presented. This method is still in advance.

KarlStabr,kstabr@uni-bohenheim.de 


\title{
List of Participants
}

\author{
Abdal, Mahdi \\ Anwar, Chairil \\ Ardiansyah, Muhammad \\ Bardgett, Richard \\ Barkmann, Jan \\ Barus, Henry \\ Bawa, Kamal \\ Beck, Erwin \\ Behling, Hermann \\ Bidin, Arifuddin \\ Binternagel, Norbert \\ Brown, Timothy \\ Cicuzza, Danielle \\ Clough, Yann \\ Cook, Ellyn \\ Culmsee, Heike \\ Daenner, Karl Maximilian \\ Damayanti Buchori, Dami \\ Erasmi, Stefan \\ Faust, Heiko \\ Feintrenie, Laurène \\ Finkeldey, Reiner \\ Fischer, Markus \\ Freitag, Hendrik \\ Kuwait Insitute for Scientific Research \\ mabdal@kisr.edu.k.w \\ University of Palu \\ anwarchairil@hotmail.com \\ University of Bogor \\ ardysaja@yahoo.com \\ University of Lancaster \\ r.bardgett@lancaster.ac.uk. \\ University of Göttingen \\ jbarkma@gwdg.de \\ University of Palu \\ Henbarus@hotmail.com \\ University of Massachusetts and ATREE \\ kamal.bawa@umb.edu \\ University of Bayreuth \\ roswitha.schoenwitz@dfg.de \\ University of Göttingen \\ Hermann.Bebling@bio.uni-Göttingen.de \\ University of Palu \\ arif_bidin@yahoo.com \\ University of Göttingen \\ norbert.binternagel@email.de \\ The World Bank \\ brownth@cbn.net.id \\ University of Göttingen \\ danielecicuzza@yahoo.it \\ University of Göttingen \\ yclough@gwdg.de \\ University of Göttingen \\ Ellyn.Cook@biologie.uni-Göttingen.de \\ University of Göttingen \\ beike.culmsee@bio.uni-Göttingen.de \\ University of Göttingen \\ kdaenne@gwdg.de \\ University of Bogor \\ dami@kehati.or.id \\ University of Göttingen \\ serasmi@uni-goettingen.de \\ University of Göttingen \\ bfaust@gwdg.de \\ CIFOR \\ l.feintrenie@.cgiar.org \\ University of Göttingen \\ rfinkel@gwdg.de \\ University of Bern \\ markus.fischer@ips.unibe.ch \\ Dresden Zoological Museum \\ bendrik.freitag@gmx.de
}


Gerold, Gerhard

Grosse, Melanie

Guhardja, Edi

Gutzler, Carsten

Hafsah

Hairiah, Kurniatun

Harding, James

Hasanah, Uswah

Haug, Gerald

Heidhues, Franz

Hein, Jonas

Hemp, Andreas

\section{Hendrayanto}

Hölscher, Dirk

Horna, Viviana

Huete, Alfredo

Hugenschmidt, Cindy

Iskandar, Lapanjang

Iswandi, Anas

Juhrbandt, Jana

June, Tania

Kadir Paloloang, Abdul

Kalaba, Felix Kanungwe

Keil, Alwin

Kirleis, Wiebke

Klasen, Stephan

Köhler, Michael
University of Göttingen ggerold@gwdg.de

University of Göttingen mgrosse@uni-goettingen.de

University of Bogor storma-ipb@indo.net.id University of Göttingen cgutzle@gwdg.de

University of Palu bafsab_62@yahoo.com University of Brawijaya k.hairiab@cgiar.org Green Mountain College hardingj@greenmtn.edu University of Palu uswahmughni@yahoo.co.id University of Zurich gerald.hang@erdw.ethz.ch University of Hohenheim beidhues@uni-bohenheim.de University of Göttingen Ibromon62@yahoo.de University of Potsdam andreas.hemp@uni-potsdam.de University of Bogor bendrayanto@gmail.com University of Göttingen dhoelsc@gwdg.de

University of Göttingen vhorna@gwdg.de University of Arizona abuete@cals.arizona.edu University of Hohenheim cindy.hugenschmidt@uni-hohenbeim.de

University of Palu

benbarus@hotmail.com

University of Bogor

aiswandi@indo.net.id

University of Göttingen jjubrba@gwdg.de University of Bogor taniajune@yahoo.com

University of Palu paloloang_akp@yahoo.com Copperbelt University kanungwekalaba@yaboo.co.uk University of Hohenheim alwin.keil@uni-hohenheim.de University of Kiel wiebke.kirleis@ufg.uni-kiel.de University of Göttingen sklasen@gwdg.de University of Göttingen 
Köhler, Stefan

Kreilein, Heinrich

Laffiteau, Charles

Lakitan, Benjamin

Lanini, Agus

Leitner, Daniela

Leuschner, Christoph

Lipu, Sance

Lorenz, Wolfram

Maas, Bea

Makuli, H. Alpin

Mappatoba, Marhawati

Matthews, Robin

McCarthy, Shane

Mehring, Marion

Michalzik, Beate

Monde, Anthon

Moser, Gerald

Murdiyarso, Daniel

Mustafa, Sahabuddin

Nazario-Leary, Cynthia

Neef, Andreas

Nelson Rodong, Kudiag

Nilawati, Jusri

Nuryartono, Nunung mikoe1@gmx.net

University of Göttingen

skoeble2@gwdg.de

University of Göttingen

bkreile@gwdg.de

University of Texas

claffitean@sbcglobal.net

State Ministry of Research and Technology, Jakarta

blakitan@ristek.go.id

University of Palu

aguslanini@hotmail.com

University of Göttingen

dleitne@gwdg.de

University of Göttingen

cleusch@gwdg.de

University of Palu

sancelipu@yahoo.com

University of Göttingen

wlorenz@gwdg.de

University of Vienna

beamaas@gmx.at

Research Department of Central Sulawesi Province, Palu

University of Palu

wati_chairi@botmail.com

Macaulay Institute

r.matthews@macaulay.ac.uk

National Cooperative Business Association and

Cooperativa Cafe Timor

psmccarthy.ncba@gmail.com

University of Greifswald

marion.mehring@uni-greifswald.de

University of Jena

beate.michalzik@uni-jena..de

University of Palu

anthonmonde@yahoo.com

University of Göttingen

gmoser@gwdg.de

CIFOR (Center for International Forestry Research)

d.murdiyarso@cgiar.org

University of Palu

University of Hawaii

cnazario@bawaii.edu

University of Hohenheim

a_neef@usa.net

RCESDO-CAM.

rcesdo7@yahoo.com

University of Palu

jnilawati_98@yahoo.com

University of Bogor

nnuryar@ipb.ac.id 
Oswald, Patrick

Page, Susan

Palar Mogea, Johanis

Panferov, Oleg

Pethig, Rüdiger

Pitopang, Ramadanil

Poehling, Hans-Michael

Pohle, Perdita

Priebe, Jan

Priess, Joerg

Prihastanti, Erma

Propastin, Pavel

Pujaningsih, Retno Iswarin

Puspitawati, Herien

Rauf, Abdul

Rizali, Akhmad

Rollenbeck, Rütger

Rudolf, Robert

Sahari, Bandung

Saharia, Saha

Saint-Macary, Camille

Sanim, Bunasor

Sarma, Ma'mun

Sartano, Agus

Schmidt, Carsten

Schoenwitz, Roswitha

Schuldt, Bernhard
DED \& Kantor BAPPEDA

Patrickoswald@gmx.de

University of Leicester

sep5@le.ac.uk

Herbarium Bogoriense - Research Center for Biology LIPI

jopamogea@yahoo.com

University of Göttingen

opanfyo@gwdg.de

University of Siegen

pethig@vwl.wiwi.uni-siegen.de

University of Palu

pitopang_64@yahoo.com

University of Hannover

Poebling@ipp.uni-hannover.de

University of Erlangen-Nürnberg

ppoble@geographie.uni-erlangen.de

University of Göttingen

jpriebe@uni-goettingen.de

University of Kassel

priess@uni-kassel.de

University of Diponegoro

eprihast@yahoo.co.id

University of Göttingen

ppropas@uni-goettingen.de

University of Diponegoro

retnoip@telkom.net

University of Bogor

berien_puspitawati@email.com

University of Palu

rauf_cca@yahoo.com

Peka Indonesia Foundation

a_rizali@yahoo.com

University of Marburg

rollenbeck@lcrs.de

University of Göttingen

rrudolf@uni-goettingen.de

Peka Indonesia Foundation

bandung_sahari@peka-indonesia.org

University of Palu

sabaria_kassa@yahoo.com

University of Hohenheim

stmacary@uni-bohenheim.de

University of Bogor

storma-ipb@indo.net.id

University of Bogor

mamun_sarma@email.com

University of Palu

University of Göttingen

carstenLE@web.de

Deutsche Forschungsgemeinschaft

roswitha.schoenwitz@dfg.de

University of Göttingen

bschuld2@gwdg.de 
Schuler, Ulrich

Schulze, Christian

Schwarze, Stefan

Schwendenmann, Luitgard

Seeberg-Elverfeldt, Christina

Setiawan, Budi Indra

\section{Shahabuddin}

Sintawardani, Neni

Sri Ariyanti, Nunik

Stahr, Karl

Stenchly, Kathrin

Stoll-Kleemann, Susanne

\section{Sudarmiyati Tjitrosoedirdjo, Sri}

Sugema, Iman

Sukara, Endang

Tantu, Fadly

Tarigan, Suria

Tellu, Tanra

Tillar, Tommy

Timmer, Vic

Tjitrosoedirdjo, Soekisman

Tjoa, Aiyen

Tremblay, Anne-Marie

Triadiati

Tscharntke, Teja

Umrah
University of Chiang Mai uschuler@uni-hobenheim.de University of Vienna christian.schulze@univie.ac.at University of Göttingen s.schwarze@agr.uni-goettingen.de University of Göttingen lschwen@gwdg.de University of Göttingen c.seeberg@agr.uni-goettingen.de University of Bogor budindra@ipb.ac.id University of Palu shababuddin_slb@yaboo.com Indonesian Institute of Science, Jakarta neni.sintawardani@lipi.go.id

University of Bogor nuniksa@yahoo.com

University of Hohenheim

kstahr@uni-bohenheim.de

University of Göttingen stenchly@yahoo.de

University of Greifswald susanne.stoll-kleemann@uni-greifswald.de SEAMEO BIOTROP sudarmiyati@biotrop.org University of Bogor imansipb@yahoo.com Indonesian Institute of Science, Jakarta esukara@yahoo.com

University of Palu ftantu@yahoo.com University of Bogor storma-ipb@indo.net.id University of Palu tellu33@yahoo.com University of Palu

University of Toronto vic.timmer@utoronto.ca SEAMEO BIOTROP sukisman@indo.net.id University of Palu aiyenb@yahoo.com University of Hohenheim atremb5@yahoo.fr University of Bogor tria_24@hotmail.com University of Göttingen ttschar@gwdg.de

University of Palu umrab_2004@yaboo.com 
van Edig, Xenia

van Noordwijk, Meine

van Straaten, Oliver

Veldkamp, Edzo

Vidal, Stefan

von Walter, Frank

Wardah

Widagdo

Widodo

Wiegand, Kerstin

Zach, Alexandra

Zeller, Manfred

Zittartz-Weber, Suzanne
University of Göttingen

xedig@agr.uni-goettingen.de

World Agroforestrfy Centre, ICRAF-SEA

m.vannoordwijk@rgiar.org

University of Göttingen

ostraat@gwdg.de

University of Göttingen

eveldka@gwdg.de

University of Göttingen

svidal@gwdg.de

University of Göttingen

f2walter2@gwdg.de

University of Palu

wardah_pali@yahoo.co.id

National Park Lore Lindu, Central Sulawesi

University of Bogor

widodo@ipb.ac.id

University of Jena

kerstin.wiegand@uni-jena.de

University of Göttingen

alzac@gmx.de

University of Hohenheim

manfred.zeller@uni-hohenheim.de

Deutsche Forschungsgemeinschaft

suzanne.zittartz-weber@dfg.de 
Human-induced land-use intensification and climate change are major global change drivers likely to continue for a long time. This international symposium provides an open platform for all scientists from socio-economic and natural sciences interested in the effects of global change on rainforests and agroforests. Balancing the ecological and socio-economic benefits of different agroforestry systems, comparing patterns and processes in managed agroforest and natural forest, and modeling the dynamics of land-use change and related resource degradation under various policy scenarios are major topics of this symposium.

The Symposium is jointly organized by the Universities of Kassel, Bogor, Tadulako, and Göttingen

U N I K A S S E L

V $\begin{array}{lllllll} & \mathbf{R} & \mathbf{S} & \mathbf{I} & \mathbf{T} & \text { "A" } & \mathbf{T}\end{array}$
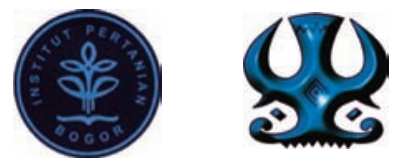

GEORG-AUGUST-UNIVERSITÄT GÖTTINGEN
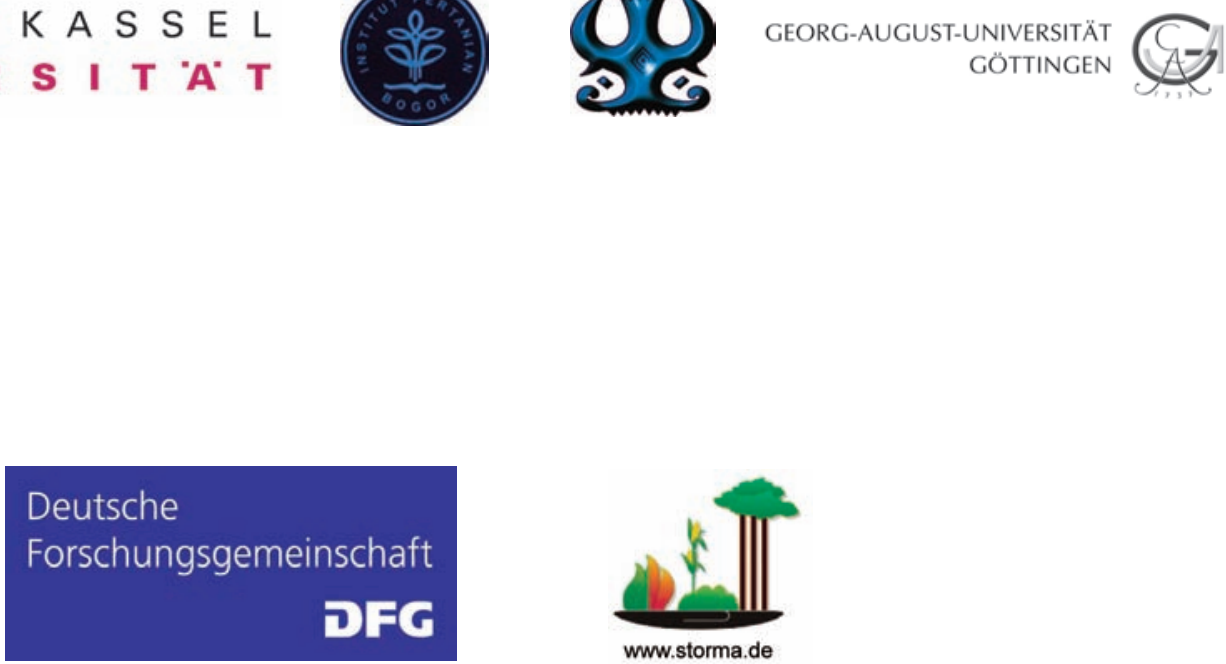

Funded by

German Research Foundation (DFG)

as SFB 552 